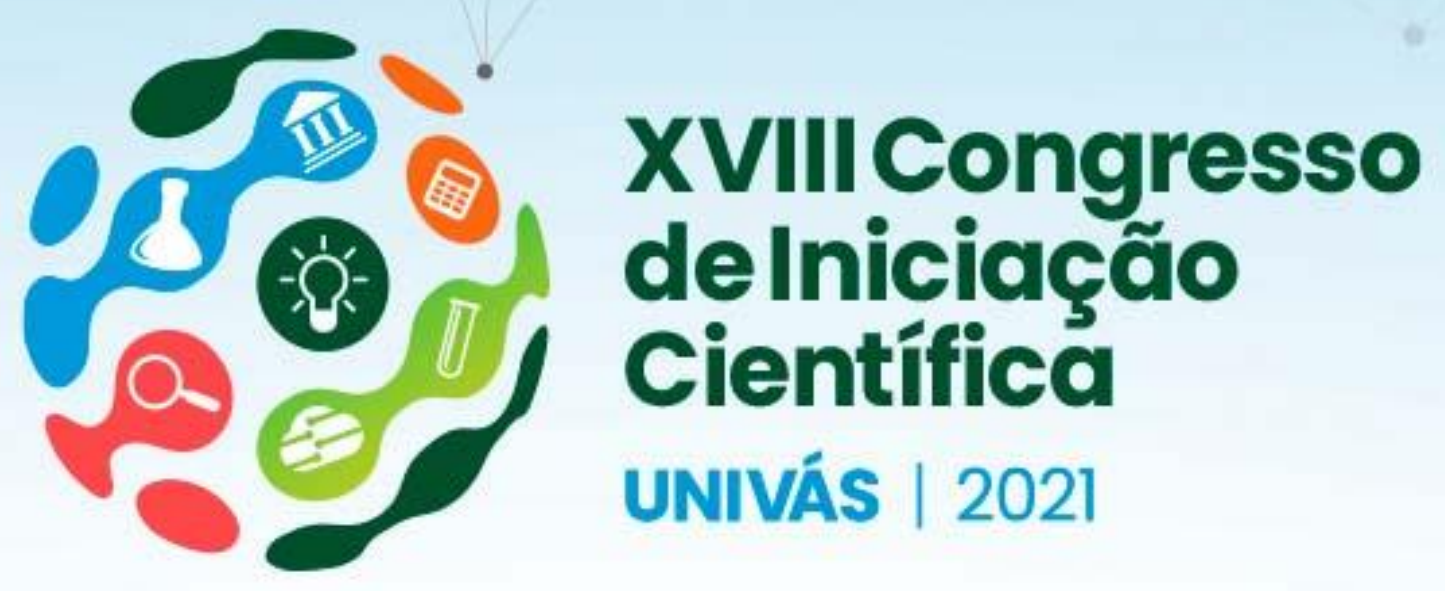

\title{
Anais Eletrônicos do XVIII Congresso de Iniciação Científica
}

\author{
$10^{a}$ Edição \\ Pouso Alegre - Univás 2021
}

Pró-Reitoria de

Pós-Graduação e Pesquisa
Pró-Reitoria de Extensãoe Assuntos Comunitários 


\title{
UNIVERSIDADE DO VALE DO SAPUCAÍ-UNIVÁS
}

Anais Eletrônicos do XVIII Congresso de Iniciação Científica da Univás 2021

\author{
10ํㅡㄹ Edição \\ Pouso Alegre - Univás 2021
}




\section{Anais Eletrônicos do XVIII Congresso de Iniciação Científica da Univás 2021}

O conteúdo dos textos é de inteira responsabilidade dos autores 


\section{Comissão organizadora:}

Amanda Marilyn Figueiredo Silva Antônio Carlos Aguiar Brandão Antônio Homero Rocha de Toledo Flávio Fraga Vilela Gislaine Bittencourt Pereira Guilherme Oliveira Santos
João Inácio Migliorini Silva José Dias da Silva Neto

Silvia Mara Tasso

Tatiane Rosidelma da Silva Taylor Brandão Schnaider

Thalita Aparecida Mamedes

\section{Comissão Técnica:}

Eduardo Isidoro Gonçalves

Gabriel Morais Maroco

Sabrina Meireles Coelho Teodoro 


\title{
Universidade do Vale do Sapucaí
}

\section{Reitoria}

Prof. Dr. Antonio Carlos Aguiar Brandão

Reitor

Prof. Dr. José Dias da Silva Neto

Pró-Reitor de Graduação

Pró-Reitor de Pós-Graduação e Pesquisa

Prof. Antônio Homero Rocha de Toledo

Pró-Reitor de Extensão e Assuntos Comunitários

Prof. Dr. Félix Carlos Ocáriz Bazzano

Diretor da Faculdade de C. da Saúde Dr. José Antônio Garcia Coutinho

Prof. Me. Guilherme Luiz Ferrigno Pincelli

Diretor da Faculdade de Filosofia, Ciências e Letras Eugênio Paccelli

\section{Fundação de Ensino Superior do Vale do Sapucaí}

\author{
Conselho Diretor
}

Pythágoras de Alencar Olivotti

Presidente

Elísio Meirelles de Miranda

Vice-Presidente

Leonardo de Oliveira Rezende

Vogal

Igor Souza Nogueira Oshiro

Diretor Executivo

Celina Aparecida Siqueira da Costa

Secretária da Presidência 
DOI Anais Eletrônicos: https://doi.org/10.54665/CIC.18.2021.univas

DOI do Congresso: https://doi.org/10.54665/CICXVIII.2021

Dados Internacionais de Catalogação na Publicação - CIP

Silva Neto, José Dias da (Org.).

Anais eletrônicos do XVIII Congresso de Iniciação Científica da Univas 2021 / organização de José Dias da Silva Neto, Antônio Homero Rocha de Toledo, Taylor Brandão Schnaider ... [et al.]. - 10.ed. - Pouso Alegre: Univás, 2021.

$102 \mathrm{p}$.

Vários autores

ISBN: 978-85-67647-78-4

Formato: e-book

1. Iniciação científica. 2. Ciências - Estudo e ensino. 3. Pesquisas. 4. Iniciação científica - Congressos. 5. Produção cientifica. I. Toledo, Antonio Homero Rocha de org. II. Schnaider, Taylor Brandão, org. III. Título. 
Projeto Gráfico: ASCOM

Editoração Eletrônica: Guilherme Oliveira Santos

Formato: E-book

№ de Páginas: 102

Edição: Novembro de 2021

Editora: Editora Univás

$10^{\mathrm{a}}$ Ediç̧ão

Ano da Edição: 2021 
UNIVÁs | 2021

\section{Comitê Científico}

Adriana Rodrigues dos Anjos Mendonça

Ana Carolina Brasil e Bernardes

Ana Cláudia Neves Gonçalves

Ana Claudia Raposo Ramos

Ana Lúcia Francisco

Antônio Homero Rocha de Toledo

Atílio Catosso Salles

Bruna Leonel Carlos

Camila Claudiano Quina Pereira

Carla Aparecida Pacheco

Cássio José de Oliveira Silva

Daniela Francescato Veiga

Demétrius Tierno Martins

Diba Maria Sebba Tosta de Souza

Diego Henrique Pereira

Emilene Bueno Rodrigues

Eugênio Fernandes de Magalhães

Fabiola Cunha Bernardes e Rezende

Fiorita Gonzales Lopes Mundim

Geovany Rosa Pires

Jair Pinto de Assis Júnior

Jaqueline Helen Viana Pires

Jaqueline Jóice Muniz

Joelma Pereira de Faria Nogueira

Juliana Aparecida dos Santos

Laís Prudente de Andrade
Lariana Paula Pinto

Lyliana Coutinho Resende Barbosa

Maria Camila Moreira Fonseca

Maria Cristina Porto e Silva

Marta Garroni Magalhães

Michele de Santana Carmelossi

Patrícia de Campos Lopes

Paula Chiaretti

Paulo Roberto Maia

Peterson Beraldo de Andrade

Ricardo da Silva Alves

Rita de Cássia Pereira

Roberto Ribeiro Rocha

Rodrigo Machado Pereira

Rodrigo Rios Faria de Oliveira

Rogério Lobo Sáber

Rosilene de Lima Machado Silva

Rosimeire Aparecida Soares Borges

Silvia Mara Tasso

Suzana Costa Coutinho

Taylor Brandão Schnaider

Valter Henrique Marinho dos Santos

Vanessa da Fontoura Custódio Monteiro

Vitor Ângelo Carlucio Galhardo

Viviane Aparecida de Souza Silveira 


\section{Realização}

Prof. Dr. José Dias da Silva Neto

Pró-Reitoria de Graduação e Pós-Graduação e Pesquisa

Prof. Me. Antônio Homero Rocha de Toledo

Pró-Reitoria de Extensão e Assuntos Comunitários

Prof. Flávio Fraga Vilela e Prof. Dr. Taylor Brandão Schnaider

Coordenadoria de Pesquisa

\section{Apoio}

Universidade do Vale do Sapucaí - UNIVÁS

Fundação de Ensino Superior do Vale do Sapucaí- FUVS

Fundação de Amparo à Pesquisa do Estado de Minas Gerais- FAPEMIG

\section{Patrocínio}

Instituto Sul Mineiro de Oncologia - ONCOMINAS 


\section{APRESENTAÇÃO}

O Congresso de Iniciação Cientifica é o maior evento científico da Universidade do Vale do Sapucaí - UNIVÁS, congregando alunos e professores das mais diferentes áreas do conhecimento e de várias instituições de ensino e pesquisa da região do Sul de Minas Gerais e de outros estados do Brasil. É o momento científico em que os alunos mostram os resultados obtidos em suas pesquisas de Iniciação Científica, sob a forma de comunicação oral, participam de minicursos, com o objetivo de propiciar uma maior interatividade entre o público inscrito e disseminação de conhecimento por meio de demonstrações de técnicas, metodologias, ferramentas e aplicações, tendo ainda a oportunidade de publicarem seus trabalhos nos Anais do evento.

Em 2021, devido à pandemia, o Congresso ocorrerá de forma online e as apresentações acontecerão apenas na modalidade Comunicação oral, via Plataforma Microsoft Teams. A modalidade oral é obrigatória para os acadêmicos da UNIVÁS que foram contemplados em um dos nossos programas de Iniciação Científica. Alunos de outras instituições também poderão apresentar os resultados das Pesquisas de Iniciação Científica desenvolvidas em suas Instituições.

O Congresso não aborda apenas a apresentação dos trabalhos dos discentes, mas cumpre com a missão de evidenciar a cultura científica da UNIVÁS, por meio da prática reflexiva, produção de saber e principalmente contribuição para a formação de recursos humanos para a pesquisa, ao permitir ao aluno a iniciação no método científico, às técnicas de cada área e o desenvolvimento da criatividade na ciência, processo este que é orientado por um docente pesquisador qualificado.

Nesta edição do Congresso teremos o Prêmio "Destaque Iniciação Científica Oncominas 2021 Jovem Pesquisador", que terá o objetivo de identificar os três melhores trabalhos apresentados. Esta é uma iniciativa da Univás que contará com o patrocínio do Instituto Sul Mineiro de Oncologia ONCOMINAS. Além da premiação foi atribuído ao evento e aos Anais eletrônicos o DOI, "Identificador de Objeto Digital", que é um padrão que serve para identificar documentos virtuais de forma permanente.

Os resumos aprovados para apresentação estão disponibilizados a seguir e o leitor poderá avaliar a qualidade, a atualidade e a relevância das pesquisas aqui desenvolvidas.

Prof. Dr. José Dias da Silva Neto Pró-Reitoria de Pós-Graduação e Pesquisa 


\section{SUMÁRIO}

A CASCA DA BANANA VERDE PARA CONTROLE DO PRURIDO DE ÚLCERAS CRÔNICAS .......... 18

ISADORA ANDRÉ DE CAMARGO PACHECO*; BRUNA DE CÁSSIA SOUSA; MAYCON CRISTIAN GOMES DE PAULA; YUJI ATARASHI TAVARES; DÊNIA AMÉLIA NOVATO CASTELLI VON ATZINGEN; ADRIANA RODRIGUES DOS ANJOS ............................................. 18

A EDUCAÇÃO FINANCEIRA COMO INSTRUMENTO DE AUXÍLIO NA GESTÃO DAS FINANÇAS PESSOAIS

LAURA PEREIRA SIVA*; GEOVANY ROSA PIRES

A PERCEPÇÃO DA TELEMEDICINA POR ACADÊMICOS DE MEDICINA DURANTE A PANDEMIA DO COVID-19.

ANNA JÚLIA DE PAULA RESENDE*; JULIANA OLIVEIRA MOREIRA; MAYCON CRISTIAN GOMES DE PAULA; NATHAN FERREIRA DE MELO;

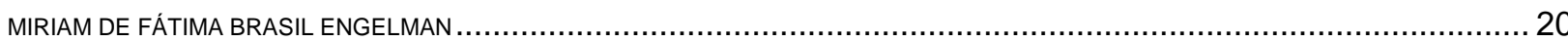

A PERCEPÇÃO DE PROFESSORES SOBRE O USO DE TIC EM TEMPOS DE COVID-19................ 21

JÉSSICA RAFAELA FONSECA PATROCÍNIO*; LAÍS REZENDE DA COSTA; LARIANA PAULA PINTO .........................................21

A PORNOGRAFIA INFANTIL LEGALIZADA: SEXUALIZAÇÃO DE MENORES DE IDADE EM ANIMAÇÕES JAPONESAS

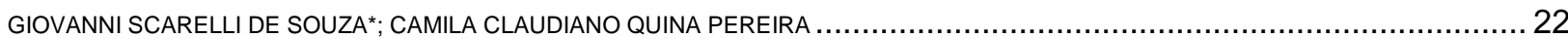

AMIDO RESISTENTE EM RECEITAS: ANÁLISE SENSORIAL DE PICOLÉ DE CHOCOLATE COM BIOMASSA DE BANANA VERDE

MARIANNE ZORDAN*; MICHELE CRISTINA DA COSTA SILVA

ANÁLISE CORRELACIONAL ENTRE O USO DA FOTOGRAMETRIA COMPUTADORIZADA E DA PLATAFORMA WII BALANCE BOARD® PARA MENSURAÇÃO DA PROJEÇÃO DO CENTRO DE MASSA CORPORAL

RODRIGO ALVES ROBERTO*; GIOVANNI TENÓRIO LAGATTA; RICARDO DA SILVA ALVES

ANÁLISE DA ATIVIDADE ANTIBACTERIANA DO EXTRATO HIDROALCOÓLICO DA CASCA DE SCHINUS TEREBINTHIFOLIUS (AROEIRA) SOBRE STAPHYLOCOCCUS AUREUS E STREPTOCOCCUS PYOGENES

AMANDA MARIA DE ALMEIDA RIBEIRO*; TULIO CUSTÓDIO REIS; DEBORA APARECIDA DA ROSA SOUZA; FRANCISCO EDUARDO DE CARVALHO COSTA; GISLAINE CRISTINA SCODELER; RODRIGO MACHADO PEREIRA ............................................... 25

ANÁLISE DA ATIVIDADE HEMOLÍTICA DOS EXTRATOS HIDROALCÓOLICOS DA CASCA DE SCHINUS TEREBINTHIFOLIUS (AROEIRA) E STRYPHNODENDRON ADSTRINGENS (BARBATIMÃO) EM ÁGAR SANGUE

DÉBORA APARECIDA DA ROSA SOUZA*; TULIO CUSTÓDIO REIS; AMANDA MARIA DE ALMEIDA RIBEIRO; GISLAINE CRISTINA SCODELER; RODRIGO MACHADO PEREIRA; GISLAINE CRISTINA SCODELER; RODRIGO MACHADO PEREIRA ....................................226

ANÁLISE DA CONFIABILIDADE INTER E INTRAEXAMINADOR DO USO DE DISPOSITIVO ARDUÍNO PARA AVALIAÇÃO DA FORÇA MUSCULAR ISOMÉTRICA DOS MÚSCULOS ABDUTORES DO OMBRO.

KAUANY NASCIMENTO FAGUNDES*; ISABELLA VIEIRA GOMES; BRUNA LEONEL CARLOS; RICARDO DA SILVA ALVES 27

ANÁLISE DA DOR EM PACIENTES PORTADORES DE ÚLCERAS CRÔNICAS EM USO DO GEL DA CASCA DA BANANA VERDE

BRUNA DE CÁSSIA SOUSA*; ISADORA ANDRÉ DE CAMARGO PACHECO; MAYCON CRISTIAN GOMES DE PAULA; YUJI ATARASHI TAVARES DÊNIA AMÉLIA NOVATO CASTELLI VON ATZINGEN; ADRIANA RODRIGUES DOS ANJOS MENDONÇA. 
ANÁLISE DA INCIDÊNCIA DE VIOLÊNCIA DOMÉSTICA NO IML DE POUSO ALEGRE/MG E SUAS LESÕES PROVOCADAS

KENNEDY MENDES ALMEIDA*; ANA LUIZA BASTOS PEREIRA; CAMILA DESTEFANI ROSSI; BEATRIZ JEREMIAS; LUCAS DE MOURA CORSO;

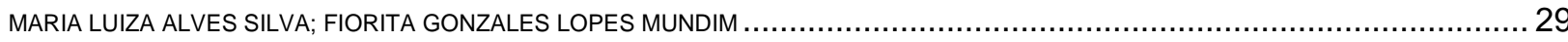

ANÁLISE DA INFLUÊNCIA DA SOBRECARGA DE TRABALHO NA SAÚDE FÍSICA E MENTAL DE CUIDADORES DE PACIENTES COM CÂNCER: ESTUDO PRELIMINAR.

JULLIAN STEFANI VIANA*; NICOLE MARIANA VEIGA; BRUNA LEONEL CARLOS; RICARDO DA SILVA ALVES .............................. 30

ANÁLISE DE CORRELAÇÃO E CONCORDÂNCIA ENTRE TESTES LÚDICOS ADAPTADOS VERSUS TESTES CONVENCIONAIS DE AVALIAÇÃO FUNCIONAL DE IDOSOS

SARA TALINE CORRÊA DA SILVA*; CAMILA DE CÁSSIA SANTOS; MAYRA KIANE DE MELO RIBEIRO; POLLIANA GABRIELA DE PAULA SILVEIRA; BRUNO MENDES; RICARDO DA SILVA ALVES

ANÁLISE DO EQUILÍBRIO POSTURAL E DESEMPENHO MOTOR DE CRIANÇAS PRATICANTES DE BALLET 32

GABRIELA DO PRADO CORRÊA*; CAROLINE PEREIRA DE MELO; BRUNA LEONEL CARLOS; RICARDO DA SILVA ALVES................... 32

ANÁLISE HISTOPATOLÓGICA E HISTOMORFOMÉTRICA DO INTESTINO DELGADO EM RATOS WISTAR SUBMETIDOS À INGESTÃO DIÁRIA DE ÁLCOOL

THAÍS SANTA CRUZ MORAES*; SARA SEMAAN SILVEIRA; FIORITA GONZALES LOPOES MUNDIM; RODRIGO MACHADO PEREIRA ......... 33

ANUROFAUNA EM UNIDADE DE CONSERVAÇÃO MUNICIPAL, POUSO ALEGRE, SUL DE MINAS GERAIS.

RAISSANE FURTADO DE MENDONÇA*; ALLYSON LUCIANO VIEIRA; GUSTAVO CRUZ LIMA; LEANDRO GUSTAVO DO PRADO; THAIS HELENA

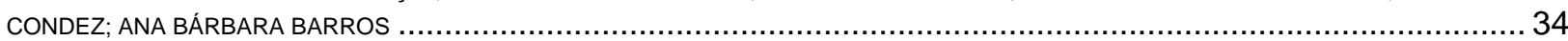

APLICATIVO MÓVEL PARA O INSTRUMENTO “RASTREAMENTO DO PÉ DIABÉTICO DE ALTO RISCO: UMA FERRAMENTA DE 60 SEGUNDOS" 35

RAYSSA BARROS*; JOÃO VÍTOR DE OLIVEIRA; BEATRIZ BERTOLACCINI MARTÍNEZ ….............................................................................35 APLICATIVO PARA RASTREAMENTO DO CÂNCER COLORRETAL E VIGILÂNCIA PÓSPOLIPECTOMIA 36

MIRELLE DE PAULA RIBEIRO*; LAÍS PRUDENTE DE ANDRADE; CARLOS ROBERTO AMORIM; TAYLOR BRANDÃO SCHNAIDER .............36

AQUECIMENTO GLOBAL E A AMEAÇA À SAÚDE HUMANA. DISCUSSÃO ÉTICA.......................... 37

LUCAS EDUARDO OLIVEIRA DE REZENDE*; RAFAEL LAZZAROTTO SIMIONI; MANOEL ARAUJO TEIXEIRA .................................. 37

ARGUMENTAÇÃO E HISTÓRIA: UM ESTUDO DOS DISCURSOS DOS PRESIDENCIÁVEIS ............ 38

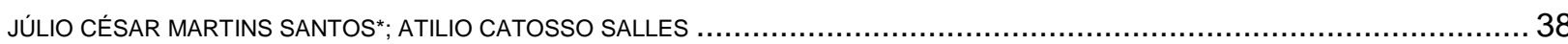

ATIVIDADE ANTIBACTERIANA DO EXTRATO HIDROALCOÓLICO DAS FOLHAS DE PSIDIUM GUAJAVA LINN.

JAQUELINE APARECIDA PIRES*; FABIO LUIZ PEREIRA FERREIRA; LUIZ FRANCISLEY DE PAIVA; RODRIGO MACHADO PEREIRA ......... 39

ATIVIDADE ANTIMICROBIANA DO EXTRATO ETANÓLICO DAS FOLHAS DE EUGENIA UNIFLORA.

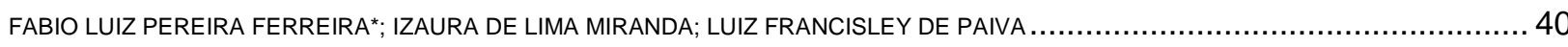

ATIVIDADE ANTIMICROBIANA DO EXTRATO ETANÓLICO DE SCHINUS MOLLE L. ........................ 41

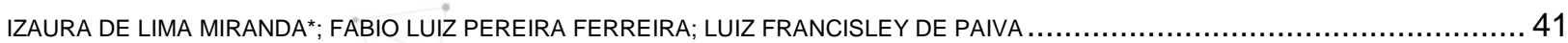

AUTOESTIMA, OTIMISMO E ESPERANÇA EM PROFESSORES EM TEMPOS DE COVID-19..........42

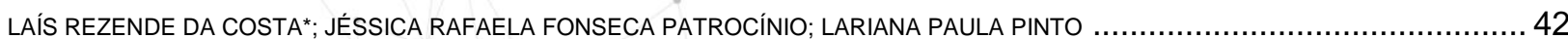


AVALIAÇÃO ALIMENTAR E CONSUMO DE CARBOIDRATO EM PRATICANTES DE MUSCULAÇÃO E SUA RELAÇÃO COM A COMPOSIÇÃO CORPORAL

MICHELE TAÍS NATO*; ANDRÉA TIENGO; CAMILA BLANCO GUIMARÃES

AVALIAÇÃO DA ATIVIDADE CARRAPATICIDA DO ÓLEO ESSENCIAL DE MELALEUCA ARMILLARIS SOBRE CARRAPATOS

MAISA VILAS BOAS SILVA*; ANDRÉ DE SOUZA E SILVA; ADRIANA RODRIGUES DOS ANJOS MENDONÇA.

AVALIAÇÃO DA CICATRIZAÇÃO DE FERIDAS CRÔNICAS TRATADAS COM O PÓ DA CASCA DA BANANA MUSA SAPIENTUM VERDE.

YUJI ATARASHI TAVARES*; MAYCON CRISTIAN GOMES DE PAULA; BRUNA DE CÁSSIA SOUSA; ISADORA ANDRÉ DE CAMARGO PACHECO; DÊNIA AMÉLIA NOVATO CASTELLI VON ATZINGEN; ADRIANA RODRIGUES DOS ANJOS MENDONÇA

AVALIAÇÃO DA CINÉTICA INFLAMATÓRIA INDUZIDA POR EXTRATOS HIDROALCÓOLICOS DA CASCA DE SCHINUS TEREBINTHIFOLIUS (AROEIRA) E STRYPHNODENDRON ADSTRINGENS (BARBATIMÃO) EM VESÍCULAS NO TECIDO SUBCUTÂNEO DE RATAS WISTAR .

TÚLIO CUSTÓDIO REIS*; AMANDA MARIA DE ALMEIDA RIBEIRO; DÉBORA APARECIDA DA ROSA SOUZA; GISLAINE CRISTINA SCODELER; RODRIGO MACHADO PEREIRA; FABÍOLA CUNHA BERNARDES E REZENDE.

AVALIAÇÃO DA INCIDÊNCIA E DA FAIXA ETÁRIA PREVALENTE DO ÍNDICE DE ABORTAMENTO NO HOSPITAL DAS CLÍNICAS SAMUEL LIBÂNIO

ANNA JÚLIA DE PAULA RESENDE*; JULIANA OLIVEIRA MOREIRA; LUCAS ALVES BARTELEGA; NATHAN FERREIRA DE MELO; FIORITA GONZALES LOPES MUNDIM.

AVALIAÇÃO DAS CARACTERÍSTICAS MECÂNICA DO PLA, IMPRESSA EM 3D, PARA BIOMATERIAIS 48

GABRIEL YUDY PEREIRA SATO*; IGOR SOUZA NOUGUEIRA OSHIRO; HULISSES BONETI MARCON 48

AVALIAÇÃO DO DESTINO DOS EFLUENTES GERADOS NA ZONA RURAL, EM ANHUMAS, POUSO ALEGRE - MG.

JOYCE DA SILVA BALBINO*; VANESSA DA FONTOURA CUSTÓDIO MONTEIRO; FARLEY SOARES BRAZ; VANESSA DA FONTOURA CUSTÓDIO MONTEIRO

AVALIAÇÃO FITOQUÍMICA DA ESPÉCIE JACARANDA CUSPIDIFOLIA MART ..............................50

LARA EMILLY BRANDÃO*; MARENNA CARDINALLI FÉLIX; CÁSSIA MARIA FURLAN

AVALIAÇÃO MORFOLÓGICA E IMUNO-HISTOQUÍMICA DE LINFOMAS NÃO-HODGKIN DIAGNOSTICADOS NO LABORATÓRIO DE ANATOMIA PATOLÓGICA DO HOSPITAL DAS CLÍNICAS SAMUEL LIBÂNIO (HCSL) DE POUSO ALEGRE, ENTRE 2014 E 2018

ANA TERESA SANTOS RABELO*; ELISA DE PAULA PINTO; CAMILA PIRES DE OLIVEIRA; GABRIELA APARECIDA DE ASSIS; THAÍS SANTA CRUZ MORAES; FIORITA GONZALES LOPES MUNDIM; MIRIAM DE FÁTIMA BRASIL ENGELMAN ..................................... 51

BREAST-Q: EXPECTATIVAS DE PACIENTES BRASILEIRAS QUANTO À RECONSTRUÇÃO MAMÁRIA

LUANA OLIVEIRA DE FARIA*; NATHALIA ALVES SANTOS; TAINARA RITA PEZZINI; IVANILDO ARCHANGELO JUNIOR; LUCIANA CHAMONE

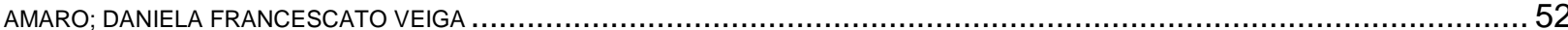

COMPOSIÇÃO FLORÍSTICA DE MATA CILIAR COMO SUBSÍDIO PARA RESTAURAÇÃO FLORESTAL EM POUSO ALEGRE - MG

DANILO AUGUSTO DA SILVA*; PABLO JOSÉ REZENDE MOURA; VANESSA DA FONTOURA CUSTÓDIO MONTEIRO; FARLEY SOARES BRAZ

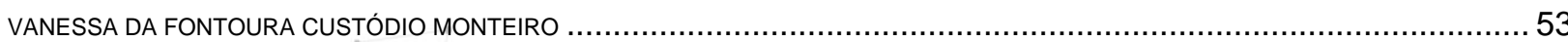

CONDIÇÕES DE SAÚDE DE ACADEMICOS DE ENFERMAGEM DURANTE A PANDEMIA DE COVID-19 
CORRELAÇÃO ENTRE A RELAÇÃO CINTURA-QUADRIL E OS VALORES DA PRESSÃO ARTERIAL EM ESTUDANTES DE MEDICINA

GUSTAVO PAIVA AZEVEDO*; LUIZ GIOVANNI TEIXEIRA RIGATO; GUSTAVO ALBERTO LEMES SANTOS; LIVIA COUTO MELO; MARINA VILLELA FREIRE; PAULO ROBERTO MAIA; SILVIA MARA TASSO.....

CORRELAÇÃO ENTRE ALONGAMENTO E MOBILIZAÇÃO NA MELHORA DA AMPLITUDE ARTICULAR DE PRATICANTES DE MUSCULAÇÃO

LUANA APARECIDA DOS SANTOS*; SARAH DE PAULA PINTO; DIEGO GUIMARÃES OPENHEIMER; RICARDO DA SILVA ALVES 57

DESENVOLVIMENTO DE ALGORITMO E APLICATIVO SOBRE CUIDADOS PÓS-OPERATÓRIOS EM RECONSTRUÇÃO MAMÁRIA

IARA PAIVA GERÔNIMO*; EVELYNE BORGES DE MATTOS ANDRADE; DRA. DANIELA FRANCESCATO VEIGA ................................ 58

DESVELANDO A REPRODUÇÃO ASSISTIDA PELO SISTEMA ÚNICO DE SAÚDE ...........................59

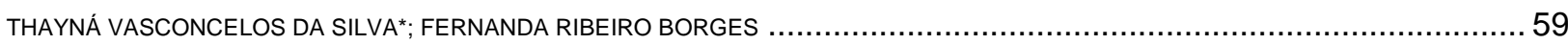

DISPENSAÇÃO DE MEDICAMENTOS EM AMBULATÓRIO OCUPACIONAL DE UMA EMPRESA DE

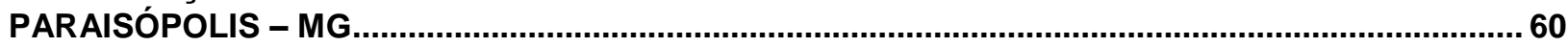

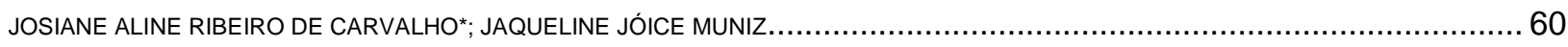

EFEITO AGUDO DA MOBILIZAÇÃO COM MOVIMENTO EM PACIENTES COM DOR LOMBAR ........61

TAYLA MARIA FRAGA CAMARGO*; MARCELO RENATO MASSAHUD JUNIOR ; RICARDO DA SILVA ALVES................................. 61

EFEITO DA INTERVENÇÃO FISIOTERAPÊUTICA NA HÉRNIA DE DISCO LOMBAR: REVISÃO DE LITERATURA.

ADRIELLE DANDARA RIBEIRO RAMOS ${ }^{*}$; LUCAS DE OLIVEIRA MACHADO; RICARDO CUNHA BERNARDES ................................... 62

EFEITOS DA EXPOSIÇÃO À LUZ DE DISPOSITIVOS ELETRÔNICOS NO CICLO CIRCADIANO ..... 63 GUSTAVO JUNHO TOLEDO*; MATEUS GOMES POLO; VINICIUS FONSECA BERNARDES; GUILHERME MIRANDA BÓCOLI; JOSÉ DIAS DA SILVA NETO.

ELABORAÇÃO E VALIDAÇÃO DE UMA CARTILHA DE ORIENTAÇÕES PARA CUIDADORES DE PACIENTES PORTADORES DE ESCLEROSE LATERAL AMIOTRÓFICA. 64

MARIA EDUARDA CALIXTO COVELO*; BRUNA LEONEL CARLOS 64

ESPIRITUALIDADE E EDUCAÇÃO: EM DEFESA DE UMA PEDAGOGIA HOLÍSTICA .......................65

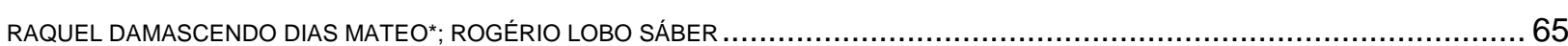

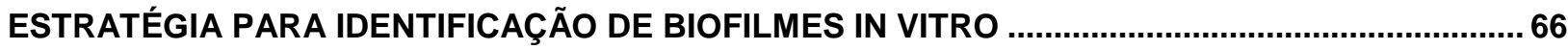

JOÃO VITOR DE SOUSA TOLEDO*; RODRIGO MACHADO PEREIRA; GUSTAVO BRUNELLI VALLIM; LIVIA ROCHA MARTINS; LUIZ FRANCISLEY DE PAIVA; DIBA MARIA SEBBA TOSTA DE SOUZA

ESTRESSE E QUALIDADE DE VIDA EM ESTUDANTES DE MEDICINA NO CONTEXTO DA COVID19

GUSTAVO PAIVA AZEVEDO*; GABRIEL CARNEIRO BRANDÃO DE MELO; ANTÔNIO HOMERO ROCHA DE TOLEDO; JOSÉ DIAS NETO .... 67 ESTUDO HISTOLÓGICO DA PELE DE TRUTA ARCO-ÍRIS (ONCORHYNCHUS MYKISS).................68 MAYRA FARIA GOULART*; ANA CAROLINA SOARES; LUCAS BRAGA DE ANDRADE; GABRIELLA LUDOVICO FRAGA; LUIZ FRANCISLEY DE PAIVA; WELLINGTON DELFINO; RODRIGO MACHADO PEREIRA

EXAME DE SUFICIÊNCIA DO CONSELHO FEDERAL DE CONTABILIDADE: OBSERVAÇÕES DOS ALUNOS DO CURSO DE CIÊNCIAS CONTÁBEIS

FATORES DA PERSONALIDADE E A EVASÃO E PERMANÊNCIA NO ENSINO SUPERIOR .............70 
UNIVÁs | 2021

FIGURAÇÕES DA INFÂNCIA NA LITERATURA GÓTICA: UMA LEITURA PSICANALÍTICA DA OBRA

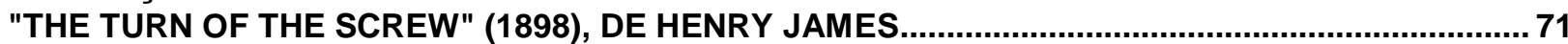

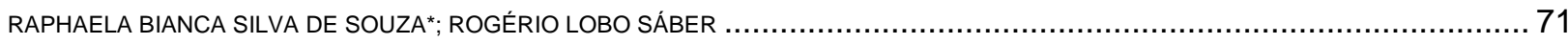

FIGURAÇÕES E DINÂMICA DA VIOLÊNCIA EM LIGHT IN AUGUST (1932), DE WILLIAM

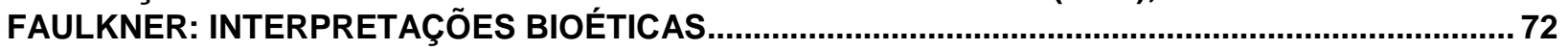

JOÃO MATHEUS VILHENA DOS SANTOS*; STEPHANY VITÓRIA COSTA GONÇALVES; ROGÉRIO LOBO SÁBER .............................. 72

FRATURA DE ACETÁBULO: COMPARAÇÃO DO RESULTADO FUNCIONAL ENTRE AS VIAS DE STOPPA E ILIOINGUINAL; REVISÃO SISTEMÁTICA DE LITERATURA

MATEUS GOMES POLO*; GUSTAVO JUNHO TOLEDO; ANA CAROLINA MONÇÃO BASSO; VINICIUS FONSECA BERNARDES; DIÓGENES

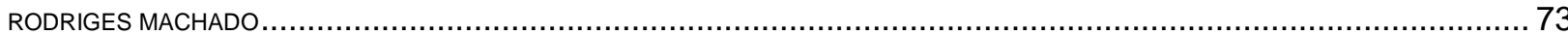

GEL DESBRIDANTE PARA FERIDAS CRÔNICAS, PRODUZIDO COM A CASCA VERDE DA BANANA.

MAYCON CRISTIAN GOMES DE PAULA*; YUJI ATARASHI TAVARES; BRUNA DE CÁSSIA SOUSA; ISADORA ANDRÉ DE CAMARGO PACHECO; DÊNIA AMÉLIA NOVATO CASTELLI VON ATZINGEN; ADRIANA RODRIGUES DOS ANJOS MENDONÇA ..................................... 74

GEL FITOTERÁPICO PARA O TRATAMENTO DE MELASMAS .................................................... 75

LUCAS MENDES NUNES*; DÊNIA AMÉLIA NOVATO CASTELLI VON ATZINGEN; JAQUELINE JOICE MUNIZ; RAFAELA FERNANDA OLIVEIRA DE

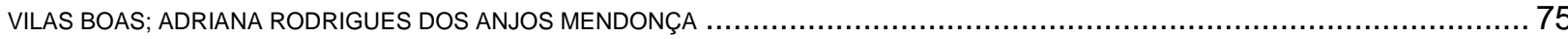

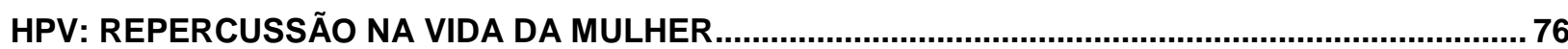

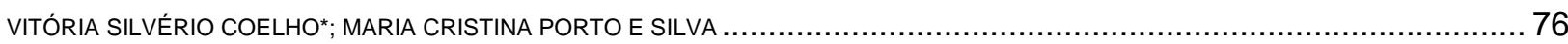

INFLUENCIA DA ANSIEDADE NO COMPORTAMENTO ALIMENTAR DOS UNIVERSITÁRIOS DA REDE DE ENSINO PRIVADO DOS CURSOS DE ENFERMAGEM E NUTRIÇÃO .................................77

LILIANE APARECIDA PEREIRA*; LILIANE APARECIDA PEREIRA; ANA CAROLINA BRASIL E BERNARDES ................................. 77

LEVANTAMENTO PARASITOLÓGICO DAS AVES SILVESTRES EM MANTENEDOURO DE FAUNA NO MUNICÍPIO DE POUSO ALEGRE, MINAS GERAIS ................................................................ 78

STHEFANIE CAROLINE RODRIGUES DE LIMA*; ANA BÁRBARA BARROS; SÁVIA PERINA PORTILHO FALCI.................................. 78

MANUAL FISIOTERAPÊUTICO PARA GESTANTES E PUÉRPERAS: PREVENINDO A

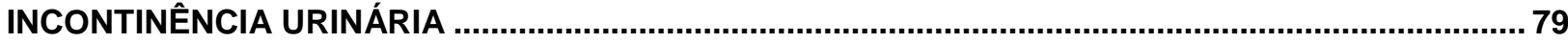

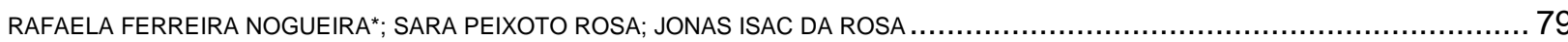

MANUAL PARA ORIENTAR O PROFISSIONAL DA SAÚDE NO TRATAMENTO DE ÚLCERA VENOSA

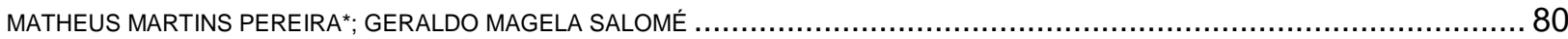

MASTOFAUNA EM FRAGMENTO DE MATA ATLÂNTICA, PORÇÃO SUL DE MINAS GERAIS ......... 81

ALYSON JOSÉ GONÇALVES DOS SANTOS*; TADEU GOMES DE OLIVEIRA; ALEXANDRE MARTINS COSTA LOPES; ANA BARBARA

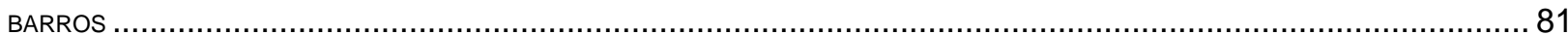

MULTISENSE NO EXAME NEUROLÓGICO PERIFÉRICO EM DIABÉTICOS ...................................... 82

MARIA VITÓRIA SOUZA ROSA*; BEATRIZ BERTOLACCINI MARTÍNEZ; BRUNO TAVARES VALE; BRUNO TAVARES VALE; BEATRIZ

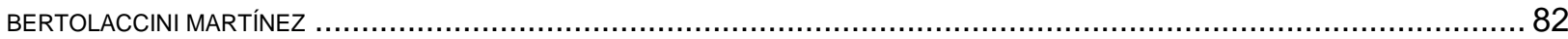

NÍVEL DE ATIVIDADE FÍSICA, ESTADO NUTRICIONAL E SÍNDROME METABÓLICA EM POLICIAIS

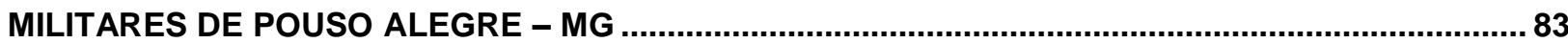

GABRIELLY APARECIDA SILVEIRA REZENDE*; CAMILA BLANCO GUIMARÃES ................................................... 83

O CAMAROTE DAS PRINCESAS: A LEGITIMAÇÃO VISUAL DO LUGAR DA MULHER NA COROAÇÃO DE DOM PEDRO II DE MANUEL DE ARAÚJO PORTO-ALEGRE. 84

JÚLIA KLEHM FERMINO*; RAFAEL LAZZAROTTO SIMIONI 
O MANUAL “METODOLOGIA DA MATEMÁTICA” DE IRENE DE ALBUQUERQUE (1954): UM ESTUDO DA ARITMÉTICA

ELANIA KELLY DE ARAUJO SOUSA*; ELANIA KELLY DE ARAÚJO SOUSA; ROSIMEIRE APARECIDA SOARES BORGES; ROSIMEIRE

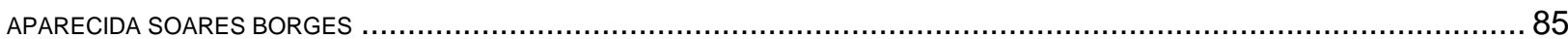

O QUE A DEPRESSÃO E O SUICÍDIO (C)FALAM ATARVÉS DA PSICANÁLISE E A CANÇÃO "DESCONSTRUÇÃO" DE TIAGO IORC 86

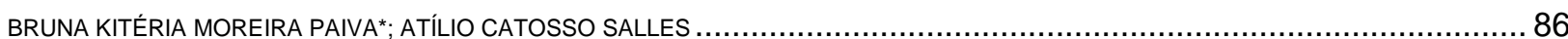

OS DIGITAL INFLUENCERS E O (SEU) DISCURSO DE MODA NO YOUTUBE ................................. 87

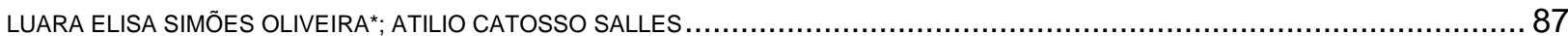

PADRONIZAÇÃO DO MÉTODO DE COLORAÇÃO HISTOQUÍMICA UTILIZANDO TANINOS OBTIDOS DE RESÍDUOS DA MADEIRA DE EUCALIPTO …........................................................... 88

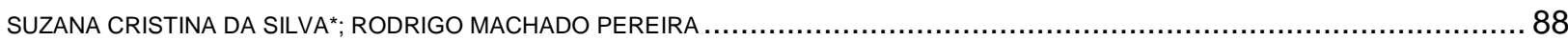

PANCREATITE PTH DEPENDENTE

ISABELLA STEPHANIE SIMÕES*; RUBIA PINHEIRO; JORGE LUIZ DE CARVALHO MELO ............................................ 89

PERCEPÇÃO DOS FAMÍLIARES DE DEPENDENTES QUIMICOS SOBRE O TRATAMENTO NO CENTRO DE ATENÇÃO PSICOSSOCIAL- CAPS AD

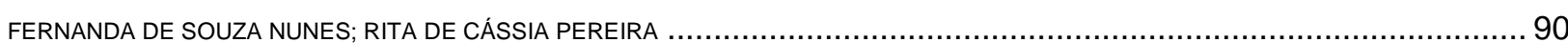

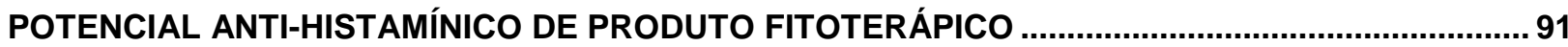

MARIA SYLVIA RENNÓ KALLÁS*; NAYANNE GOMES MARCIANO; RAFAELA PRADO GUIMARÃES; ADRIANA RODRIGUES DOS ANJOS MENDONÇA

PRÁTICAS INTEGRATIVAS E COMPLEMENTARES: AVALIAÇÃO DA AROMATERAPIA EM IDOSOS.

JÚLIA DE PAULA OLIVEIRA*; JÚLIA SIQUEIRA COSTA PAPI; JOSÉ VITOR DA SILVA; ADRIANA RODRIGUES DOS ANJOS MENDONÇA ......92

PREDITORES DE DOR NA COLUNA LOMBAR EM UNIVERSITÁRIOS ............................................93

ANDRESSA BATISTA DO PATROCÍNIO SANTOS*; ANDRESSA BATISTA DO PATROCÍNIO SANTOS; TÁBATA CAROLINE TERRA VILELA;

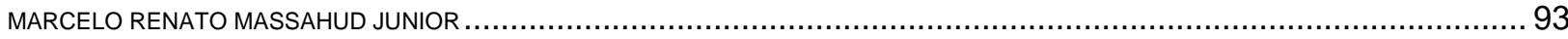

PRESERVAÇÃO DA FERTILIDADE DE PACIENTES ONCOLÓGICAS: ABORDAGEM BIOÉTICA.... 94

ANA SOFIA FORTUNATO BORGES*; LYLIANA COUTINHO RESENDE BARBOSA; JOSÉ DIAS DA SILVA NETO ..............................99

PRODUTO FITOTERÁPICO PARA TRATAMENDO DE ACNE EM PACIENTES JOVENS...................95

RAFAELY TAYNARA RODRIGUES TORQUATO NUNES*; MARINA ARAÚJO RABELO; DANIELLE APARECIDA FERREIRA DE OLIVEIRA

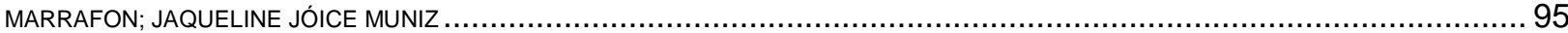

QUALIDADE DE VIDA DE PACIENTES COM DOENÇAS CARDIOVASCULARES EM TERAPIA COM ANTICOAGULANTES EM POUSO ALEGRE

MILENA BARBOSA DE ARAUJO; ELIANA NACARATO VIANNA DE ANDRADE; SARA SANTOS ARAUJO; AUGUSTO CASTELLI VON

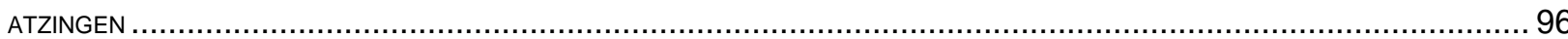

RELAÇÃO DA INCIDÊNCIA DOS SUBTIPOS DE CÂNCER DE MAMA COM A IDADE DAS PACIENTES NO SERVIÇO DE PATOLOGIA DO HOSPITAL DAS CLÍNICAS SAMUEL LIBÂNIO POUSO ALEGRE - MG

ELISA KEIKO DE SOUZA IGARASHI*; AMANDA MUNIZ FONTES; GUSTAVO BRUNELLI VALLIM; MIRIAM DE FÁTIMA BRASIL ENGELMAN; FIORITA GONZALES LOPES MUNDIM .

RELEVÂNCIA DA REABILITAÇÃO FISIOTERAPÊUTICA PARA MINIMIZAR OS IMPACTOS DA SÍNDROME PÓS-COVID: UM ESTUDO OBSERVACIONAL 
RESISTENCIA MEDICAMENTOSA EM DOENTES EM TRATAMENTO DA TUBERCULOSE COM COMORBIDADE.

MAYARA MARQUES LIMA*; LAIZ MANGINI CICCHELERO; ADRIANA ZILLY; MARIA LUZIA TOPANOTTI; REINALDO ANTONIO DA SILVA SOBRINHO

TUMORES ÓSSEOS:CONDUTAS CLÍNICAS E CIRÚRGICAS DO OSTEOSSARCOMA, CONDROSSARCOMA E SARCOMA DE EWING; REVISÃO DE LITERATURA 100

MATEUS GOMES POLO*; DAVI JOSÉ DE CARVALHO MACEDO; EUGÊNIO CÉSAR MENDES 100

USOS E EFEITOS DA RELIGIÃO NA VIDA DE UM DETENTO: UMA REVISÃO BIBLIOGRÁFICA DA LITERATURA A RESPEITO DA INFLUÊNCIA RELIGIOSA NAS PRISÕES BRASILEIRAS 101

GIOVANA BRAGA SANTOS*; CAMILA CLAUDIANO QUINA PEREIRA

VALIDAÇÃO PARA APLICABILIDADE DO APLICATIVO HC PROTECTION 102

ANNA GABRIELA ALMEIDA ALVES*; ANA CAROLINA DE OLIVEIRA; BRUNA DE CÁSSIA SOUSA; HELGA DOS SANTOS CABECEIRA; DIBA MARIA SEBBA TOSTA DE SOUZA. 
UNIVÁs | 2021

\section{A CASCA DA BANANA VERDE PARA CONTROLE DO PRURIDO DE ÚLCERAS CRÔNICAS}

ISADORA ANDRÉ DE CAMARGO PACHECO*; BRUNA DE CÁSSIA SOUSA; MAYCON CRISTIAN GOMES DE PAULA; YUJI ATARASHI TAVARES; DÊNIA AMÉLIA NOVATO CASTELLI VON ATZINGEN; ADRIANA RODRIGUES DOS ANJOS

UNIVÁS - Universidade do Vale do Sapucaí

INTRODUÇÃO: Úlceras venosas são resultados de anormalidades congênitas nas veias e/ou decorrente da dilatação varicosa, levando a um aporte sanguíneo insuficiente e consequentemente lesões e ulcerações na pele. A terapia padrão recomendada deve se pautar por quatro condutas: tratamento da estase venosa, terapia tópica, controle de infecção através de antibioticoterapia sistêmica e prevenção de recidivas. Uma possível opção para a terapia tópica seria o uso de fitoterápicos e plantas medicinais, reconhecidas como alternativa viável de tratamento pela Organização Mundial de Saúde. OBJETIVO: avaliar a intensidade e o tipo de prurido relatado por pacientes com úlceras crônicas tratadas com o gel da casca da banana verde MÉTODOS: Estudo clínico, longitudinal, com amostragem por conveniência. 20 pacientes foram divididos em Grupo Estudo, as úlceras dos pacientes foram tratadas com o gel da casca da banana verde e no Grupo Controle, o curativo foi realizado com Colagenase. A avaliação do prurido foi realizada antes do início do tratamento e uma vez por semana, durante mais 3 semanas. Foi utilizada a escala de Prurido, adaptada a partir da Escala de Dor Emador. Os dados foram organizados em planilha Excel e avaliados pelo Testes de Mann-Whitney e Kruskal Wallis. O nível de significância utilizado como critério de aceitação ou rejeição nos testes estatísticos foi de $5 \%(p<0,05)$. RESULTADOS: a comparação das medianas dos valores de prurido relatados pelos pacientes dos dois grupos, tanto em relação a intensidade quanto ao tipo, não apresentou diferenças estatísticas, com valores de $p>0,05$. CONCLUSÃO: o gel contendo $10 \%$ da casca da banana verde, não causa prurido diferente ao apresentado pelo uso do tratamento com Colagenase.

\section{REFERÊNCIAS}

ATZINGEN, Dênia Amélia Novato Castelli Von et al . Repair of surgical wounds in rats using a $10 \%$ unripe Musa sapientum peel gel. Acta Cir. Bras., São Paulo, v. 30, n. 9, p. 586-592, Sept. 2015 Available from<http://www.scielo.br/scielo.php?script=sci_arttext\&pid=S01026502015000900586\&lng=en\&nrm=is o>. access on 18 Jul. 2019. http://dx.doi.org/10.1590/S0102-865020150090000001.

GRECCO, O.; MOTTA, A. A. Prurido Cutâneo Crônico. In Ed(s). MOTTA, A. A.; AGONDI R. C. Alergia e Imunologia: Aplicação Clínica. São Paulo: Atheneu, 2015.

REZENDE HA, COCCO MIM.The phytoterapy utilization in the rural population routine.Ver Esc Enferm USP 2002.

PALAVRAS-CHAVE: Prurido. Úlcera venosa. Musa sapientum. 


\title{
A EDUCAÇÃO FINANCEIRA COMO INSTRUMENTO DE AUXÍLIO NA GESTÃO DAS FINANÇAS PESSOAIS
}

\author{
LAURA PEREIRA SIVA*; GEOVANY ROSA PIRES \\ UNIVÁS - Universidade do Vale do Sapucaí
}

INTRODUÇÃO: É notório que organizar as finanças pessoais é algo que exige muita disciplina e empenho e, na verdade para inúmeros brasileiros, esse é justamente o maior obstáculo a ser superado. Sabe-se que não é nada fácil manter o rigoroso e assíduo compromisso de anotar as inúmeras despesas que ocorrem no dia a dia e ainda sem perder de vista o controle das compras parceladas bem como das aquisições não planejadas, com o objetivo de equilibrar o orçamento mensal. Além de toda essa dificuldade percebe-se que ano após ano os índices de inadimplência familiar estão se elevando cada vez mais, sendo assim, por meio desse fato corrobora-se a necessidade das pessoas e famílias tomarem conhecimento das suas próprias finanças, ou seja, educar-se financeiramente. Dessa maneira conhecer suas próprias finanças é um ato de zelar por elas, na verdade são atitudes determinantes e conscientes que todo cidadão deveria tomar. Na verdade, essas respectivas atitudes conscientes podem auxiliar para que os índices de inadimplência familiar que estão elevados tornem-se menores. Deste modo justifica-se o objetivo da pesquisa que é demonstrar a importância da educação financeira como instrumento de auxílio na gestão das finanças pessoais. Sendo assim, compreender e praticar a educação financeira pode ser uma das formas de se ter uma vida feliz, saudável e bem-sucedida. METODOLOGIA: O presente trabalho apresenta uma pesquisa descritiva, bibliográfica e documental. RESULTADOS/DESENVOLVIMENTO: Conforme Cherobim (2011, p1), "finanças pessoais é a ciência que estuda a aplicação de conceitos financeiros nas decisões financeiras de uma pessoa ou família". Conforme exposto pelo autor, sobre finanças pessoais, pode-se considerar todos os eventos financeiros individuais em cada fase da vida do indivíduo, onde por meio do planejamento financeiro pessoal é possível adequar o rendimento familiar ou pessoal, percebe-se que o planejamento será capaz de identificar possíveis gastos supérfluos, permitindo um maior controle do dinheiro. O planejamento financeiro pessoal permitirá que a pessoa bem como toda família visualizem de forma mais organizada suas contas na data atual e possíveis projeções futuras (SANTOS, 2014). Fica evidente que a educação financeira pode trazer inúmeros benefícios para as famílias, dentre os benefícios pode-se observar a possibilidade de equilibrar as finanças pessoais, preparar possíveis imprevistos financeiros bem como auxiliar na aposentadoria (CHEROBIM, 2011;SANTOS, 2013). CONCLUSÃO: Segundo o presente trabalho utilizando uma média anual, em 2020 o número de famílias endividadas era de 65,79\% das famílias em 2021 esse número passou para $73,62 \%$, um aumento de $11,9 \%$. Das famílias que estavam endividadas no ano de 2020 , $37,7 \%$ das famílias estavam com contas em atraso e a em 2021 esse percentual passou para 40,35\% um aumento de 7,03\%. Ressalta-se que no ano de 2020, 41,32\% das famílias não teriam condições de pagar as dívidas já no ano de 2020 houve um aumento de aproximadamente $14,64 \%$. Com relação ao tipo de dívida em 2020, 78,31\% corresponde a dívidas com cartão de crédito e em 2021 esse percentual passou para $86,93 \%$ um aumento de aproximadamente $11 \%$. Percebe-se que muitos indivíduos contraem dívidas devido ao consumo excessivo, comprometendo dessa maneira uma parcela significante de sua renda, dessa maneira pode-se dizer que as finanças pessoais auxiliam na elaboração de um planejamento financeiro eficiente e eficaz.

\section{REFERÊNCIAS}

CHEROBIM, A.P.M.S. O que são finanças pessoais. In: CHEROBIM, A.P.M.S. (Org.); CONFEDERAÇÃO NACIONAL DO COMÉRCIO DE BENS, SERVIÇOS E TURISMO. Pesquisa

nacional de endividamento e inadimplência do consumidor (Peic) - set. 2021. Disponível em: < https://www.portaldocomercio.org.br/publicacoes/pesquisa-de-endividamento-e-inadimplencia-doconsumidor-peic-setembro-de-2021/378600 >. Acesso em: 10 de outubro de 2021.

SANTOS, José Odálio dos. Finanças pessoais para todas as idades um guia prático. São Paulo: Atlas, 2014.

PALAVRAS-CHAVE: Educação financeira. Finanças pessoais. Planejamento Financeiro. 


\title{
A PERCEPÇÃO DA TELEMEDICINA POR ACADÊMICOS DE MEDICINA DURANTE A PANDEMIA DO COVID-19
}

\author{
ANNA JÚLIA DE PAULA RESENDE*; JULIANA OLIVEIRA MOREIRA; MAYCON CRISTIAN GOMES DE \\ PAULA; NATHAN FERREIRA DE MELO; MIRIAM DE FÁTIMA BRASIL ENGELMAN \\ UNIVÁS - Universidade do Vale do Sapucaí
}

INTRODUÇÃO: A telemedicina tornou-se essencial na pandemia do vírus Sars-Cov-2 por ser um facilitador ao permitir a assistência à distância, reduzir o tempo entre diagnóstico e tratamento, racionalizar custos e ampliar o acesso a serviços especializados. Esta pesquisa teve como objetivo investigar o conhecimento e a convicção dos acadêmicos de Medicina a respeito das vantagens e desvantagens sobre a aplicabilidade da telemedicina no cenário de pandemia pelo COVID-19. METODOLOGIA: Para este estudo qualitativo, descritivo, transversal e não controlado foram coletados os dados de 211 estudantes do curso de Medicina através de um questionário online com 10 questões de múltipla-escolha. Nove das dez questões foram avaliadas com a Escala de Likert, sendo a décima uma pesquisa de opinião sobre o preparo do país para a aplicação da telemedicina, no qual a maioria foi solícita. RESULTADOS/DESENVOLVIMENTO: Grande parte demonstrou domínio sobre a telemedicina, reconhecendo sua importância no cenário de pandemia e mais de $90 \%$ destacou que há preparo suficiente no país para a instalação deste serviço. As principais preocupações foram relativas à privacidade das informações coletadas durante a consulta, à concorrência criada pelo atendimento à distância, à possível redução do salário e o efeito negativo sobre a relação médico-paciente. Além disso, os estudantes divergiram em relação a quais profissionais podem atuar através da telemedicina e qual treinamento deve ser oferecido. CONSIDERAÇÕES FINAIS: Tais dados destacam a importância do envolvimento dos acadêmicos de Medicina neste tema devido à influência da telemedicina no presente e no futuro da especialidade médica.

\section{REFERÊNCIAS}

MALDONAD, Jose Manuel Santos de Varge, et al. Telemedicine: challenges to dissemination in Brazil.Cad. Saúde Pública [Internet]. 2016 [cited 2019 Oct 3];Vol.32DOI 10.1590/0102-311X00155615. Disponível em: https://www.scielo.br/scielo.php?script=sci_arttext\&pid=S0102-311X2016001402005. Acesso em: 22 set. 2021.

CHAET, Danielle, et al.Ethical practice in Telehealth and Telemedicine. Journal of General Internal Medicine [Internet]. 2017 [cited 2019 Oct 3]; DOI 10.1007/s11606-017-4082-2. Disponível em: https://www.ncbi.nlm.nih.gov/pmc/articles/PMC5602756/. Acesso em: 22 set. 2021.

PALAVRAS-CHAVE: Telemedicina; COVID-19; Pandemia 


\title{
A PERCEPÇÃO DE PROFESSORES SOBRE O USO DE TIC EM TEMPOS DE COVID-19
}

\author{
JÉSSICA RAFAELA FONSECA PATROCÍNIO*; LAÍS REZENDE DA COSTA; LARIANA PAULA PINTO \\ UNIVÁS - Universidade do Vale do Sapucaí
}

INTRODUÇÃO: A pandemia de Covid-19 provocou alterações no âmbito das aulas em todos os níveis escolares, entre eles o universitário, obrigando gestores de faculdades e universidades a adotarem normativas preconizadas pelo Ministério da Educação, que autorizou a substituição das disciplinas presenciais por aulas que utilizem meios e tecnologias de informação e comunicação (JOWSEY; FOSTER; COOPER-IOELU; JACOBS, 2020). Os docentes enfrentaram o desafio de conduzirem o aprendizado através de Tecnologias da Informação e Comunicação (TIC) (SILVA; ESTRELA; LIMA; ABREU, 2020). Considerando esse cenário, o presente estudo teve como objetivo a percepção dos professores de ensino superior em relação à execução de sua prática docente em tempos de pandemia da COVID-19. METODOLOGIA: O presente estudo tratou-se de uma pesquisa quantitativa, aplicada, descritiva e de campo. Participaram 17 professores, com idades entre 28 e 74 anos $(M=49,1$; $D P=14,1)$, e todos lecionaram no período da pandemia da Covid-19. Quanto às variáveis sociodemográficas, $14(82,4 \%)$ eram do gênero feminino, e $3(17,6 \%)$, do masculino; $15(88,2 \%)$ se declararam brancos, e $2(11,8 \%)$, pardos. Os participantes responderam um Questionário de identificação e da percepção dos professores, que envolvia um conjunto de perguntas para obter informações acerca da caracterização da amostra, além de quatro questões abertas sobre a percepção de professores quanto à transição das aulas presenciais para a modalidade remota. As questões versavam sobre o relato de como foi a mudança na rotina de ensino, como o trabalho vem sendo desempenhado, qual o maior desafio frente às aulas remotas e o uso das tecnologias digitais de comunicação e o sentimento em relação a essas mudanças dos métodos de ensino. Os dados foram coletados através de formulário online, na plataforma Google Forms, em que os participantes responderam ao TCLE autorizando o uso de seus dados na pesquisa, bem como aos instrumentos. A pesquisa foi aprovada no Comitê de Ética em Pesquisa da UNIVÁS sob parecer número 4.664.779. RESULTADOS: Após serem analisadas todas as respostas fornecidas pelos participantes da pesquisa, as mesmas foram agrupadas em sete categorias, sendo elas: adaptação, ansiedade, período assustador, dificuldade tecnológica, momento desafiador, falta de interação, e rendimento reduzido. Nesse sentido, observou-se que a categoria adaptação apareceu conjuntamente a categoria falta de interação em três respostas, sendo a relação de maior frequência. No que se refere à relação entre a categoria rendimento reduzido e entre a falta de interação, a mesma foi observada em duas respostas. A categoria período assustador aparece relacionada com a categoria dificuldade tecnológica em dois trechos. Outrossim, as categorias dificuldade tecnológica e falta de interação também apareceram juntas. Além disso, houve a correlação das três categorias: dificuldade tecnológica, falta de interação e período desafiador. As categorias momento assustador, dificuldade tecnológica e ansiedade também apareceram associadas em alguns trechos. CONSIDERAÇÕES FINAIS: Com base na análise das respostas dos professores, verificou-se que as condições relacionadas à nova modalidade remota de ensino promoveram o surgimento de sentimentos de preocupações. Esse novo formato acabou provocando mudanças na rotina, e, consequentemente, na vida pessoal e profissional dos professores, podendo desencadear alterações e impactos no âmbito da saúde mental.

\section{REFERÊNCIAS}

JOWSEY, T.; Foster, G; COOPER-IOELU, P.; JACOBS, S. Blended learning via distance in preregistration nursing education: A scoping review. Nurse education in practice, v. 44, p. 102775. 2020.

SILVA, Andrey Ferreira da et al. Saúde mental de docentes universitários em tempos de pandemia. Physis: Revista de Saúde Coletiva, v. 30. 2020.

PALAVRAS-CHAVE: Covid-19; Professores; Tecnologias da Informação e Comunicação 


\title{
A PORNOGRAFIA INFANTIL LEGALIZADA: SEXUALIZAÇÃO DE MENORES DE IDADE EM ANIMAÇÕES JAPONESAS
}

\author{
GIOVANNI SCARELLI DE SOUZA*; CAMILA CLAUDIANO QUINA PEREIRA \\ UNIVÁS - Universidade do Vale do Sapucaí
}

As animações japonesas crescem sua popularidade a cada dia entre o público jovem. Elas movimentam grande parte da indústria do entretenimento ao redor do globo, propagando a cultura "kawaii", dos fãs de animes e da cultura japonesa, denominados "otakus". Um movimento cultural que cresce ao redor dos animes e produz impactos na realidade daqueles que consomem, desde a forma de comportar até a maneira que se relacionam. Entretanto, $O$ Conselho de Direitos Humanos das Nações Unidas aponta preocupação com o conteúdo que é comercializado e representado nas animações, uma brecha para a pornografia infantil legalizada e pede para que o Japão restrinja suas leis para tal conteúdo animados ou desenhados. Diante desse material, analisa-se a cultura "lolicon", termo frequentemente utilizado para retratar a atração por meninas menores de idades, categorizadas como fofas e inocentes. Mais profundo a isso encontra-se "Chaku Ero", uma categoria de pornografia que não exibe genitais, mas sexualiza crianças reais em poses sugestivas. Já nos desenhos, essa modalidade de pornografia apenas censura as partes intimas de menores de idade. A partir da análise do simbolismo e da linguagem carregada nas imagens que normalizam a pedofilia em escala mundial, constata-se que a sexualização de menores de idade representados nos animes produzem realidades e comportamentos nocivos a eles.

\section{REFERÊNCIAS}

Bourke, M. L., Fragomeli, L., Detar, P. J., Sullivan, M. A., Meyle, E., \& O

PALAVRAS-CHAVE: Animes; lolicon; pornografia infantil; representação; 


\title{
AMIDO RESISTENTE EM RECEITAS: ANÁLISE SENSORIAL DE PICOLÉ DE CHOCOLATE COM BIOMASSA DE BANANA VERDE
}

\author{
MARIANNE ZORDAN*; MICHELE CRISTINA DA COSTA SILVA \\ UNIVÁS - Universidade do Vale do Sapucaí
}

Muitos estudos mostram que o amido resistente pode ter grandes benefícios à saúde, sendo a biomassa de banana verde rica desse componente natural, um tipo de carboidrato que não é digerido pelo intestino e que funciona como uma fibra que ajuda a controlar a glicemia, reduzir o colesterol e dar mais saciedade após a refeição. Muitos alimentos podem ser produzidos a partir da biomassa, dentre eles o picolé, produto com alto teor de aceitabilidade entre adultos e crianças. Com o intuito de agradar o paladar, agregar valores nutritivos e trazer benefícios ao organismo, o presente trabalho tem como objetivo inserir a biomassa em uma receita que normalmente não possui valor funcional, agregando sem modificar a sensação de prazer alimentar. Realizou-se, então, uma pesquisa observacional de abordagem quantitativa do tipo descritivo e transversal, sendo que os questionários foram estruturados através do Google Forms $\AA^{\circledR}$ e enviados para os participantes. A amostra constituiu-se de 33 estudantes de cursos de diversas áreas da saúde da Universidade do Vale do Sapucaí, por meio de aplicação do questionário sociodemográfico e de analise sensorial. Observou-se que 33,3\% frequentavam o curso de medicina; $78,8 \%$ eram do sexo feminino; $63,6 \%$ tinham idade de 18 a 22 anos e $97 \%$ eram solteiros. Como principais resultados, no aspecto cor do produto, 51,5\% gostaram muitíssimo; em relação ao aroma, 36,4\% gostaram muitíssimo; no tocante ao sabor, 39,4\% gostaram muito; no quesito textura, $45,5 \%$ gostaram muitíssimo. No que se refere à aceitação global, $54,5 \%$ gostaram muito e quanto à aceitação do produto $33,3 \%$ comeriam sempre. Conclui-se que o produto é viável em termos de aceitação pelo consumidor, sendo que maior parte dos provadores demonstraram gostar do mesmo.

\section{REFERÊNCIAS}

BRASIL, Ministério da Saúde - Secretaria de Atenção à Saúde. Guia alimentar para a população brasileira: promovendo a alimentação saudável / Ministério da Saúde, Secretaria de Atenção à Saúde . - Brasília : Ministério da Saúde, 2008.

CORREIA, R. T. P.; MAGALHÃES, M. M. dos A.; SILVA PEDRINI, M. R. da; CRUZ, A. V. F. da; CLEMENTINO, I. PICOLÉs elaborados com leite caprino e bovino: composição química e propriedades de derretimento. Revista Ciência Agronômica, v. 39, n. 02, p. 251-256, Abr.- Jun., 2008.

IZIDORO, D. R.; SCHEER, A. de P.; NEGRE, M. F. de O.; HAMINIUK, C. W. I; SIERAKOWSKI, M.

R. Avaliação físico-química, colorimétrica e aceitação sensorial de emulsão estabilizada colo

PALAVRAS-CHAVE: Análise sensorial; biomassa de banana verde; amido resistente. 


\title{
ANÁLISE CORRELACIONAL ENTRE O USO DA FOTOGRAMETRIA COMPUTADORIZADA E DA PLATAFORMA WII BALANCE BOARD® PARA MENSURAÇÃO DA PROJEÇÃO DO CENTRO DE MASSA CORPORAL
}

\author{
RODRIGO ALVES ROBERTO*; GIOVANNI TENÓRIO LAGATTA; RICARDO DA SILVA ALVES \\ UNIVÁS - Universidade do Vale do Sapucaí
}

O equilíbrio postural é capacidade de manter o COM dentro de uma base suporte. Os métodos como fotogrametria avaliado pelo Software de Avaliação Postural (SAPO) e plataforma Wii permitem estimar o centro de massa do corpo (COM), mas a obtenção desses dados do equilíbrio são obtidos em condições diferentes. Portanto, objetivo desse estudo foi correlacionar o uso da plataforma Wii Balance Board®\&\#65039; (WBB) com a fotogrametria computadorizada para estimar a projeção do COM. Métodos: Foi conduzido um estudo transversal e correlacional, com 35 voluntários (feminino=82,85\%; masculino= $17,15 \%)$, com idade média $23,400 \pm 3,743$ anos. Para todos os voluntários a estimativa de uma momento da projeção do COM foi obtido por meio da coleta de imagens fotográficas nas vistas anterior, lateral direita e lateral esquerda, no mesmo instante temporal. Em seguida, as imagens foram analisadas pelo SAPO. Em seguida, a avaliação do projeção do COM foi obtida usando a WBB, com o game Wii Fit Plus. Resultados: Foram observados moderada correlação significativa entre os valores do momento de projeção do COM no plano frontal obtido pelo SAPO com os resultados da plataforma WBB (esquerdo: $r=$ $-0,458, p=0,006$; direito: $r=0,468, p=0,005$ ), para as demais variáveis não foram encontradas correlações significativas. Conclusão: Foi possível observar uma correlação moderada entre os métodos, indicando que o seu uso para mensuração do equilíbrio postural.

\section{REFERÊNCIAS}

DUNSKY, A.; ZEEV, A.; NETZ, Y. Balance Performance Is Task Specific in Older Adults. Biomed Res Int., v. 2017, p. 1-7, 2017.

ALVES, R. S., PEREIRA, I. C., IUNES, D. H., ROCHA, C. B. J., BOTELHO, P., CARVALHO, L. C.

Análise intra e interavaliadores da projeção do centro de massa do corpo obtido por fotogrametria. Fisio Pesq, v. XX, n. XX, 2017.

NITZ, J. C., KUYS, S., ISLES, R., FU, S. Is the Wii Fit ${ }^{\mathrm{TM}}$ a new-generation tool for improving balance, health and well-being? A pilot study. Climacteric, v. 3, p. 487-491, 2010

PALAVRAS-CHAVE: Equilíbrio postural, quedas, terapia de exposição à realidade virtual. 


\title{
ANÁLISE DA ATIVIDADE ANTIBACTERIANA DO EXTRATO HIDROALCOÓLICO DA CASCA DE SCHINUS TEREBINTHIFOLIUS (AROEIRA) SOBRE STAPHYLOCOCCUS AUREUS E STREPTOCOCCUS PYOGENES
}

\author{
AMANDA MARIA DE ALMEIDA RIBEIRO*; TULIO CUSTÓDIO REIS; DEBORA APARECIDA DA ROSA \\ SOUZA; FRANCISCO EDUARDO DE CARVALHO COSTA; GISLAINE CRISTINA SCODELER; \\ RODRIGO MACHADO PEREIRA \\ UNIVÁS - Universidade do Vale do Sapucaí
}

INTRODUÇÃO: Diversos tipos de infecções graves são causados pelas bactérias gram-positivas, Staphylococcus aureus e Streptococcus pyogenes. A busca de compostos antimicrobianos contra estes agentes tem sido cada vez maior. A planta Schinus terebinthifolius, popularmente conhecida como aroeira, é utilizada há muitos anos por possuir propriedades medicinais anti-inflamatória, cicatrizante e antimicrobiana. Seu uso é referido desde as primeiras edições da Farmacopéia Brasileira (FALCÃO, et al. 2015). Neste sentido, torna-se um interessante candidato a fitoterápico antimicrobiano. OBJETIVO: O objetivo deste estudo foi analisar a atividade antibacteriana do extrato de Aroeira (S. terebinthifolius) sobre cepas de S. aureus e S. pyogenes. METODOLOGIA: Amostras de casca de aroeira foram coletadas na zona rural de Santa Rita do Sapucaí - MG, levadas ao laboratório de Fitoterapia da Univás, secas em estufa a $50^{\circ} \mathrm{C}$ e trituradas em moinho de facas. Realizou-se a extração em sistema de Soxhlet a $60^{\circ} \mathrm{C}$ por cerca de 2 horas, utilizando álcool $70^{\circ}$ como solvente. O excesso alcóolico foi retirado por ebulição a $60^{\circ} \mathrm{C}$, restando apenas a fração aquosa. A atividade antimicrobiana foi avaliada pelo teste de Kirby-Bauer (teste de sensibilidade) sobre três cepas: ATCC 6538 (S. aureus), ATCC 25923 (S. aureus) e ATCC 19615 (S. pyogenes). Suspensões dos microrganismos em solução salina ( $\mathrm{NaCl} 0,85 \%)$ foram incubadas em tubos contendo caldo Müller Hinton por 24 horas a $37^{\circ} \mathrm{C}$. De cada cultura, foi retirada uma alíquota de $100 \mu \mathrm{L}(1$ a $2 \times 108 \mathrm{UFC} / \mathrm{ml}-0,5$ na escala de McFarland) e inoculada em placas de teste. A semeadura do inóculo foi feita em placas de petri $(100 \mathrm{~mm})$ com meio de cultivo Ágar Mueller Hinton. Os antibióticos eritromicina e amoxicilina com clavulanato de potássio foram utilizados como controles positivos. Água destilada foi utilizada como controle negativo. Cada placa recebeu 3 discos de papel filtro estéreis secos e impregnados com $100 \mu \mathrm{L}$ do tratamento (água, antibióticos ou extrato). As placas foram incubadas à $37^{\circ} \mathrm{C}$ por 24 horas. Fez-se a medição dos halos de inibição e considerou-se apenas aqueles que foram iguais ou superiores a $6 \mathrm{~mm}$. Os valores foram avaliados pelo teste estatístico Anova. RESULTADOS/DESENVOLVIMENTO: O controle negativo não apresentou qualquer atividade antimicrobiana. Ambos os antibióticos utilizados como controle positivo, apresentaram atividade contra ATCC 6538 (Eri: $17 \mathrm{~mm}$, Amx: 25mm ), ATCC 25923 (Eri: 29mm, Amx: 22mm) e ATCC 19615 (Eri: 19mm, Amx: 28mm). O extrato de Schinus sp. exibiu atividade frente as cepas de $\mathrm{S}$. aureus, sendo maior para ATCC $25923(12 \mathrm{~mm})$ em relação à ATCC 6538 $(8 \mathrm{~mm})$. Não foi detectado atividade inibitória frente a cepa de S. pyogenes (ATCC19615). CONCLUSÃO: Pode-se inferir que o extrato de Schinus terebinthifolius. possui capacidade antimicrobiana satisfatória a S. aureus.

\section{REFERÊNCIAS}

GOMES, Laura Jane et al. Pensando a biodiversidade: aroeira (Schinus terebinthifolius RADDI.). Embrapa Florestas-Livro científico (ALICE), 2013.

ALVES, Jaqueline Evangelista et al. Atividade antibacteriana do extrato hidroalcoólico de jatobá-docerrado (Hymenaea stigonocarpa Mart. ex Hayne) e barbatimão (Stryphnodendron adstringens (Mart.) Coville). Revista Bionorte, v. 5, n. 1, 2016.

FALCÃO, Maria Priscila Mendes Muniz et al. Schinus terebinthifolius Raddi, Aroeira, e suas propriedades na Medicina Popular. Revista verde de agroecologia e desenvolvimento sustentável, v. 10, n. 5, p. 5, 2015.

PALAVRAS-CHAVE: bactérias, aroeira, extrato, antibiótico, fitoterapia. 


\title{
ANÁLISE DA ATIVIDADE HEMOLÍTICA DOS EXTRATOS HIDROALCÓOLICOS DA CASCA DE SCHINUS TEREBINTHIFOLIUS (AROEIRA) E STRYPHNODENDRON ADSTRINGENS (BARBATIMÃO) EM ÁGAR SANGUE
}

\author{
DÉBORA APARECIDA DA ROSA SOUZA*; TULIO CUSTÓDIO REIS; AMANDA MARIA DE ALMEIDA \\ RIBEIRO; GISLAINE CRISTINA SCODELER; RODRIGO MACHADO PEREIRA; GISLAINE CRISTINA \\ SCODELER; RODRIGO MACHADO PEREIRA
}

UNIVÁS - Universidade do Vale do Sapucaí

INTRODUÇÃO: A grande aplicabilidade de extratos vegetais se faz desde os tempos imemoriais, o uso de plantas por populações indígenas e tradicionais para o tratamento de enfermidades formam a base da etnobotânica, contudo, faz-se necessário o desenvolvimento de novos estudos para averiguação das possíveis capacidades biológicas. OBJETIVO: O objetivo deste estudo foi avaliar a atividade hemolítica dos extratos hidroalcóolicos de aroeira (Schinus terebinthifolius) e barbatimão (Stryphnodendron adstringens). METODOLOGIA: As amostras de cascas tanto de aroeira quanto barbatimão foram coletadas no bairro Timburé na zona rural de Santa Rita do Sapucaí (MG) e levadas ao laboratório de Fitoterapia da Univás para processamento. O material vegetal foi seco em estufa a $55^{\circ} \mathrm{C}$ por 72 horas e processadas em moinho de facas. Para extração, utilizou-se o pó ( $30 \mathrm{~g}$ para $300 \mathrm{ml}$ de Álcool $70 \%)$. A mistura foi aquecida a $60^{\circ} \mathrm{C}$ por cerca de 2 horas. $\mathrm{O}$ excesso alcóolico foi retirado por ebulição para obtenção da fração aquosa. A avaliação da atividade hemolítica foi realizada pelo método de disco-difusão em ágar sangue. O agente surfactante Triton X-100 foi utilizado como grupo controle positivo, e os extratos como grupo teste. Pipetou-se sobre discos de filtro quantitativo $100 \mu \mathrm{L}$ dos extratos, esperou-se 1 minuto para absorção, e foram dispostos sobre placas de petri contendo meio Ágar Sangue de Carneiro. Após 24 horas foram realizadas medidas do diâmetro dos halos de hemólise formados. Os testes foram realizados em duplicata, e reproduzidos para confirmação dos resultados. RESULTADOS/DESENVOLVIMENTO: As placas que receberam os discos impregnados com os extratos de $\mathrm{S}$. adstringens e $\mathrm{S}$. terebinthifolius não apresentaram formação de halos de hemólise. As placas que receberam os discos impregnados com Triton X-100 apresentaram formação de halos de hemólise iguais ou superiores a $2 \mathrm{~cm}$. CONCLUSÃO: A atividade hemolítica de um determinado componente pode torná-lo inseguro para alguns usos terapêuticos. Porém, pode-se inferir que os extratos hidroalcóolicos de S. adstringens e S. terebinthifolius não apresentam atividade hemolítica, que é uma característica interessante para a aplicação em estudos de experimentação animal.

\section{REFERÊNCIAS}

BEDNARCZUK, V. O. et al. Testes in vitro e in vivo utilizados na triagem toxicológica de produtos naturais. Visão Acadêmica, v. 11, n. 2, 2010.

KRABBE, ELISETE CRISTINA, et al. "ações inovadoras e interdisciplinares de educação e saúde para o êxito da promoção e prevenção da saúde do escolar." revista interdisciplinar de ensino, pesquisa e extensão-revint 3.1 (2016).

RAMOS, R. M., FEITOSA, J. M., DA SILVA LIMA, V., DA CONCEIÇÃO SANTOS, R., DE OLIVEIRA, A. M., SOARES, L. A. L., \& DA SILVA, G. C. (2020). Estudo comparativo da composição fitoquímica, citotoxidade e potencias antioxidante e fotoprotetor da casca e folha de Erythrina velutina. Brazilian Journal of Development, 6(6), 33140

PALAVRAS-CHAVE: hemólise, extratos, etnobotânica. 


\title{
ANÁLISE DA CONFIABILIDADE INTER E INTRAEXAMINADOR DO USO DE DISPOSITIVO ARDUÍNO PARA AVALIAÇÃO DA FORÇA MUSCULAR ISOMÉTRICA DOS MÚSCULOS ABDUTORES DO OMBRO
}

\author{
KAUANY NASCIMENTO FAGUNDES*; ISABELLA VIEIRA GOMES; BRUNA LEONEL CARLOS; \\ RICARDO DA SILVA ALVES \\ UNIVÁS - Universidade do Vale do Sapucaí
}

A força muscular é um parâmetro essencial na avaliação e na determinação de intervenções terapêuticas precisas. Comumente, os testes de força muscular são realizados manualmente, levando a subjetividade na coleta e análise dos resultados. Por outro lado, a dinamometria permite mensurar com precisão a força muscular, mas os custos financeiros, ambientes físicos e softwares inviabilizam o seu uso na prática clínica. Nesse sentido, o uso do microcontrolador Arduíno possibilita ser acoplado junto aos dinamômetros isométricos, com baixo custo financeiro, funcional e de fácil programação. Portanto, o objetivo desse estudo é analisar a confiabilidade inter e intra-examinador do dinamômetro isométrico controlado por sistema Arduíno. Métodos: Foram avaliados 35 voluntários, ambos os sexos, com idade $22,40 \pm 2,57$ anos. Todos os voluntários foram submetidos à avaliação da força muscular de deltoídes médio de ambos os ombros. O procedimento foi realizado da seguinte forma: examinador 1 (Av 1): realizou a coleta do pico de força máxima dos músculos deltoídes médios. Após uma semana, o examinador 2 ( Av 2) realizou a coleta dos dados dos respectivos músculos. Após uma semana, os voluntários foram reavaliados pelo Av 1. Para análise estatística, foi usado coeficiente de correlação intraclasse (ICC) intra-examinador (ICC 1,1) e interexaminador (ICC 1,2), e para estimar a mudança mínima detectável (MMD), foi utilizado o erro padrão (EP) Resultados: Foram observados excelentes níveis de confiabilidade para ambos os músculos deltoídes (ICC 1,1: direito=0,981, $\mathrm{MMD}=0,965$; esquerdo=0,976, $\mathrm{MMD}=0,985)$ e $(\mathrm{ICC} 1,2$ : direito=0,979, $\mathrm{MMD}=1,036$; esquerdo=0,982, $\mathrm{MMD}=0,844$ ). Conclusão: $\mathrm{O}$ dinamômetro isométrico controlado por sistema Arduíno demonstrou ser um recurso confiável de avaliação da força muscular com excelente nível de confiabilidade intra e interexaminador.

\section{REFERÊNCIAS}

BAMAÇ, B. et al. 'Isokinetic performance in elite volleyball and basketball players', Kinesiology v. 40, p.183-189, 2008.

BERNARD, J. C. et al. Isokinetic trunk muscle performance in pre-teens and teens with and without back pain. Ann Phys Rehabil Med, v. 57, p. 38-54, 2014.

CAMARGO, M. R., et al. Força Muscular Isométrica do Tornozelo. Dinamometria: Descrição de uma Nova Técnica Measurement of Ankle Isometric Muscular Strength. R Bras Ci Saúde, v. 13, n. 2, p. 89- 96, 2009.

PALAVRAS-CHAVE: Dinamômetro de força muscular; força muscular; cinesiologia; reabilitação. 


\section{ANÁLISE DA DOR EM PACIENTES PORTADORES DE ÚLCERAS CRÔNICAS EM USO DO GEL DA CASCA DA BANANA VERDE}

BRUNA DE CÁSSIA SOUSA*; ISADORA ANDRÉ DE CAMARGO PACHECO; MAYCON CRISTIAN GOMES DE PAULA; YUJI ATARASHI TAVARES; DÊNIA AMÉLIA NOVATO CASTELLI VON ATZINGEN; ADRIANA RODRIGUES DOS ANJOS MENDONÇA

UNIVÁS - Universidade do Vale do Sapucaí

Introdução: A pele é um órgão cuja integridade é fundamental para o ser humano e para o perfeito funcionamento fisiológico do organismo. Há fatores, porém que propiciam o desenvolvimento de lesões na pele, prejudicando sua integridade e o desempenho de suas funções, como a existências de doenças, uso de medicamentos, hábitos de higiene inadequados, e outros. E um dos grandes desafios enfrentados pelos pacientes portadores de úlceras crônicas é a dor. Objetivo: analisar os níveis de dor relatados pelos pacientes em uso do gel da casca da banana verde. Método: Os pacientes foram divididos em 2 grupos (Grupo Banana e Grupo Controle). O Grupo Banana foi formado por pacientes que utilizam o gel misturado com $10 \%$ do pó da casca da banana Musa sapientum verde somado ao tratamento convencional para feridas; já o Grupo Controle (GC), foi formado por pacientes que receberam apenas o tratamento convencional para feridas. O cuidado convencional foi realizado através da lavagem com água comum de torneira e remoção de tecidos necróticos da ferida. A escala foi aplicada uma vez por semana, em um total de quatro semanas. Ao final, as escalas foram agrupadas de acordo com cada grupo e os resultados foram tabelados, analisados e comparados. Resultados: a análise dos dados mostrou que o uso do gel da casca da banana não trouxe eficácia quando se trata de dor. Conclusão: A propriedade anestésica do gel não foi comprovada e novas ferramentas e métodos terão que ser criados para aliviar a dor dos pacientes portadores de úlceras crônicas.

\section{REFERÊNCIAS}

ALMEIDA, Leiliane Aparecida de Determinação de taninos em extratos de casca de banana. 2014.

30 f. TCC (Graduação) - Curso de EnGBnharia Química, Instituto de Ciência e Tecnologia, Universidade Federal de Alfenas, Poços de Caldas, 2014.

VON ATZINGBN, Dênia Amélia Novato Castelli et al. Repair of surgical wounds in rats using a $10 \%$ unripe Musa sapientum peel GBI. Acta Cirúrgica Brasileira, São Paulo, v. 30, n. 9, p.591, set. 2015. PEREIRA, A. Avaliação das atividades cicatrizante e antitumoral de extratos provenientes da casca de banana cultivar Prata Anã (Musa spp). 2010. 154 f. Dissertação (Mestrado em Biotecnologia) - Universidade Federal de Santa Catarina. Florianópolis, 2010.

PALAVRAS-CHAVE: Dor. Úlcera. Musa sapientum 


\section{ANÁLISE DA INCIDÊNCIA DE VIOLÊNCIA DOMÉSTICA NO IML DE POUSO ALEGRE/MG E SUAS LESÕES PROVOCADAS.}

KENNEDY MENDES ALMEIDA*; ANA LUIZA BASTOS PEREIRA; CAMILA DESTEFANI ROSSI; BEATRIZ JEREMIAS; LUCAS DE MOURA CORSO; MARIA LUIZA ALVES SILVA; FIORITA GONZALES LOPES MUNDIM UNIVÁS - Universidade do Vale do Sapucaí

INTRODUÇÃO: A violência doméstica trata-se de qualquer tipo de relação de abuso praticado em contexto familiar sob diferentes formas, sendo um problema de grande dimensão que atinge, principalmente, mulheres, crianças, idosos e pessoas com deficiência. O Brasil ocupa, atualmente, a $5^{\underline{a}}$ colocação mundial no ranking de violência contra a mulher(modalidade mais comum de agressão domiciliar), atrás de El Salvador, Colômbia, Guatemala e Rússia, mostrando a importância do debate acerca desse tema no país (ACNUDH, 2020)1. Além disso, as taxas de homicídio contra mulheres dentro de casa aumentaram 8,3\% entre os anos de 2013 e 2018, indicando um crescimento dos feminicídios pelo território nacional (IPEA, $2020)^{2}$. Este trabalho tem por objetivo analisar a incidência dos casos de violência doméstica da região de Pouso Alegre/MG através de dados do Instituto Médico Legal (IML), levando em consideração toda sua abrangência. METODOLOGIA: Os trabalhos foram realizados a partir da coleta de dados no IML de Pouso Alegre/MG, no período de 2019 a 2020, utilizando a infraestrutura de informática (PCNET) da Polícia Civil e os laudos físicos dos exames periciais, sendo feito o apanhado do tipo/característica das lesões, do instrumento utilizado, da localização, da data/horário do evento e das idades e gêneros da vítima e do suspeito. A pesquisa foi então aplicada de forma quantitativa e descritiva, fazendo uma análise e organização epidemiológicas dos elementos de estudo. RESULTADOS: Foram amostrados 460 casos de violência doméstica confirmados pelos laudos no tempo delimitado, sendo 283 no ano de 2019 e 177 no ano de 2020. Na grande maioria a violência contra a mulher foi a mais impactante $(51,4 \%)$, seguido da violência contra a criança (33,8\%), abrangendo tanto a forma física quanto a sexual em ambos os casos. Vale ressaltar que dentre os mais de 2 mil laudos estudados, diversos não foram possíveis confirmar a hipótese de violência doméstica, ou por falta de provas ao exame pericial ou por falta de informação presente no sistema do IML. O gênero masculino foi o principal suspeito $(76,7 \%)$, sendo ex-marido ou o atual parceiro o que mais aparece nos laudos amostrados. Em um número significativo de situações, funcionários(as) de escolas/creches cometerem atos de abuso sexual contra crianças $(1,3 \%)$. A importância dos períodos estudados mostrou um paradoxo, no qual o ano de 2019 teve mais casos reportáveis de violência doméstica quando comparado com 2020, pelo fato de durante a pandemia da COVID-19 o acesso a serviços de apoio às vítimas foi reduzido. Portanto, não há dúvidas que os casos durante $\mathrm{o}$ ano da crise de saúde aumentaram devido ao isolamento social que vivemos somado à dificuldade de a vítima fazer a denúncia, porém, o número de denúncias diminuiu, pois, a população alvo desse crime se viu desamparada nesse intervalo de tempo. CONSIDERAÇÕES FINAIS: Esse estudo provou ser de grande relevância social, apontando a violência doméstica como importante problema que persiste no Brasil e, com o período da pandemia, aumentou consideravelmente apesar dos números oficiais dizerem o contrário, pois houve menos denúncias ${ }^{3} .0$ apanhado de dados levou a concluir que tanto as características da vítima quanto as do suspeito se repetem na maioria dos casos, assim como o horário e instrumento utilizado. Logo, deve-se reforçar a importância do atendimento às vítimas por canais governamentais e do incentivo a campanhas publicitárias que levam o conhecimento à população.

\section{REFERÊNCIAS}

Alto Comissariado das Nações Unidas para os Direitos Humano (ACNUDH). Disponível em: https://acnudh.org/pt-br/brasil-2/

Atlas da Violência 2020. Disponível em:

https://www.ipea.gov.br/atlasviolencia/download/24/atlas-da-violencia-2020

Elementos precipitadores/intensificadores da violência conjugal em tempo da Covid-19.

Disponível em: https://www.scielo.br/j/csc/a/yFfYg7zWxBwVRJp7GrLwJpf/?lang=pt

PALAVRAS-CHAVE: violência doméstica; perícias médicas; pandemia; COVID-19 


\title{
ANÁLISE DA INFLUÊNCIA DA SOBRECARGA DE TRABALHO NA SAÚDE FÍSICA E MENTAL DE CUIDADORES DE PACIENTES COM CÂNCER: ESTUDO PRELIMINAR
}

\author{
JULLIAN STEFANI VIANA*; NICOLE MARIANA VEIGA; BRUNA LEONEL CARLOS; RICARDO DA SILVA \\ ALVES \\ UNIVÁS - Universidade do Vale do Sapucaí
}

O diagnóstico e tratamento de câncer interfere na qualidade de vida do paciente e nas pessoas que realizam os cuidados desses indivíduos. Na maioria das vezes, os cuidadores de pacientes com câncer são informais, familiares e/ou amigos, que podem se sentir sobrecarregados física e psicologicamente, afetando a qualidade de vida. Nesse sentido, o objetivo deste estudo foi avaliar a sobrecarga de trabalho, aspectos relacionados à qualidade de vida, sintomas de ansiedade e depressão de cuidadores de pacientes com câncer. Métodos: Foi conduzido um estudo transversal, com 15 voluntários, de ambos os sexos, cuidadores de idosos (feminino=86,66\%; masculino=13,34\%), com idade 36,928 $\pm 14,652$ anos Todos os voluntários foram avaliados quanto a sobrecarga de trabalho pelo questionário de Avaliação da Sobrecarga do Cuidador Informal (QASCI), nível de ansiedade avaliado pelo Inventário de Ansiedade Traço-Estado (IDATE), avaliação dos aspectos relacionados à qualidade de vida por meio do questionário The Functional Assessment of Chronic Illness Therapy- Fatigue (FACIT-F). Resultados: Foi observado que os cuidadores apresentam alto nível de sobrecarga de trabalho (QASCI $=54,428 \pm 13,619)$, nível médio de ansiedade pelo IDATE (Traço: 47,785 6,750 ; Estado: 45,785 $\pm 4,886$ ) e baixo nível de qualidade de vida (FACIT-F=67,473 $\pm 12,318$ ). Conclusão: os cuidadores de pacientes com câncer apresentaram níveis elevados de sobrecarga de trabalho, associado com ansiedade e baixa qualidade vida, necessitando de maior atenção a essa população.

\section{REFERÊNCIAS}

GUERRA, H. S. et al. A sobrecarga do cuidador domiciliar. Revista Brasileira em promoção da Saúde, v. 30, n. 2, p. 179-186, 6 jun. 2017.

ISHIKAWA, N. M. et al. Validation of the Portuguese version of Functional Assessment of Cancer TherapyFatigue (FACT-F) in Brazilian cancer patients. Supportive Care in Cancer, v. 18, n. 4, p. 481-490, 2010. WEBSTER, K.; CELLA, D.; YOST, K. The Functional Assessment of Chronic Illness Therapy (FACIT) Measurement System: Properties, applications, and interpretationHealth and Quality of Life OutcomesHealth Qual Life Outcomes, dez. 2003.

PALAVRAS-CHAVE: Cuidadores, fadiga, qualidade de vida, câncer, sobrecarga de trabalho. 


\title{
ANÁLISE DE CORRELAÇÃO E CONCORDÂNCIA ENTRE TESTES LÚDICOS ADAPTADOS VERSUS TESTES CONVENCIONAIS DE AVALIAÇÃO FUNCIONAL DE IDOSOS
}

\author{
SARA TALINE CORRÊA DA SILVA*; CAMILA DE CÁSSIA SANTOS; MAYRA KIANE DE MELO RIBEIRO; \\ POLLIANA GABRIELA DE PAULA SILVEIRA; BRUNO MENDES; RICARDO DA SILVA ALVES \\ UNIVÁS - Universidade do Vale do Sapucaí
}

INTRODUÇÃO: A senescência é o processo de desenvolvimento e de conservação da capacidade funcional, permitindo que o idoso possua bem-estar, mesmo na idade avançada. Já a senilidade provoca processos de mudança que podem levar a falta de sua adaptação, declínio funcional e, por fim, à sua morte. Então, levando em conta todo esse processo de perdas, novos meios de mensuração desse declínio podem ser feitos por meio de formas mais lúdicas. O lúdico consegue facilitar a aprendizagem, desenvolver o ser humano em âmbito pessoal, social e cultural, colabora para uma boa saúde mental, facilita a socialização, a comunicação e o conhecimento. OBJETIVO: Analisar o nível de correlação e concordância de atividades lúdicas como propostas de testes para a avaliação funcional dos idosos. METODOLOGIA: Foi conduzido um estudo transversal e correlacional, utilizando 27 participantes (feminino $=62,96 \%$ masculino $=37,03 \%$ ), com idade média $\pm 69,107$ anos. Todos os participantes foram avaliados em atividades funcionais convencionais e adaptados para avaliação da força muscular de membros superiores e dos membros inferiores, da coordenação motora de membros inferiores e dos membros superiores, do equilíbrio estático e da velocidade da marcha. RESULTADO: Somente o teste de coordenação motora para membro superior esquerdo com os olhos abertos (OA) apresentou uma moderada correlação significativa entre os testes adaptados e convencionais $(r=0,418 ; p=0,030)$. No entanto, foi observado uma concordância de entre os testes para a força muscular de MMSS (MSD: $p=0,301$; MSE: $p=0,431)$, velocidade de marcha $(p=0,687)$ e equilíbrio com olhos abertos (direito: $p=$ 0,444 ; esquerdo: $p=0,130$ ) e olhos fechados (direito: $p=0,805$; esquerdo: $p=0,868$ ). CONCLUSÃO: Não foram encontradas correlação significativas entre os testes adaptados com os testes funcionais, porém se mostraram concordantes para avaliar a avaliação funcional de idosos.

\section{REFERÊNCIAS}

LESSARD, I. et al. Validity and reliability of the LEMOCOT in the adult ARSACS population: A measure of lower limb coordination. J Neurol Sci. n. 15, p. 193-196, 2017.

RIKLI, R. E.; JONES, C. J. To design an effective exercise program, you must know your clients' physical state. But choosing the right assessment tools can prove a challenge. The Journal on Active Aging. p. 2430, 2002.

PALAVRAS-CHAVE: Jogo e brinquedos. Fisioterapia. Idoso. Testes de Aptidão. 


\title{
ANÁLISE DO EQUILÍBRIO POSTURAL E DESEMPENHO MOTOR DE CRIANÇAS PRATICANTES DE BALLET
}

\author{
GABRIELA DO PRADO CORREAA*; CAROLINE PEREIRA DE MELO; BRUNA LEONEL CARLOS; \\ RICARDO DA SILVA ALVES \\ UNIVÁS - Universidade do Vale do Sapucaí
}

O ballet é uma combinação única de esporte e arte que pode trazer uma série de efeitos positivos ao desenvolvimento de crianças. O objetivo deste projeto foi comparar o nível das habilidades motoras de crianças praticantes e não praticantes de ballet. Trata-se de um estudo transversal e controlado, onde os voluntários foram distribuídos em dois grupos: ballet (GB: $n=15$, Idade: 9,500 1,581 anos), formado por praticantes desta atividade, e grupo controle (GC: $n=15$; Idade: 9,666 $\pm 1,497$ anos), formado por não praticantes de ballet. Ambos os grupos foram avaliados acerca da estimativa de um momento da projeção do centro de massa (COM) na fotogrametria, através do Software para Avaliação Postural (SAPO), e do COM por meio da plataforma Wii Balance Board (WBB). Além disso, foram realizadas avaliações do desempenho motor e retenção de aprendizagem por meio da pontuação obtidas em três jogadas do jogo Río Abajo, pertencente ao game Wii Fit Plus (Nintendo, Co, Kyoto, Japão). Resultados: Foi observado uma diferença significativa da assimetria da estimativa da projeção do COM no plano sagital (GB: 10,010 $\pm 11,361$; GC: $40,925 \pm 21,711 ; p=<0,001$ ) e do desempenho motor nas pontuações do Rio Abajo (GB: $496,363 \pm 228,045 ; G C: 383,714 \pm 46,508 ; p=0,049$ ). No GC houve aumento da pontuação no desempenho motor $(p=0,004)$, indicando melhora da aprendizagem. Conclusão: $O$ grupo ballet apresentou menor alteração da projeção do COM no plano sagital, através da avaliação pelo SAPO, com melhor nível de aprendizagem e desempenho motor durante o exergaming, se comparado ao grupo controle.

\section{REFERÊNCIAS}

TEIXEIRA, C.L. Equilíbrio e controle postural. Brazilian Journal of Biomechanics. 2010, vol. 11, n.20. JANURA, M. et al. Standing balance of professional ballet dancers and non-dancers under different conditions. PLOS ONE, v. 14, n. 10, p. 1-12, 2019.

HAAS, A. N.; GARCIA, A. C. D.; BERTOLETTI, J. Imagem corporal e bailarinas profissionais. Revista Brasileira de Medicina do Esporte, v. 16, n. 3, p. 182-185, 2010.

PALAVRAS-CHAVE: Crianças, ballet, habilidades motoras, equilíbrio postural, fotogrametria. 


\title{
ANÁLISE HISTOPATOLÓGICA E HISTOMORFOMÉTRICA DO INTESTINO DELGADO EM RATOS WISTAR SUBMETIDOS À INGESTÃO DIÁRIA DE ÁLCOOL
}

\author{
THAIIS SANTA CRUZ MORAES*; SARA SEMAAN SILVEIRA; FIORITA GONZALES LOPOES MUNDIM; \\ RODRIGO MACHADO PEREIRA \\ UNIVÁS - Universidade do Vale do Sapucaí
}

INTRODUÇÃO: O consumo excessivo de álcool está diretamente relacionado a efeitos deletérios sobre a saúde e bem-estar do indivíduo, o que o tipifica como um dos maiores problemas de saúde pública na atualidade. O uso constante dessa substância pode, a longo prazo, gerar consequências negativas a todos os sistemas orgânicos do corpo. Nesse contexto, alterações morfológicas e funcionais do trato gastrointestinal após a ingestão do etanol têm sido descritas em humanos e em animais experimentais, caracterizando-se, principalmente, pela interferência nas células epiteliais e na manutenção da flora microbiana residente prejudicando a absorção intestinal. OBJETIVO: Avaliar o efeito do consumo crônico de álcool no intestino delgado de ratos Wistar através de análise histopatológica e histomorfométrica. METODOLOGIA: Foram utilizados 30 ratos Wistar machos divididos em três grupos: ingestão de água (Controle, $n=10)$, ingestão de solução alcoólica a $5 \%(E t O H ~ 5 \%, n=10)$ e ingestão de solução alcoólica a $20 \%$ (EtOH 20\%, n=10). Os grupos EtOH 5\% e EtOH 20\% receberam álcool apenas durante a noite, e intermitentemente durante o final de semana, por 80 dias. Os animais foram anestesiados e sacrificados após a experimentação. Os intestinos foram coletados, fixados em formalina 10\% tamponada e clivados longitudinalmente. As peças histológicas foram processadas, incluídas em parafina e seccionadas por microtomia a $3 \mu \mathrm{m}$. Foram realizadas colorações de Hematoxilina-Eosina, Tricrômico de Masson e Ácido Periódico-Schiff. As lâminas foram analisadas quanto à presença de hemorragia, descamação de células, desnudação, degeneração de vilosidades, ulceração, necrose de células epiteliais, edema de mucosa e fibrose. Células mononucleares, neutrófilos, eosinófilos e erosão foram avaliadas semi-quantitativamente em uma escala de 0 a 3 . Estes valores foram analisados pelo teste Anova. Fotomicrografias foram realizadas ao microscópio óptico para análise histomorfométrica. Foram mensurados microscopicamente os comprimentos das vilosidades intestinais de cada amostra através do software ImageJ versão 1.53. Os dados foram comparados pelo teste de Kruskal-Wallis. RESULTADOS: Comparados ao grupo controle, animais que ingeriram álcool apresentaram quantidades superiores de eosinófilos e células mononucleares $(p=0,012)$ na mucosa intestinal. Também foi constatado maior frequência de degenerações das vilosidades nos grupos alcoólatras $(p=0,01)$. O comprimento médio destas estruturas foi significativamente maior para o grupo controle $(855,3 \mu \mathrm{m})$ comparado aos grupos $\mathrm{EtOH} 5 \%(660,0 \mu \mathrm{m}, \mathrm{p}<0,001)$ e $\mathrm{EtOH} 20 \%(666,0 \mu \mathrm{m}, \mathrm{p}<0,001)$. Não foi significativa a alteração entre estes dois últimos $(p=0,437)$. Os demais parâmetros avaliados também não apresentaram relevância estatística. CONSIDERAÇÕES FINAIS: Os resultados demonstram que o álcool promoveu atrofia da mucosa intestinal, atribuída a uma atividade degenerativa. Além disso, foi constatado o aumento de células de inflamação crônica. Com isso, conclui-se o efeito inflamatório e deletério do álcool no intestino delgado.

\section{REFERÊNCIAS}

KRAWISZ J. F. et al. Quantitative Assay for Acute Intestinal Inflammation Based on Myeloperoxidase Activity. 1984. Artigo científico - Universidade de Washington, St. Louis, Missouri, Estados Unidos, 1984. JASON C. Lambert et al. Preservation of Intestinal Structural Integrity by Zinc Is Independent of Metallothionein in Alcohol-Intoxicated Mice. 2004. (American Journal of Pathology vol.164)- Universidade de Medicina de Lousville, Estados Unidos, 2004.

JOHAN D. So"derholm, et al. Chronic Stress Induces Mast Cell-Dependent Bacterial Adherence and Initiates Mucosal Inflammation Rat in Intestine. 2002. Artigo científico (Gastroenterology vol.123)universidade de Toronto, Canada, 2002.

PALAVRAS-CHAVE: Etanol; alcoolismo; intestino delgado; degeneração; inflamação. 


\title{
ANUROFAUNA EM UNIDADE DE CONSERVAÇÃO MUNICIPAL, POUSO ALEGRE, SUL DE MINAS GERAIS
}

\author{
RAISSANE FURTADO DE MENDONÇA*; ALLYSON LUCIANO VIEIRA; GUSTAVO CRUZ LIMA; \\ LEANDRO GUSTAVO DO PRADO; THAIS HELENA CONDEZ; ANA BÁRBARA BARROS \\ UNIVÁS - Universidade do Vale do Sapucaí
}

INTRODUÇÃO. Conhecidos popularmente como rãs, sapos e pererecas, os anfíbios anuros são animais muito sensíveis às alterações ambientais, uma vez que suas características fisiológicas denotam uma relação estreita com seu hábitat, evidenciando aparente vulnerabilidade em relação às alterações do mesmo. Estão presentes em todos os continentes, e no Brasil compreendem, atualmente, 1144 das 1188 espécies de anfíbios descritas, sendo representados por 20 famílias e 107 gêneros. Por ser um grupo altamente vulnerável às alterações do ambiente, a fragmentação e a consequente perda de hábitat constituem um dos principais fatores de ameaça à sua biodiversidade. Esses impactos também implicam em alterações nas características ecológicas, interferindo diretamente na cadeia alimentar, uma vez que os anfíbios ocupam as mais diversas posições, desde presas e hospedeiros, a predadores, demonstrando extrema importância na dinâmica trófica de ecossistemas. Embora Minas Gerais seja considerado um dos estados mais privilegiados na composição de seus recursos naturais, características essas que favorecem a alta diversidade de anfíbios anuros, o conhecimento sobre a anurofauna do estado é ainda muito escasso e insatisfatório, pois muitas regiões apresentam-se subamostradas, principalmente no que se diz respeito à porção sul do estado. Dessa forma, o objetivo deste estudo foi analisar a composição da anurofauna no Parque Natural Municipal Professor Doutor Fernando Afonso Bonillo Fernandes, uma vez que os dados obtidos são fundamentais para a compreensão da biodiversidade, bem como para apresentar importantes subsídios para futuras estratégias de manejo e conservação. MATERIAIS E MÉTODOS. O estudo foi realizado no Parque Natural Municipal Prof. Doutor Fernando Afonso Bonillo Fernandes, localizado no município de Pouso Alegre, Minas Gerais. O parque apresenta uma área total de 204,33 ha, tendo como formação vegetal predominante a fitofisionomia de Floresta Estacional Semidecidual Montana, genericamente conhecida como Mata Atlântica, e encontra-se inserido em uma matriz urbana. Métodos de amostragem. As buscas foram conduzidas de Janeiro/2020 a Outubro/2021, no período noturno, contabilizando 20 meses de amostragem. Para a amostragem foram delimitadas duas áreas para realização das trilhas, sendo elas: Trilha dos lagos (TL) e Trilha da pedreira (TP). Para a coleta de dados da fauna utilizou-se os seguintes métodos de amostragem: Procura Ativa; Armadilhas de Interceptação e Queda; Encontros Ocasionais. RESULTADOS E DISCUSSÕES. Foram registradas até o presente momento 21 espécies de anfíbios anuros, distribuídos em 7 famílias: Brachycephalidae, Bufonidae, Craugastoridae, Hylidae, Leptodactylidae, Microhylidae e Phyllomedusidae. Em suma, a família Hylidae apresentou o maior número de espécies para o presente estudo, correspondendo com o padrão observado por diversos autores para a região Neotropical. Os indivíduos pertencentes a essa família são adaptados ao hábito arborícola, por consequência ocupam com sucesso ambientes de grande heterogeneidade estrutural, como as florestas. Tendo em vista os resultados alcançados, evidencia-se a importância dos fragmentos florestais em matriz urbana como forma de manutenção e abrigo da biodiversidade. Neste contexto, salienta-se a importância da elaboração de planos de manejo, bem como a definição de ações que visam a conservação e preservação destes ambientes.

\section{REFERÊNCIAS}

BARROS, A.B. 2011. Herpetofauna do Parque Nacional da Serra da Canastra, Minas Gerais, Brasil. Dissertação de Mestrado, Universidade Federal de Viçosa, Viçosa, Minas Gerais, Brasil.

FRANCISCO, J.F. 2017. Anfíbios anuros em fragmentos de Floresta Semidecidual Montana no sul de Minas Gerais. Trabalho de conclusão de curso. Instituto Federal de Educação, Ciência e Tecnologia do Sul de Minas Gerais - Campus Inconfidentes.

SEGALLA, M.V. et al. 2021. List of Brazilian Amphibians. Acessible at http://www.sbherpetologia.org.br. Sociedade Brasileira de Herpetologia. Último acesso 19 jun 2021.

PALAVRAS-CHAVE: Anuros, Mata Atlântica, Conservação, Biodiversidade, Minas Gerais 


\title{
APLICATIVO MÓVEL PARA O INSTRUMENTO "RASTREAMENTO DO PÉ DIABÉTICO DE ALTO RISCO: UMA FERRAMENTA DE 60 SEGUNDOS"
}

\author{
RAYSSA BARROS*; JOÃO VÍTOR DE OLIVEIRA; BEATRIZ BERTOLACCINI MARTÍNEZ \\ UNIVÁS - Universidade do Vale do Sapucaí
}

Considerando-se que $85 \%$ das amputações em diabéticos são precedidas por úlceras, essas lesões destacam-se como fator de risco importante para amputação. Reconhecer os principais fatores que levam à ulceração facilitará no planejamento de intervenções de caráter preventivo e curativo frente às complicações que ocorrem em pacientes portadores de diabetes mellitus. Sendo assim, a disponibilização de instrumentos para rastrear e referenciar pacientes diabéticos com alterações vasculares e ou neuropáticas nos pés, de baixo custo, fácil manuseio e aplicabilidade para o serviço público de saúde, possuem um valor muito significativo na prevenção dessas comorbidades. Dessa forma, mostrou-se necessário desenvolver um aplicativo móvel para o instrumento "Rastreamento do pé diabético de alto risco: uma ferramenta de 60 segundos". Assim, a pesquisa desenvolveu-se na Universidade do Vale do Sapucaí, de 2020 a 2021, na cidade de Pouso Alegre (MG), após aprovação do Comitê de Ética em Pesquisa, parecer CAE 69829317.2.0000.5102. A ferramenta "Screening for the High-risk Diabetic Food: A 60-second Tool", desenvolvida por Sibbald e colaboradores em 2012, foi traduzida, validada e teve as propriedades de medidas testadas através de quatro tradutores bilíngues juramentados e independentes, sendo dois para a tradução do inglês para o português e dois para a retro tradução; três profissionais especialistas em pé diabético para revisão e traduções. : A partir da ferramenta "Rastreamento do Pé Diabético de Alto Risco: Uma Ferramenta De 60 Segundos" foi construído um fluxograma com os elementos do instrumento, para o desenvolvimento de aplicativo móvel para IOS e ANDROID.

\section{REFERÊNCIAS}

$M D$, González AD, Silva AM. Risk factors for foot ulcers-A cross sectional survey from a primary care setting in Brazil. Prim Care Diabetes. 2013;75(13):44-8.

Craig J, Shenton R, Smith A. Economic analysis of soft-heel casting for diabetic foot ulcer: prevention and treatment. J Wound Care. $2013 ; 22(1): 44-8$.

PALAVRAS-CHAVE: diabetes mellitus, pé diabético, Estudos de Validação, Programas de Rastreamento, Aplicativos em Dispositivos Móveis 


\title{
APLICATIVO PARA RASTREAMENTO DO CÂNCER COLORRETAL E VIGILÂNCIA PÓS- POLIPECTOMIA
}

\author{
MIRELLE DE PAULA RIBEIRO*; LAÍS PRUDENTE DE ANDRADE; CARLOS ROBERTO AMORIM; \\ TAYLOR BRANDÃO SCHNAIDER \\ UNIVÁS - Universidade do Vale do Sapucaí
}

Introdução: O câncer colorretal (CCR) é o terceiro câncer mais comum no mundo, com altas taxas de mortalidade. É possível melhorar esse cenário por meio do rastreamento e da adequada vigilância após a ressecção de lesões pré-neoplásicas. Apesar de existirem guidelines orientando essa prática, seu uso é aquém do desejado. Sendo assim, são necessários recursos para aumentar sua aplicação, como os aplicativos móveis, que são cada vez mais utilizados como ferramentas para consulta durante a rotina profissional dos médicos. Objetivo: Criar um aplicativo a partir do desenvolvimento e validação de algoritmos, para auxiliar profissionais médicos no rastreamento do câncer colorretal e vigilância póspolipectomia. Métodos: Estudo descritivo na modalidade de Tecnologia e Aplicativos de Software. O projeto foi aprovado pelo Comitê de Ética em Pesquisa (CEP) da Universidade do Vale do Sapucaí (UNIVÁS), com parecer número 3.514.756 sob o CAAE18193519.4.0000.5102 em 19/08/2019. Foi realizada revisão junto às bases de dados das Ciências da Saúde, PubMed (U.S. National Institutes of Health's National Library of Medicine), SciELO (Scientific Eletronic Library Online), LILACS (Literatura Latino Americana e do Caribe em Ciência da Saúde) e Biblioteca Cochrane, sendo selecionados 37 artigos e guidelines publicados de 2017 a 2020 e, a seguir, desenvolvidos algoritmos sobre o rastreamento do câncer colorretal e vigilância pós-polipectomia. Para avaliação da confiabilidade de conteúdo do algoritmo, foram convidados 20 juízes. Destes, 17 retornaram a pesquisa, sendo 12 do sexo masculino e 5 do sexo feminino, com idades entre 35 e 81 anos, média de 50,65 anos. Quanto à especialidade, 6 são gastroenterologistas (35,29\%) e 11 são coloproctologistas $(64,71 \%)$, com tempo de formação de 11 a 45 anos (média 26,24 anos) e média de 22,12 anos de atuação na especialidade. Os itens avaliados pelos juízes foram: sequência de informações, facilidade de entendimento, linguagem do algoritmo e pertinência do conteúdo. Conforme tabela abaixo, o Índice de Validação do Conteúdo Global foi de 95,59\%, demonstrando que os juízes concordaram em todos os itens avaliados. Em relação à consistência interna do questionário, foi realizado o cálculo do coeficiente alfa de Cronbach e o presente trabalho apresentou um escore final de 0,7030 , demonstrando que o algoritmo tem substancial consistência interna. Resultado: Os algoritmos apresentaram boa confiabilidade e foram transformados no aplicativo "Colon App" por um profissional de Tecnologia em Informação (TI), contendo informações do rastreamento do CCR e da vigilância de lesões pré-neoplásicas. Conclusão: Esse estudo desenvolveu um aplicativo que reúne as recomendações mais recentes acerca do rastreamento do câncer colorretal e vigilância pós-polipectomia, com intuito de auxiliar os médicos na aplicação dos guidelines e, dessa forma, melhorar o panorama da doença.

\section{REFERÊNCIAS}

Ahnen DJ, Patel SG. Cost-effectiveness and national effects of initiating colorectal cancer screening for average-risk persons at age 45 years instead of 50 years. Gastroenterology. 2019;157(6):1691-2.

Gini A, Jansen EEL, Zielonke N, Meester RGS, Senore C, Anttila A, et al. Impact of colorectal cancer screening on cancer-specific mortality in Europe: A systematic review. European Journal of Cancer. 2020;127:224-35.

Grundy QH, Wang Z, Bero LA. Challenges in assessing mobile health app quality. American Journal of Preventive Medicine. 2016;51(6):1051-9.

PALAVRAS-CHAVE: Neoplasias Colorretais; Programas de Rastreamento; Pólipos Intestinais; Aplicativos Móveis 


\title{
AQUECIMENTO GLOBAL E A AMEAÇA À SAÚDE HUMANA. DISCUSSÃO ÉTICA
}

\author{
LUCAS EDUARDO OLIVEIRA DE REZENDE*; RAFAEL LAZZAROTTO SIMIONI; MANOEL ARAUJO \\ TEIXEIRA \\ UNIVÁS - Universidade do Vale do Sapucaí
}

Introdução: Os bioeticistas podem desempenhar um papel importante no debate sobre mudanças climáticas. Para alguns autores como Gardiner a participação de nesta temática é cheia de obstáculos que podem em determinados momentos ocasionar a retirada da reflexão bioética e ocasionar somente a discussões científicas de especialistas no assunto. Por isso, durante a reflexão sobre Atmosfera e Mudança do Clima deve ser levado em consideração dificuldades como a natureza abstrata das mudanças climáticas, a necessidade de cooperação global para tomadas de medidas efetivas, problemas com as noções tradicionais de responsabilidade moral aplicada às mudanças climáticas; compromissos difíceis entre interesses econômicos de curto prazo e efeitos adversos em longo prazo, a falha do mercado para explicar os custos ambientais (ou externalidades) das mudanças climáticas; aumento das demandas de energia e alimentos, crescimento populacional e desenvolvimento econômico, a saúde das gerações vindouras, entre outros. Objetivo: Levantar alguns números indicadores que mostre a situação atual do Brasil em relação à atmosfera e mudança no clima e correlacionar com as possíveis transformações na saúde humana para as futuras gerações. Metodologia: Levantamento realizado por meio de dados liberados pelo Ministério do Meio Ambiente em sua pagina da internet: https//: www.mma.gov.br.Os principais indicadores observados foram as emissões de gases de efeito estufa (GEE) por setores e por fontes antrópicas, identificação da intensidade energética do Produto Interno Bruto (PIB) e verificação da efetividade das ações para proteção da camada de ozônio. Resultados/desenvolvimento: As GEE no período de 2005 a 2010 caiu 38,7\% no Brasil, a redução do desmatamento na Amazônia é apontada como principal causa desse efeito. Por outro lado foi verificado o aumento de $35 \%$ das emissões de GEE pela agropecuária no ano de 2010 , seguido pela energia com aumento de $32 \%$. Com relação a efetividade das ações para proteção da camada de ozônio aos gases Clorofluorcarbonos (CFC), Hidroclorofluorcarbonos (HCFC) e Brometo de metila ( $\mathrm{CH} 3 \mathrm{Br}$ ) houve a redução deste tipo de poluente nos últimos anos. O Brometo de metila praticamente não é mais utilizado no Brasil desde 2006. Em se tratando de fontes de emissão de GEE por fontes antrópicas os principais gases poluentes são o monóxido de Carbono (CO), óxido de Nitrogênio (NOx), hidrocarbonetos totais (HC) e material particulado (MP). Entre 2002 e 2012 o Brasil dobrou a sua frota de veículos, que chegou aos 48 milhões. Mesmos com esse aumento houve a redução de gases poluentes como o CO em mais de 50\%; NOx em mais de $13 \%$; HC em mais de $46 \%$; e por fim MP em mais de $46 \%$. Conclusão: os números mostram resultados positivos em alguns setores, no entanto conciliar desenvolvimento sustentável e saúde da população é um desafio que precisa ser discutido com outros profissionais para que possam antever futuras epidemias que podem ser perigosas e ameaçadoras para o homem e sua sobrevivência. A revisão mostrou que os dados de sustentabilidade precisam ser mensurados em relação a saúde da população e não apenas como dados de resistência ambiental global.

\section{REFERÊNCIAS}

Ministério do meio Ambiente. Secretaria Executiva - SECEX. PNIA 2012 PAINEL NACIONAL DE INDICADORES AMBIENTAIS - Referencial teórico, composição e síntese dos indicadores da versãopiloto. Brasília, 2014, 97p

PALAVRAS-CHAVE: Bioética; indicadores; meio ambiente; modernidade; saúde 


\title{
ARGUMENTAÇÃO E HISTÓRIA: UM ESTUDO DOS DISCURSOS DOS PRESIDENCIÁVEIS
}

\author{
JÚLIO CÉSAR MARTINS SANTOS*; ATILIO CATOSSO SALLES \\ UNIVÁS - Universidade do Vale do Sapucaí
}

INTRODUÇÃO: A argumentação é, nas palavras de Orlandi (1998), um "observatório do político". Cabe aqui a ressalva: o político a que se faz referência, de acordo com a Análise de Discurso, "significa que o sentido é sempre divido, sendo que esta divisão tem uma direção que não é indiferente às injunções das relações de força que derivam da forma da sociedade na história" (idem, p. 74). No campo da política, por sua vez, a disputa pelo eleitorado exige recursos retóricos os mais variados, postos em prática a fim de convencer, conquistar, persuadir. Em alguns casos, e partindo do pressuposto suscitado por Orlandi, também na produção de identificação a um determinado grupo específico, filiado a certas formações discursivas que visam marcar essa divisão significante constitutiva. Neste estudo, buscamos compreender as estratégicas discursivas de Jair Messias Bolsonaro, atual presidente do Brasil, por meio da análise do vídeo Depois de encontro com Fux, Bolsonaro reza Pai Nosso, de 12 de julho de 2021, em que ele, confrontado por jornalistas, utiliza a oração do Pai Nosso, vinculada ao universo cristão, em uma de suas respostas. METODOLOGIA: Preconizamos uma abordagem qualitativa, exploratória e descritiva, baseada num levantamento bibliográfico que, após definir um recorte - a saber, o vídeo antes mencionado -, configurou o corpus analítico. Mobilizamos neste estudo, então, um arquivo conceitual subsidiado no aporte teórico da Análise de Discurso. RESULTADOS/ DESENVOLVIMENTO: Na materialidade significante analisada, investigamos as "relações de poder simbolizadas em uma sociedade dividida" (ORLANDI, 2017, p. 55), isto é, o modo como essa divisão é explorada a partir de uma posição-sujeito de autoridade, a de chefe de Estado brasileiro, ocupada por Jair Bolsonaro. Para reforçar a patente divisão experienciada atualmente na conjuntura política nacional, o presidente mobiliza estratégias argumentativas calcadas, neste caso específico, no discurso religioso e numa confrontação que aqui chamaremos "bélica". CONCLUSÃO: De acordo com Pêcheux (2014, p. 77), a "antecipação do que o outro vai pensar parece constitutiva de qualquer discurso". Instado por esta premissa, o presidente brasileiro Bolsonaro se utiliza de uma estratégia discursiva agressiva, fazendo com que suas bases eleitorais estejam sempre mobilizadas e prontas a disparar sua reconhecida máquina de ódio. Desta forma, concluímos que esse recurso argumentativo não é desprovido de método, uma vez que "os sentidos e os sujeitos são divididos e têm uma direção que não é indiferente à sua relação com a ideologia" (ORLANDI, 2017, p. 55).

\section{REFERÊNCIAS}

ORLANDI, E. Discurso e argumentação: um observatório do político. Fórum Linguístico, v. 1, n. 1, p. 7381, 1998.

ORLANDI, E. Documentário: acontecimento discursivo, memória e interpretação. In: ORLANDI, E. Discurso em análise: sujeito, sentido e ideologia. 3. ed. Campinas, SP: Pontes, 2017.

PÊCHEUX, M. Análise Automática do Discurso (AAD - 69). In: GADET, F.; HAK, T. (Orgs.). Por uma análise automática do discurso: uma introdução à obra de Michel Pêcheux. 5. ed. Campinas, SP: Editora da UNICAMP, 2014.

PALAVRAS-CHAVE: Análise de Discurso, Argumentação, Bolsonaro, Político. 


\title{
ATIVIDADE ANTIBACTERIANA DO EXTRATO HIDROALCOÓLICO DAS FOLHAS DE PSIDIUM GUAJAVA LINN
}

\author{
JAQUELINE APARECIDA PIRES*; FABIO LUIZ PEREIRA FERREIRA; LUIZ FRANCISLEY DE PAIVA; \\ RODRIGO MACHADO PEREIRA \\ UNIVÁS - Universidade do Vale do Sapucaí
}

INTRODUÇÃO: Bactérias são microrganismos procariontes presentes em vários tipos de ambientes, inclusive nos mais inóspitos como em locais muitos quentes ou muito salinos. São também encontradas em nosso organismo e auxiliam no bom funcionamento do corpo. Essas bactérias normalmente não causam problemas ao ser humano, no entanto algumas de suas variações são responsáveis por causar doenças como gastroenterites, meningites, cistites, entre outras (ARAGUAYA, 2020). Nesse contexto, cabe mencionar que uma das propriedades farmacológicas da casca e das folhas da planta Psidium guajava Linn (Goiabeira) pode ser eficaz no combate a essas bactérias, pois possui atividade antimicrobiana já observada em outros estudos (GRANDI, 2014). Assim, o objetivo deste estudo foi o de avaliar o efeito antimicrobiano do extrato hidroalcoólico das folhas de P. guajava Linn frente a bactérias de interesse clínico. METODOLOGIA: As folhas de P. guajava Linn foram coletadas de planta adulta. O material vegetal foi lavado em água corrente e submetido à secagem a $50{ }^{\circ} \mathrm{C}$ por 3 dias. $\mathrm{O}$ material seco foi então pulverizado em moinho de facas e o extrato etanólico foi obtido através do método de extração de lixiviação por meio de uma solução hidroalcoólica à $70 \%(\mathrm{v} / \mathrm{v})$ que foi trocada constantemente por um período de 24 horas à temperatura ambiente. A posteriori, o extrato foi filtrado e armazenado em frascos âmbar e estocados em câmara fria. A atividade antimicrobiana foi realizada pela técnica de disco-difusão de acordo com a metodologia de Kirby-Bauer seguindo o documento M2-A8 (NCCLS/CLSI, 2003) com modificações. Após a semeadura dos inóculos padronizados na escala 0,5 de McFarland, foram inseridos discos de papel de filtro Whatman № 1 de $6 \mathrm{~mm}$ de diâmetro estéreis sobre o meio de cultura e sobre cada disco foram dispensados $5 \mu \mathrm{L}$ do extrato. Cada placa recebeu um disco e foram vedadas e incubadas a $35{ }^{\circ} \mathrm{C}$. O teste foi realizado em triplicata. Os halos quando presentes foram mensurados com auxilio de um paquímetro. Os microrganismos utilizados foram às cepas referências de: Escherichia coli ATCC8739, Staphylococcus aureus ATCC6538, Pseudomonas aeruginosa ATCC9027 e Salmonella typhimurium ATCC14028. RESULTADOS: O extrato das folhas de P. guajava Linn apresentou atividade antibacteriana apenas contra a cepa de Staphylococcus aureus. O diâmetro dos halos variaram de 10 à $13 \mathrm{~mm}$. CONCLUSÃO: O extrato hidroalcoólico das folhas de P. guajava Linn possui atividade antibacteriana contra $S$. aureus. O resultado negativo frente às outras bactérias sugere que o extrato não possui atividade antibacteriana frente a microrganismos Gram negativos, no entanto, o potencial fitoterápico desta planta deve ser melhor estudado e compreendida por outras técnicas.

\section{REFERÊNCIAS}

ARAGUAIA, M. "Escherichia coli". Brasil Escola. Disponível em: $<$ https://brasilescola.uol.com.br/biologia/escherichia-coli.htm> Acesso em: 28 de maio 2020.

GRANDI, T. S. M. Tratado das plantas medicinais mineiras, nativas e cultivadas. Belo Horizonte: Adequatio Estúdio, 2014.

NCCLS. Performance Standards for Antimicrobial Disk Susceptibility Tests. Approved Standard - Eighth Edition. NCCLS document M2-A8. Wayne, Pennsylvania: 2003.

PALAVRAS-CHAVE: Plantas medicinais; Antibacterianos; Testes de Sensibilidade a Antimicrobianos por Disco-Difusão. 


\title{
ATIVIDADE ANTIMICROBIANA DO EXTRATO ETANÓLICO DAS FOLHAS DE EUGENIA UNIFLORA
}

\author{
FABIO LUIZ PEREIRA FERREIRA*; IZAURA DE LIMA MIRANDA; LUIZ FRANCISLEY DE PAIVA \\ UNIVÁS - Universidade do Vale do Sapucaí
}

INTRODUÇÃO: O uso indiscriminado de antimicrobianos disponíveis hoje no mercado vem contribuindo para o aumento da quantidade de patógenos resistentes ocasionando quadros de recidiva. Nos últimos anos, tem sido dada uma atenção expressiva à utilização de compostos antimicrobianos de origem natural. Essa crescente procura por novos compostos bioativos, parte do conhecimento de que, algumas plantas medicinais apresentam, com frequência, atividade antimicrobiana (AKINNIBOSUN et al., 2008). Assim, o objetivo deste estudo foi o de avaliar o efeito antimicrobiano do extrato etanólico das folhas de Eugenia uniflora (Pitanga) frente a microrganismos de interesse clínico. METODOLOGIA: As folhas de E. uniflora foram coletadas de planta adulta no período vespertino do mês de maio de 2021. A planta foi identificada utilizando critérios morfológicos junto ao Herbário UNIVÁS da mesma universidade pela curadora prof. Dr. V.F.C. Monteiro e teve uma exsicata depositada sob número tombo UNIVAS-005. Inicialmente, as folhas de E. uniflora lavadas em água corrente e submetidas à secagem a $105^{\circ} \mathrm{C}$ por 24 horas. O material seco foi então pulverizado em moinho de facas e o extrato etanólico foi obtido através do método de maceração utilizando $30 \mathrm{~g}$ das folhas e $300 \mathrm{~mL}$ de etanol absoluto durante 7 dias. Após este período, o extrato foi filtrado utilizando papel filtro e a mistura foi submetida ao processo de remoção do álcool utilizando aparelho de Soxhlet. A atividade antimicrobiana foi realizada pela técnica de disco-difusão de acordo com a metodologia de Kirby-Bauer seguindo os documentos M2-A8 (NCCLS/CLSI, 2003) e M44-A2 (CLSI, 2009) com modificações. Após a semeadura dos inóculos padronizados na escala 0,5 de McFarland, foram inseridos discos de papel de filtro Whatman № 1 de $6 \mathrm{~mm}$ de diâmetro estéreis sobre o meio de cultura e sobre cada disco foram dispensados $5 \mu \mathrm{L}$ do extrato. Cada placa recebeu um disco e foram vedadas e incubadas a $35{ }^{\circ} \mathrm{C}$. $\mathrm{O}$ teste foi realizado em triplicata. Os halos quando presentes foram mensurados com auxilio de um paquímetro. Os microrganismos utilizados foram às cepas referências de: Escherichia coli ATCC8739, Staphylococcus aureus ATCC6538, Pseudomonas aeruginosa ATCC9027, Salmonella typhimurium ATCC14028, Candida albicans ATCC90028, Candida glabrata MYA 2950, Candida Krusei ATCC6258, Candida parapsilosis ATCC 22019, Candida utilis ATCC9950. Os dados obtidos foram submetidos à análise de variância (ANOVA), sendo as médias das medidas dos halos comparadas pelo teste Tukey, ambos a $5 \%$ de significância, utilizando-se o Software R. 2.5.1. RESULTADOS: $O$ extrato das folhas de E. uniflora mostrou atividade antifúngica e antibacteriana e houve diferença estatística nos tratamentos com valor de $p=3,637 \mathrm{e}-12$. C. krusei foi o microrganismo mais susceptível seguido de E. coli. Não houve diferença estatística na média dos halos de inibição de S. aureus, C. parapsilosis, C. utilis e

C. albicans. O extrato não apresentou atividade antimicrobiana para os microrganismos: C. glabrata,

P. aeruginosa e S. typhimurium. CONCLUSÃO: O extrato das folhas de E. uniflora possui atividade antimicrobiana, no entanto, o potencial fitoterápico desta planta deve ser melhor estudado e compreendida por outras técnicas.

\section{REFERÊNCIAS}

AKINNIBOSUN, F. I.; AKINNIBOSUN, H. A.; IBEH, I.; OSAGHAE, F. Antibacterial activity of

Phyllanthus amarus Schum and Thonn. on five vegetative organisms. Plant Archive. 2008; v.8, n.2, p.563568.

CLINICAL AND LABORATORY STANDARDS INSTITUTE. Method for antifungal disk diffusion susceptibility testing of yeast; approved guideline - 2nd ed. CLSI document M44-A2. Wayne, Pennsylvania: 2009.

NCCLS. Performance Standards for Antimicrobial Disk Susceptibility Tests. Approved Standard - Eighth Edition. NCCLS document M2:A8. Wayne, Pennsylvania: 2003.

PALAVRAS-CHAVE: Plantas medicinais; Antibacterianos; 


\title{
XVIII Congresso de Iniciação Científica
}

UNIVÁs | 2021

\section{ATIVIDADE ANTIMICROBIANA DO EXTRATO ETANÓLICO DE SCHINUS MOLLE L.}

\author{
IZAURA DE LIMA MIRANDA*; FABIO LUIZ PEREIRA FERREIRA; LUIZ FRANCISLEY DE PAIVA \\ UNIVÁS - Universidade do Vale do Sapucaí
}

INTRODUÇÃO: Segundo a Organização Mundial da Saúde, a resistência microbiana é um grave problema de saúde pública e está associada ao aumento do tempo de internação, dos custos de tratamento e das taxas de morbimortalidade dos pacientes sendo que, o uso dos antimicrobianos na comunidade e no ambiente hospitalar associado a práticas inadequadas de controle de infecção, são reconhecidamente fatores de risco para seleção e disseminação da resistência microbiana (WHO, 2015). Neste sentido, a fitoterapia representa a possibilidade de ampliação de opções terapêuticas e pode fortalecer ainda mais a inovação e a exploração da rica biodiversidade brasileira. Assim, o objetivo deste estudo foi o de avaliar o efeito antimicrobiano do extrato etanólico das folhas de Schinus molle L. (Aroeira-salsa) frente a microrganismos de interesse clínico. METODOLOGIA: As folhas de S. molle foram coletadas de planta adulta no período vespertino do mês de maio de 2021. A planta foi identificada utilizando critérios morfológicos junto ao Herbário UNIVÁS da mesma universidade pela curadora prof. Dr. V.F.C. Monteiro e teve uma exsicata depositada sob número tombo UNIVAS-004. Inicialmente, os folíolos das folhas foram separados dos pecíolos para aquisição de dois extratos com partes vegetais diferentes. Após essa etapa, o material vegetal foi lavado em água corrente e submetidos à secagem a $105^{\circ} \mathrm{C}$ por 24 horas. $\mathrm{O}$ material seco foi então pulverizado em moinho de facas e o extrato etanólico foi obtido através do método de maceração utilizando $30 \mathrm{~g}$ do material vegetal e $300 \mathrm{~mL}$ de etanol absoluto durante 7 dias. Após este período, os extratos foram filtrados e a mistura foi submetida ao processo de remoção do álcool utilizando aparelho de Soxhlet. A atividade antimicrobiana foi realizada pela técnica de disco-difusão de acordo com a metodologia de Kirby-Bauer seguindo os documentos M2-A8 (NCCLS/CLSI, 2003) e M44-A2 (CLSI, 2009) com modificações. Após a semeadura dos inóculos padronizados na escala 0,5 de McFarland, foram inseridos discos de papel de filtro Whatman № 1 de $6 \mathrm{~mm}$ de diâmetro estéreis sobre o meio de cultura e sobre cada disco foram dispensados $5 \mu \mathrm{L}$ do extrato. Cada placa recebeu um disco e foram vedadas e incubadas a $35 \stackrel{\circ}{\circ}$. $O$ teste foi realizado em triplicata. Os halos quando presentes foram mensurados com auxilio de um paquímetro. Os microrganismos utilizados foram às cepas referências de: Escherichia coli ATCC8739, Staphylococcus aureus ATCC6538, Pseudomonas aeruginosa ATCC9027, Salmonella typhimurium ATCC14028, Candida albicans ATCC90028, Candida glabrata MYA 2950, Candida Krusei ATCC6258, Candida parapsilosis ATCC 22019, Candida utilis ATCC9950. Os dados obtidos foram submetidos à análise de variância (ANOVA), sendo as médias das medidas dos halos comparadas pelo teste Tukey, ambos a $5 \%$ de significância, utilizando-se o Software R. 2.5.1. RESULTADOS: Os extratos dos folíolos e dos pecíolos das folhas de S. molle mostraram atividade antifúngica contra $\mathrm{C}$. krusei. A atividade antibacteriana contra $\mathrm{E}$. coli foi verificada na presença do extrato do folíolo e de $S$. aureus na presença do extrato do pecíolo. Nos demais microrganismos não foram produzidos halos de inibição. Houve diferença estatística nos tratamentos com valor de $p=2,2 e-16$. CONCLUSÃO: O extrato das folhas de S. molle possui atividade antimicrobiana, no entanto, o potencial fitoterápico desta planta deve ser melhor estudado e compreendidos por outras técnicas.

\section{REFERÊNCIAS}

CLINICAL AND LABORATORY STANDARDS INSTITUTE. Method for antifungal disk diffusion susceptibility testing of yeast; approved guideline - 2nd ed. CLSI document M44-A2. Wayne, Pennsylvania: 2009.

NCCLS. Performance Standards for Antimicrobial Disk Susceptibility Tests. Approved Standard - Eighth Edition. NCCLS document M2-A8. Wayne, Pennsylvania: 2003.

WORLD HEALTH ORGANIZATION. Antimicrobial resistance: draft global action plan on antimicrobial resistance. Geneva: 2015.

PALAVRAS-CHAVE: Plantas medicinais

Antibacterianos;

Testes de

Sensibilidade

a

Antimicrobianos por Disco-Difusão. 


\title{
AUTOESTIMA, OTIMISMO E ESPERANÇA EM PROFESSORES EM TEMPOS DE COVID-19
}

\author{
LAÍS REZENDE DA COSTA*; JÉSSICA RAFAELA FONSECA PATROCÍNIO; LARIANA PAULA PINTO \\ UNIVÁS - Universidade do Vale do Sapucaí
}

INTRODUÇÃO: A profissão docente é considerada como uma das mais estressantes, uma vez que ensinar se tornou uma atividade estressora que provoca alterações tanto na saúde física e mental quanto no desempenho profissional (REIS; ARAÚJO; CARVALHO; BARBALHO; SILVA, 2006). Além disso, a pandemia de COVID-19, provocou alterações no âmbito das aulas em todos os níveis escolares, entre eles o universitário, obrigando gestores de faculdades e universidades a adotarem normativas preconizadas pela Portaria no $345 / 2020$ do Ministério da Educação. Diante dessa realidade vivenciada pelos docentes, o presente estudo teve como objetivo investigar a percepção dos professores em relação à autoestima, otimismo, esperança em tempos de pandemia da COVID-19. METODOLOGIA: O presente estudo tratou-se de uma pesquisa quantitativa, aplicada, descritiva e de campo. Participaram 17 professores, com idades entre 28 e 74 anos $(M=49,1$; $D P=14,1)$, e todos lecionaram no período da pandemia da Covid-19. Os participantes responderam a três escalas, quais sejam, Escala de Autoestima de Rosenberg (HUTZ; ZANON, 2011); Teste de Orientação na Vida (BASTIANELLO; ZANON; PACICO; HUTZ, 2014); e, por fim, Teste de Esperança Cognitiva adaptado por Pacico e Bastianello (2014). Os dados foram coletados através de formulário online, na plataforma Google Forms, em que os participantes responderam ao TCLE autorizando o uso de seus dados na pesquisa, bem como aos instrumentos. A pesquisa foi aprovada no Comitê de Ética em Pesquisa da UNIVÁS sob parecer número 4.664.779. RESULTADOS: Os resultados obtidos pelos professores foram analisados, considerando os dados normativos sugeridos pelos autores das adaptações brasileiras das ferramentas. No que diz respeito à autoestima, verificou-se predominância em relação a bons resultados (acima do percentil 25) relacionados à uma valorização de si, caracterizado por uma orientação positiva de perceber a si mesmo (HUTZ; ZANON, 2011). Em relação ao otimismo, os professores respondentes apresentaram resultados expressivos, visto que $52,9 \%$ da amostra $(n=9)$ apresentou percentis maiores ou iguais a 75 , evidenciando que se trata de um grupo que espera que coisas boas aconteçam, com expectativas positivas em relação aos eventos futuros (BASTIANELLO; HUTZ, 2015). Por fim, no que tange à esperança autocentrada, que se refere à motivação por atingir objetivos futuros, sendo voltada para o eu, verificou-se que $29,5 \%(n=5)$ da amostra revelou percentis abaixo do quartil 25 , o que indica poucos recursos esperançosos a respeito de si. Por outro lado, $35,4 \%(n=6)$ da amostra apresentou percentis acima do quartil 75 . Em relação à esperança altruísta, em que a pessoa tem pensamentos positivos sobre o futuro do outro e do contexto global, 76,5\% $(n=13)$ dos participantes apresentou resultados acima do quartil 75. CONSIDERAÇÕES FINAIS: Pode-se observar que, muitas foram as dificuldades enfrentadas pelas mudanças compulsórias que a pandemia Covid-19 proporcionou, exigiu da sociedade em geral adaptações na sua rotina de vida diária. No caso do grupo de professores, a mudança aconteceu na transição de uma modalidade presencial para um formato totalmente remoto, exigindo dos professores o desenrolar de suas aulas em novos formatos, com recursos muito distintos. Entretanto, tais circunstâncias não foram suficientes para reduzir as percepções positivas dos professores no que diz respeito à sua autovalorização, e a expectativas positivas sobre o futuro.

\section{REFERÊNCIAS}

HUTZ, C. S.; ZANON, C.. Revisão da adaptação, validação e normatização da escala de autoestima de Rosenberg. Avaliação Psicológica: Interamerican Journal of Psychological Assessment, v. 10, n. 1, p. 4149. 2011.

BASTIANELLO, M. R.; PACICO, J. C.; HUTZ, C. S. Optimism, self-esteem and personality: Adaptation and validation of the Brazilian version of the Revised Life Orientation Test (LOT-R). Psico-USF, v. 19, p. 523-531. 2014.

PACICO, J. C.; BASTIANELLO, M. R. As origens da Psicologia Positiva e os primeiros estudos

brasileiros. In: HUTZ, C. S. (org.). Avaliação em Psicologia Positiva. Porto Alegre: Artmed, p. 13-23. 2014.

PALAVRAS-CHAVE: Autoestima; Otimismo; Esperança; Professores; Covid-19. 


\title{
AVALIAÇÃO ALIMENTAR E CONSUMO DE CARBOIDRATO EM PRATICANTES DE MUSCULAÇÃO E SUA RELAÇÃO COM A COMPOSIÇÃO CORPORAL
}

\author{
MICHELE TAÍS NATO*; ANDRÉA TIENGO; CAMILA BLANCO GUIMARÃES \\ UNIVÁS - Universidade do Vale do Sapucaí
}

Introdução: Para os praticantes de musculação, uma alimentação saudável e balanceada, promove, além da obtenção da melhora do desempenho físico, modificações positivas na composição corporal, contudo grande parte adere a dietas com diminuição drástica ou até mesmo a eliminação do carboidrato, com o intuito de diminuir a adiposidade corporal e atingir um menor percentual de gordura, podendo ocasionar diversas consequências ao organismo. Metodologia: Pesquisa do tipo quantitativa, observacional, transversal, descritiva e de campo, avaliada conforme os dados antropométricos de peso, altura e dobras cutâneas, e partir do questionário do dia alimentar habitual (DAH), analisando a qualidade da alimentação e a restrição de carboidrato em 40 indivíduos, sendo os participantes de ambos os sexos e com faixa etária entre 18 e 59 anos de idade, no intuito de avaliar a associação da composição corporal e ingestão de carboidratos, se a menor ou maior ingestão de carboidratos estaria relacionada à um percentual de gordura menor ou maior respectivamente. Resultados: Avaliando os 40 participantes, observou-se que referente a caloria dietética e as necessidades calóricas, $87,5 \%(n=35)$ dos indivíduos possuem classificação inadequada e $12,5 \%(n=5)$ adequada. Já em relação ao consumo do macronutriente avaliado, houve valores idênticos em que $50 \%(n=20)$ dos indivíduos apresenta restrição de carboidrato (Low Carb) e a outra metade avaliada possui o consumo adequado deste macronutriente, dieta não Low Carb. O percentual de gordura corporal que teve como média $20,77 \%$, relacionado à restrição de carboidrato teve como resultado que, praticantes que possuem um percentual de gordura corporal menor, consomem dietas sem restrição de carboidratos, dietas não Low Carb. Considerações finais: Após a realização da pesquisa, conclui-se que a qualidade da dieta dos praticantes de musculação foi desbalanceada, evidenciando que metade da amostra fazia restrição de carboidrato. $O$ baixo consumo de carboidrato não mostrou relação com o menor percentual de gordura corporal desses participantes.

\section{REFERÊNCIAS}

BIESEK, Simone; SILVA, Leila Maria Lopes da. Guia alimentar para atletas. In: BIESEK, Simone; ALVES, Letícia Azen; GUERRA, Isabela. Estratégias de nutrição e suplementação no esporte. 3. ed. Barueri, SP: Manole, 2015. p. 128.

CUPPARI, Lilian et al. Guia de nutrição: clínica no adulto. 3. ed. Barueri, SP: Manole, 2014.

DUNFORD, Marie. O que é nutrição no esporte e no exercício? In: . Fundamentos de nutrição no esporte e no exercício. Barueri, SP: Manole, 2012. p. 9.

PALAVRAS-CHAVE: Treinamento de Resistência; Alimentação; Carboidratos da Dieta; Distribuição da Gordura Corporal. 


\title{
AVALIAÇÃO DA ATIVIDADE CARRAPATICIDA DO ÓLEO ESSENCIAL DE MELALEUCA ARMILLARIS SOBRE CARRAPATOS
}

\author{
MAISA VILAS BOAS SILVA*; ANDRÉ DE SOUZA E SILVA; ADRIANA RODRIGUES DOS ANJOS \\ MENDONÇA \\ UNIVÁS - Universidade do Vale do Sapucaí
}

Introdução: Carrapatos são causadores de lesões de pele e importantes vetores na transmissão de doenças infecciosas a animais e humanos. Seu controle tem sido dificultado pela resistência aos carrapaticidas sintéticos. Objetivo: avaliar a eficácia do óleo essencial à base de Melaleuca armillaris como carrapaticida, in vitro. Métodos: estudo in vitro, realizado no Laboratório de Fitoterapia da Universidade do Vale do Sapucaí (UNIVÁS) Pouso Alegre-MG. Das folhas de M. armillaris, foram extraídos por hidrodestilação o óleo essencial e hidrolato. Foram coletados carrapatos de bovinos utilizando a técnica de rotação manual anti-horária e colocados em tubo de ensaio. Foram realizados dois ensaios: o primeiro, avaliou-se a ação carrapaticida do óleo essencial de M. armillaris, quando aplicado diretamente (gotejamento no carrapato) e indiretamente (gotejamento em gaze de vedação do tubo de ensaio). A letalidade dos carrapatos foi avaliada utilizando lupa esteroscópica. No segundo ensaio, comparou-se a ação carrapaticida do óleo essencial e hidrolato de M. armillaris, pelas técnicas de imersão e aspersão. Resultados: O óleo essencial de M. armillaris apresentou ação carrapaticida quando aplicado diretamente sobre carrapatos; o hidrolato, independente se aplicado por aspersão ou imersão, não possui ação carrapaticida. Conclusão: o óleo de Melaleuca armillaris apresentou ação carrapaticida.

\section{REFERÊNCIAS}

Dantas-Torres F. Canine vector-borne diseases in Brazil. Parasit Vectors. 2008 Aug 8;1(25): 1-17. doi: 10.1186/1756-3305-1-25. PMID: 18691408; PMCID: PMC2533296.

Nwanade CF, Wang M, Wang T, Yu Z, Liu J. Botanical acaricides and repellents in tick control: current status and future directions. Exp Appl Acarol. 2020 May;81(1):1-35. doi: 10.1007/s10493-020-00489-z. Epub 2020 Apr 14. PMID: 3229155 (a).

Raynal, JT; Souza BC, Silva AB, Bahiense TC, Silva HC, Meyer R, Portela RW. Resistência do carrapato Rhipicephalus (Boophilus) microplus a acaricidas. Revista Portuguesa de Ciências Veterinárias (RPCV). 2015, 110 (593-594): 23-9.

PALAVRAS-CHAVE: Infestações por Carrapato. Acaricidas. Fitoterapia. Melaleuca. Óleos Voláteis. 


\section{AVALIAÇÃO DA CICATRIZAÇÃO DE FERIDAS CRÔNICAS TRATADAS COM O PÓ DA CASCA DA BANANA MUSA SAPIENTUM VERDE}

YUJI ATARASHI TAVARES*; MAYCON CRISTIAN GOMES DE PAULA; BRUNA DE CÁSSIA SOUSA; ISADORA ANDRÉ DE CAMARGO PACHECO; DÊNIA AMÉLIA NOVATO CASTELLI VON ATZINGEN; ADRIANA RODRIGUES DOS ANJOS MENDONÇA

UNIVÁS - Universidade do Vale do Sapucaí

INTRODUÇÃO: Feridas crônicas são uma condição muito prevalente, afetando aproximadamente $1 \%$ da população. Essa condição leva a importantes prejuízos clínicos e sociais, como dor crônica, infecções, constrangimento social e redução da qualidade de vida. Ela leva ainda a impactos financeiros, uma vez que feridas crônicas representam até $2 \%$ do orçamento de saúde das sociedades ocidentais. O tratamento de úlceras crônicas através da fitoterapia tem sido amplamente aceito em vista de suas comprovadas propriedades antimicrobianas, antioxidantes e antifúngicas. $\mathrm{O}$ uso da Musa sapientum na cicatrização de feridas é promissor, com estudos indicando sua ação anti-inflamatória e antimicrobiana. OBJETIVO: avaliar a eficácia do gel contendo $10 \%$ do pó da casca da banana Musa sapientum verde na cicatrização de úlceras crônicas. MÉTODOS: Ensaio clínico randomizado, interventivo e longitudinal. 21 pacientes foram alocados em dois grupos: um tratado com Colagenase 0,6 U/g (grupo controle) e o outro com gel contendo $10 \%$ do pó da casca da banana Musa sapientum verde (grupo estudo). As úlceras crônicas foram observadas ao longo de 21 dias e suas medidas foram coletadas nos dias 1, 7, 14 e 21 a fim de avaliar seu grau de contração. A análise dos dados foi realizada através do software "Epi info 7". RESULTADOS: 12 pacientes fizeram parte do grupo estudo e 9 do grupo controle. Em ambos os grupos, houve predominância do sexo masculino. Não foram observadas diferenças entre as médias das idades $(p=0,20)$, que foram 66 e 64 anos para os grupos estudo e controle, respectivamente. No grupo estudo, $81 \%$ dos pacientes apresentaram redução da área da ferida ao final dos 21 dias de tratamento, comparado aos $55 \%$ dos pacientes do grupo controle. Não houve diferenças no grau de contração das lesões ao longo do período avaliado (1×14 e 1×21) em ambos os grupos. Comparando os dois grupos, nenhuma diferença estatística foi observada em relação à área inicial das feridas $(p=0,749)$, grau de contração das feridas entre os dias $1 \times 7(p=0,546)$ e dias $1 \times 14(p=0,597)$. Existe uma tendência de 0 grau de contração das feridas ser maior no grupo estudado que no grupo controle entre os dias $1 \times 21$, com um valor de $p=0,062$. CONCLUSÃO: O uso do gel contendo $10 \%$ do pó da casca da banana Musa sapientum verde para o tratamento de feridas crônicas proporciona resultados similares aos da Colagenase $0,6 \mathrm{U} / \mathrm{g}$, podendo ser uma opção terapêutica econômica, efetiva e acessível para grande parte da população.

\section{REFERÊNCIAS}

TAN, M. K. H. et al. Venous Leg Ulcer Clinical Practice Guidelines: What is AGREEd?. European journal of vascular and endovascular surgery: the official journal of the European Society for Vascular Surgery, v. 57, n.1, p. 121-129, out./2018. Disponível em: https://pubmed.ncbi.nlm.nih.gov/30287207/. Acesso em: 22 set. 2021.

SHAH, G. et al. Scientific basis for the therapeutic use of Cymbopogon citratus, stapf (Lemon grass). Journal of advanced pharmaceutical technology \& research, v. 2, n.1, p. 3-8, jan./2011. Disponível em: https://pubmed.ncbi.nlm.nih.gov/22171285/. Acesso em: 22 set. 2021.

PALAVRAS-CHAVE: Cicatrização. Úlcera venosa. Musa sapientum 


\title{
AVALIAÇÃO DA CINÉTICA INFLAMATÓRIA INDUZIDA POR EXTRATOS HIDROALCÓOLICOS DA CASCA DE SCHINUS TEREBINTHIFOLIUS (AROEIRA) E STRYPHNODENDRON ADSTRINGENS (BARBATIMÃO) EM VESÍCULAS NO TECIDO SUBCUTÂNEO DE RATAS WISTAR
}

\author{
TÚLIO CUSTÓDIO REIS*; AMANDA MARIA DE ALMEIDA RIBEIRO; DÉBORA APARECIDA DA ROSA \\ SOUZA; GISLAINE CRISTINA SCODELER; RODRIGO MACHADO PEREIRA; FABÍOLA CUNHA \\ BERNARDES E REZENDE
}

UNIVÁS - Universidade do Vale do Sapucaí

INTRODUÇÃO: As plantas Stryphnodendron adstringens (barbatimão) e Schinus terebinthifolius (aroeira) acumulam grande aplicabilidade por povos tradicionais brasileiros. Estudos realizados in vitro descrevem suas variadas propriedades, porém, poucos avaliam o comportamento e a interação destes com sistemas biológicos (in vivo). OBJETIVO: O objetivo do presente estudo foi avaliar a cinética do processo inflamatório induzido por extratos hidroalcóolicos de Stryphnodendron adstringens e Schinus terebinthifolius em tecido subcutâneo de ratas. METODOLOGIA: Amostras da casca das plantas foram usadas para preparação dos extratos que foram formulados a $30 \%$ em extrator soxhlet. Para o ensaio animal 18 animais foram separados, 6 compuseram o grupo controle, 6 o grupo teste com S. adstringens e $6 \mathrm{com} \mathrm{S}$. terebinthifolius. Inoculou-se no dorso dos animais anestesiados $6 \mathrm{~mL}$ de ar estéril por filtro milipore em 2 tempos diferentes, bolha madura, no $6^{\circ}$ dia após a $1^{\circ}$ inoculação, fez então a inoculação de $0,1 \mathrm{~mL}$ de extrato diluído em $0,9 \mathrm{~mL}$ de solução fisiológica a $0,9 \%$ nos grupos teste, e $1 \mathrm{~mL}$ de solução fisiológica no grupo controle, após 24 horas houve a eutanásia de 3 animais de cada grupo e a coleta do exsudato inflamatório das bolhas, após 72 horas fez-se a eutanásia e a coleta do exsudato dos outros 3 animais, que foi fixado em $0,1 \mathrm{~mL}$ de paraformaldeído a $4 \%$ e centrifugado a 8000 RPM por 2 minutos, o pallet formado foi suspendido em $0,2 \mathrm{~mL}$ de solução fisiológica a $0,9 \%$, realizou-se em seguida a distensão do material celular suspendido. A coloração das lâminas deu-se pelo método de Romanowsky. RESULTADOS/DESENVOLVIMENTO: A imunidade é subdividida em duas classes que constituem mecanismos de ação diferentes e até mesmo complementares, a imunidade natural é mediada por barreiras físicas e químicas (suor, epitélios, saliva) e por células fagocitárias (neutrófilos, eosinófilos, monócitos etc), seus mecanismos sempre estão presentes ou são ativados logo após a exposição ao agente agressor; a imunidade adquirida dá prosseguimento ao processo de defesa através dos mecanismos de linfócitos antígeno-específicos e células de memória. Neste trabalho avaliou-se a presença dos seguintes leucócitos: neutrófilo, monócito e linfócito. Os resultados foram tabelados em planilhas no Excel, onde realizou-se a média de cada variável. Com relação ao grupo que recebeu o extrato de aroeira, observou-se o maior percentual de monócitos, com redução após 72 horas de experimento, com aumento concomitante do número de neutrófilos e linfócitos. As ratas que receberam o extrato de barbatimão apresentaram maior percentual de neutrófilos e linfócitos após 24 horas. CONSIDERAÇÕES FINAIS: O extrato de barbatimão apresentou comportamento mais próximo ao grupo controle se comparado a aroeira. Todavia, novos estudos são necessários para confirmação da veridicidade dos dados levantados.

\section{REFERÊNCIAS}

COICO, R.; SUNSHINE. G. Elementos da imunidade natural e adquirida. In: COICO, R. Imunologia. $6^{\circ}$ edição. Rio de Janeiro: editora Guanabara Koogan, 2010. p. 11 - 27.

REZENDE, F. C. B. e. Estudo da cinética do infiltrado celular inflamatório induzido por adjuvantes de vacinas em bolhas de ar formadas no subcutâneo de camundongos. 2003. 71 f. Dissertação (Mestrado em Biotecnologia) - Universidade Federal de Santa Catarina, Florianópolis, 2003.

PALAVRAS-CHAVE: Inflamação; leucócitos; extrato vegetal; ratas. 


\title{
AVALIAÇÃO DA INCIDÊNCIA E DA FAIXA ETÁRIA PREVALENTE DO ÍNDICE DE ABORTAMENTO NO HOSPITAL DAS CLÍNICAS SAMUEL LIBÂNIO
}

\author{
ANNA JÚLIA DE PAULA RESENDE*; JULIANA OLIVEIRA MOREIRA; LUCAS ALVES BARTELEGA; \\ NATHAN FERREIRA DE MELO; FIORITA GONZALES LOPES MUNDIM \\ UNIVÁS - Universidade do Vale do Sapucaí
}

INTRODUÇÃO: O abortamento é um dos principais fatores de morte materna e apresenta-se como uma questão de saúde pública. Devido a sua relevância, a análise da incidência e prevalência da faixa etária de abortamentos no Hospital das Clínicas Samuel Libânio (HCSL), MG, Brasil, faz-se importante para criação de manobras de intervenções na atenção primaria, secundária e terciária da saúde. Esta pesquisa analisou a incidência, a faixa etária prevalente e a relação com o diagnóstico anátomo-patológico dos abortamentos no HCSL, MG, Brasil. METODOLOGIA: Para este estudo observacional, analítico, transversal e retrospectivo foram coletados dados de 2.096 pacientes submetidas ao procedimento de curetagem uterina por abortamento, no período de 2009 a 2019, através da avaliação de prontuários do Centro de Patologia de Pouso Alegre. O critério de inclusão foi a realização de curetagem uterina por abortamento nesse período e o de exclusão foi a ausência de dados necessários no prontuário. Foram selecionadas as variáveis de idade, ano e diagnóstico anátomo-patólogico e aplicados o teste de KruskalWallis e a Análise de Variância. RESULTADOS/DESENVOLVIMENTO: A incidência foi representada por 2.096 casos variando de 12 a 59 anos de idade em 10 anos, sendo 2016 o ano de maior ocorrência. Dos dados de abortamento coletados, $53,1 \%$ esteve entre 21 e 32 anos, sendo as idades mais prevalentes: 24, 30 e 32 anos (13,02\%) e as menos: 12, 49 e 59 anos ( $0,12 \%)$. Já na análise da relação faixa etária por ano, notou-se o predomínio da média de 26 a 30 anos tendo variação entre os anos $(P=0,001)$. No estudo entre faixa etária e diagnóstico anátomo-patológico $(P=0,002)$ notou-se uma predominância de diagnóstico de restos deciduais e placentários nas pacientes mais adultas (> 25 anos) com redução do diagnóstico de restos ovulares e concepto, sendo estes mais prevalentes nas pacientes mais jovens (12 - 24 anos), sugerindo prevalência de abortamento incompleto neste grupo. CONSIDERAÇÕES FINAIS: Este estudo permitiu avaliar o padrão e a incidência de abortamento no HCSL de 2009 a 2019, demonstrando que a maior prevalência esteve entre 26 e 30 anos, faixa etária não considerada como fator de risco para abortamento. Nesse contexto, ressalta-se a necessidade de investigação etiológica para maiores explicações sobre esta prevalência, associada a abordagens de prevenção e intervenção entre as mais diversas idades, uma vez que o abortamento representa um problema de saúde pública.

\section{REFERÊNCIAS}

UNSAFE Abortion: Global and Regional Incidence, Trends, Consequences, and Challenges. Journal of Obstetrics and Gynecology Canada , [S. I.], v. 31, n. 12, p. 1149-1158, 12 dez. 2009. DOI 10.1016/S17012163(16)34376-6. Disponível em:

https://www.sciencedirect.com/science/article/abs/pii/S1701216316343766?via\%3Dihub. Acesso em: 22 set. 2021.

ABORTION incidence between 1990 and 2014: global, regional, and subregional levels and trends. The Lancet, [S. I.], v. 388, n. 10041, p. 258-267, 11 maio 2016. DOI

https://doi.org/10.1016/S0140-6736(16)30380-4. Disponível em:

https://www.thelancet.com/journals/lancet/article/PIIS0140-6736(16)30380-4/fulltext. Acesso em: 22 set. 2021.

PALAVRAS-CHAVE: Abortamento; Estudos de incidência; Saúde da mulher; Pesquisa sobre aborto; Brasil 


\title{
AVALIAÇÃO DAS CARACTERÍSTICAS MECÂNICA DO PLA, IMPRESSA EM 3D, PARA BIOMATERIAIS
}

\author{
GABRIEL YUDY PEREIRA SATO*; IGOR SOUZA NOUGUEIRA OSHIRO; HULISSES BONETI MARCON \\ UNIVÁS - Universidade do Vale do Sapucaí
}

INTRODUÇÃO: Conforme Alves, o desenvolvimento de produtos para saúde, de pessoas ou animais com necessidades específicas, estão cada vez mais diversificadas e exigentes quanto à necessidade de personalização. Denominados Tecnologia Assistiva (TA), constituem-se em dispositivos desenvolvidos para permitir uma maior funcionalidade aos envolvidos, com incapacidades ou mobilidade reduzida, no auxílio de suas atividades da vida diária. Selhorst na busca pela utilização de novas tecnologias em vários setores como os da indústria e do comércio de produtos para saúde, Afirma que comparado aos processos tradicionais, como a usinagem, a impressão 3D atende com maior rapidez, mas essas podem trabalhar de modo cooperativo, uma suprindo as necessidades da outra, uma vez que são processos que necessitam de várias linhas para acabamento. Celentano afirma que a melhoria da tecnologia e sofisticação de filamentos empregada nas construções de novas e modernas impressoras, têm se tornado cada vez maior. Atualmente, podem-se encontrar polímeros, compósitos, alimentos e até mesmo tecidos humanos sendo utilizados para impressão dos mais diversos produtos. Silva afirma que a resistência mecânica é maior quanto maior for a densidade do mesmo. O ABS é um termoplástico leve e rígido, possui boa flexibilidade e resistência ao impacto, podendo ter diversas formas e cores, através da moldagem térmica a altas temperaturas e adições de pigmentos. De acordo com Simões o PLA - Poli (ácido lático), ecologicamente, é um termoplástico biodegradável (Bioplástico) derivado de fontes renováveis como amido de milho, e cana de açúcar. É um material rígido e resistente, difícil de deformar ou flexionar, com uma alta dureza, que o torna com baixa resistência ao impacto. METODOLOGIA: Os trabalhos foram realizados nos laboratórios de física e biologia da Univás. Para a fabricação dos corpos de prova foram utilizados o material polimérico, PLA - Poli (ácido lático) de acordo com a norma ASTM D638. Os corpos de prova foram fabricados em uma impressora 3D Creality Ender 3 Pro. As amostras foram caracterizadas através de um microscópio estereoscópico trinocular, zoom 1x-4x aumento 10x a 400x led - opton. Para descrever a quantidade de vazios nas estruturas de camadas foram dimensionadas com o software capture, v1.2. RESULTADOS/DESENVOLVIMENTOS: Com a macrografia das amostras foram examinadas em geral e identificados as diferentes texturas, as diferentes formas de vazios e suas quantidades nos corpos de provas em função da variação das densidades respectivamente. Comparando todas a densidades estudadas, os materiais de densidade $75 \%$ e espessura $0,2 \mathrm{~mm}$, mostraram uma compactação estrutural (densidade) do material durante sua produção de acordo estudos de Selhorts. As amostras com densidades variando de $15 \%$ à $45 \%$ forma sulcos com maiores número de vazios nos contornos com espessuras com $0,4 \mathrm{~mm}$ de diâmetros. Esses são introduzidos normalmente durante as etapas de processamento e de fabricação. A direção de impressão teve variação de $45^{\circ}$ à $135^{\circ}$. CONCLUSÃO: Os resultados mostraram que nos corpos de provas com preenchimentos com densidade de $75 \%$, direção de impressão de $135^{\circ}$, e espessura de camada de $0,2 \mathrm{~mm}$ apresentaram os menores valor no número de imperfeições de vazios. Estes resultados mostram o potencial uso de impressão 3D, sendo que o controle da quantidade de vazios pode trazer uma menor densidade, mas também uma maior resistência mecânica.

\section{REFERÊNCIAS}

Alves DCC. Aspectos ergonómicos relevantes para a concepção de tecnologia assistiva: órteses de membros inferiores. Braga: Universidade do Minho; 2012.Selhorst A Jr. Análise comparativa entre os processos de prototipagem, rápida na concepção de novos produtos: um estudo de caso para determinação de processo mais indicado. Curitiba: Pontifícia Universidade Católica do Paraná; 2008.

Silva KIM. Preparação de nanocompósitos de PLA/PEAD/TiO2 degradáveis [monografia]. Porto Alegre: UFRGS; 2014.

PALAVRAS-CHAVE: PLA; Impressão 3d; Biomateriais. 


\title{
AVALIAÇÃO DO DESTINO DOS EFLUENTES GERADOS NA ZONA RURAL, EM ANHUMAS, POUSO ALEGRE - MG
}

\author{
JOYCE DA SILVA BALBINO*; VANESSA DA FONTOURA CUSTÓDIO MONTEIRO; FARLEY SOARES \\ BRAZ; VANESSA DA FONTOURA CUSTÓDIO MONTEIRO \\ UNIVÁS - Universidade do Vale do Sapucaí
}

INTRODUÇÃO: A intensa atividade antrópica sobre os recursos naturais, uso incorreto do solo, agrotóxicos, pecuária, falta de saneamento básico, destinação de efluentes e desmatamento provocam incontáveis problemas ambientais, principalmente em áreas de nascentes, comprometendo os recursos hídricos (RIBEIRO et al., 2005). A água é essencial para a conservação de riquezas como a fauna e a flora, estabelecendo funções relacionadas com a preservação, saúde, manutenção da vida e bem-estar de todo indivíduo (OLIVEIRA et al, 2018). O abastecimento de água para toda a população e indústrias de Pouso Alegre, sul de Minas Gerais, é realizado pela Companhia de Saneamento de Minas Gerais (COPASA), detentora de um programa denominado "Pró-mananciais" que visa proteger e recuperar as microbacias hidrográficas e as áreas de recarga dos aquíferos. Para assegurar a conservação ambiental nessas áreas, é preciso adquirir conhecimento sobre aspectos socioambientais (ALVES, 2012). OBJETIVOS: Objetivou-se avaliar o destino dos efluentes gerados pelos moradores da microbacia Anhumas a fim de subsidiar projetos de educação ambiental sobre saneamento básico e preservação ambiental. METODOLOGIA: O estudo foi realizado em Anhumas, zona rural do município de Pouso Alegre - MG. Aplicou-se um questionário aos moradores do bairro maiores de 18 anos de idade. $O$ universo amostral foi constituído por 80 famílias. A execução deste estudo estabeleceu todos os princípios éticos envolvidos. A pesquisa realizada mediante a aprovação pelo Comitê de Ética em Pesquisa com Seres Humanos (CEP). Aos participantes, foi entregue e explanado o Termo de Consentimento Livre e Esclarecido (TCLE). Após a aplicação do questionário, os dados obtidos foram tabulados e analisados estatisticamente. RESULTADOS: Os resultados mostram que o uso da fossa negra é o recurso mais utilizado como destino dos efluentes ( $81,25 \%)$. Já a fossa séptica é empregada em $15 \%$ das propriedades e apenas 3,75\% possuem biodigestor. O alto índice de utilização de fossa negra é preocupante, visto que é uma solução primitiva de saneamento, contaminando lençóis freáticos e corpos hídricos. A fossa séptica, se instalada corretamente, é uma forma simples e econômica de tratar o esgoto e devolver a água ao meio ambiente com o mínimo impacto possível. No entanto, o biodigestor é o sistema de destinação de esgoto mais sustentável, visto que aproveita os resíduos para a produção de energia e adubo. Salienta-se que os moradores do local expuseram a ausência de informações sobre a importância dos recursos hídricos e saneamento básico. CONCLUSÃO: Através da pesquisa realizada pode-se obter uma visão geral sobre o destino dos efluentes gerados pelos moradores da microbacia Anhumas, em Pouso Alegre - MG. As fossas negras são consideradas um grande problema ambiental, causando a proliferação de doenças e contaminando lençóis freáticos. É necessário ações de educação ambiental a fim de incentivar o uso de medidas mais sustentáveis, como o biodigestor, buscando mitigar os impactos ambientais sobre os recursos hídricos.

\section{REFERÊNCIAS}

ALVES, T. L. B.; DE AZEVEDO, P. V.; DE FARIAS, A. A. Diagnóstico socioambiental do entorno da Microbacia Hidrográfica do Riacho Namorado no município de São João do Cariri- PB. Ateliê Geográfico, v. 6, n. 4, p. 88-109, 2012.

OLIVEIRA, D. H. R; ACORSI, M. G.; SMANIOTTO, D. A. Uso e ocupação do solo e caracterização morfométrica de microbacia na região centro-sul paranaense. Águas Subterrâneas, v. 32, n. 2, 2018. SANTOS, E. L.; BARBOSA, J. H.; MELO, M. J.; JUNIOR, D. A. P.; MEDEIROS, C. S.; SANTOS, I. V. S. Uma alternativa energética e ambientalmente sustentável ao agricultor familiar: dia de campo sobre biodigestores rurais, Diversitas Journal, v. 2, n. 1, p. 32-38, 2017.

PALAVRAS-CHAVE: Bacias hidrográficas; Esgoto; Saneamento; Zona Rural. 


\title{
AVALIAÇÃO FITOQUÍMICA DA ESPÉCIE JACARANDA CUSPIDIFOLIA MART
}

\author{
LARA EMILLY BRANDÃO*; MARENNA CARDINALLI FÉLIX; CÁSSIA MARIA FURLAN \\ UNIVÁS - Universidade do Vale do Sapucaí
}

INTRODUÇÃO: O Brasil é considerado o maior centro de biodiversidade vegetal do planeta. Na cultura popular há a utilização de várias espécies vegetais para os mais diversos fins, entre os quais o uso medicinal. A espécie Jacaranda cuspidifolia Mart. pertence à família Bignoniacea e tribo Tecomae. É conhecida popularmente como jacarandá, caroba e bolacheira e considerada árvore de médio porte, com altura de 3-10 metros, apícola. Apresenta propriedade inseticida, sendo a raiz usada no tratamento da sarna (CAMARINHA et al., 2015). É depurativa do sangue e usada em infecções bacterianas, como sífilis e blenorragia. Na literatura, encontram-se alguns estudos fitoquímicos do gênero Jacaranda. Resultados demonstraram a presença de substâncias fenólicas, triterpênicas, saponinas, flavonoides, taninos, antraderivados e glicosídeos cardiotônicos (ARRUDA et al., 2012). No entanto, estudos dos constituintes ativos, que auxiliem na comprovação científica do emprego medicinal de raízes de Jacaranda cuspidifolia Mart. ainda são escassos. Portanto, este trabalho objetiva avaliar os constituintes ativos presentes na raiz de uma espécie da família Bignoniaceae, a Jacaranda cuspidifolia Mart., através dos estudos fitoquímicos. METODOLOGIA: O estudo foi realizado com exemplares coletados na cidade de Bom Repouso-MG, em diferentes períodos, que compreenderam as quatro estações do ano. O material vegetal colhido foi imediatamente transformado em droga vegetal, através da secagem em estufa de circulação de ar a 50 ${ }^{\circ} \mathrm{C}$, durante $24 \mathrm{~h}$. Em seguida foi pulverizado até obtenção de pó semi-grosso. Foram realizados ensaios específicos para antraderivados, flavonoides, saponinas, alcaloides, taninos e óleos essenciais, conforme metodologia tradicional (SANTORO, 2015). RESULTADOS/DESENVOLVIMENTO: Nas análises fitoquímicas foram observadas, em todas as amostras analisadas, presença de taninos, saponinas e óleos essenciais, não havendo diferença qualitativa entre as diferentes estações do ano em que foram realizadas as coletas. CONCLUSÃO: A literatura é escassa para o estudo da raiz do Jacaranda cuspidifolia Mart., sendo encontrado estudos a respeito apenas das folhas, cascas e caules. A prosperação fitoquímica dos extratos hidro-etanólicos e aquosos da raiz de Jacaranda cuspidifolia Mart. detectou presença de taninos, saponinas e óleos essenciais, conforme especificado para outros órgãos, mas não encontrou flavonoides e alcaloides, que constam na literatura para as folhas e caules.

\section{REFERÊNCIAS}

ARRUDA, A. L. A. et al. Análise fitoquímica e atividade antimicobacteriana de extratos metabólicos de Jacaranda cuspidifolia Mart. (Bignoniaceae). Revista Brasil Plantas Medicinais, Botucatu, v. 14, n. 2, p. 276-281, 2012.

CAMARINHA, C. et al. Levantamento de espécies da família Bignoniaceae ocorrentes na Universidade Castelo Branco, campus Realengo - RJ. Revista Eletrônica de Biologia, v.8, n. 3, p. 299-307, 2015.

SANTORO, H. L. Farmacologia e fitoquímica de extratos e formulações de Jacaranda decurrens Cha

PALAVRAS-CHAVE: Caroba; Bignoniaceae; Jacarandá; Jacaranda cuspidifolia Mart.; Fitoquímica. 


\title{
AVALIAÇÃO MORFOLÓGICA E IMUNO-HISTOQUÍMICA DE LINFOMAS NÃO-HODGKIN DIAGNOSTICADOS NO LABORATÓRIO DE ANATOMIA PATOLÓGICA DO HOSPITAL DAS CLÍNICAS SAMUEL LIBÂNIO (HCSL) DE POUSO ALEGRE, ENTRE 2014 E 2018
}

\author{
ANA TERESA SANTOS RABELO*; ELISA DE PAULA PINTO; CAMILA PIRES DE OLIVEIRA; GABRIELA \\ APARECIDA DE ASSIS; THAÍS SANTA CRUZ MORAES; FIORITA GONZALES LOPES MUNDIM; \\ MIRIAM DE FÁTIMA BRASIL ENGELMAN \\ UNIVÁS - Universidade do Vale do Sapucaí
}

Os Linfomas não-Hodgkin ( $\mathrm{LNH}$ ) são um tipo de neoplasia do tecido linfoide e representam o 6ำ câncer mais prevalente no mundo, sendo que sua incidência está aumentando $4 \%$ ao ano. Este trabalho tem como objetivo revisar os laudos anatomopatológicos e imuno-histoquímicos de LNH diagnosticados no Laboratório de Patologia do Hospital das Clínicas Samuel Libânio (HCSL) em Pouso Alegre, entre os anos de 2014 a 2018, e com isso gerar dados epidemiológicos da microrregião citada. Trata-se de um estudo descritivo, observacional, longitudinal retrospectivo, grupal e não controlado, onde foram analisados os laudos de relatórios de exames anatomopatológicos e imuno-histoquímicos de biópsias de linfonodos com diagnóstico de $\mathrm{LNH}$ de 34 pacientes. O diagnóstico final das análises foi dividido em 9 categorias: Neoplasias de grandes células B, neoplasias de pequenas células B, neoplasias de células do manto, linfoma de Burkitt, linfoma linfocítico de células $B$, neoplasia de células T periféricas, linfoma linfoblástico $\mathrm{T}$, e neoplasias de grandes células anaplásicas. Foram revisados os prontuários destes pacientes com diagnóstico de Linfoma não Hodgkin nos arquivos do HCSL para obter as seguintes informações: idade, sexo, estadiamento clínico e/ou patológico, presença dos marcadores CD20 e Ki67, e taxa de sobrevida. A taxa de sobrevida foi definida como a porcentagem de pacientes que viveram pelo menos 5 anos após o diagnóstico da doença. Foi constatado que dos 34 pacientes da amostra, houve prevalência dos LNH em homens com mais de 55 anos. Além disso, o estadiamento dos tumores revela maior número de diagnósticos de neoplasias de células $B$, sendo que o $\mathrm{LNH}$ difuso de grandes células $B$ foi predominante e, consequentemente o marcador CD20 acompanhou a variável estadiamento e manteve-se prevalente na amostra. Na pesquisa, a maioria dos pacientes apresentou Ki67 elevado, o que representa uma alta proliferação dos LNH analisados, sendo que mais de $40 \%$ da amostra teve um índice de proliferação maior que $70 \%$. Os pacientes da amostra apresentaram um pior prognóstico, quando comparados os dados da pesquisa com a literatura, sendo que a taxa de sobrevida do estudado foi de $64,7 \%$. Os dados epidemiológicos obtidos se equiparam aos dados estabelecidos pela literatura. O presente estudo mostrou prevalência dos $\mathrm{LNH}$ em indivíduos do sexo masculino, com mais de 55 anos. Revelou que a maioria dos tumores que acometem esta faixa etária são $\mathrm{LNH}$ de células $\mathrm{B}$ e, consequentemente, a maioria da amostra apresentava marcador CD20 positivo. O tipo de neoplasia mais prevalente no estudo foi o LNH difuso de grandes células $B$. A análise da pesquisa também demonstrou que esse tipo de câncer possui uma rápida evolução, já que o marcador Ki67 estava presente em mais de $60 \%$ dos casos, sendo que na maioria destes o índice de proliferação foi maior que 70\%. Por fim, apesar dos altos índices de mortalidade, mais de $60 \%$ da amostra apresentou sobrevida em 5 anos, o que revela a evolução dos tratamentos para este tipo de neoplasia.

\section{REFERÊNCIAS}

FERREIRA, Cristina. IMUNOFENOTIPAGEM NO DIAGNÓSTICO DOS LINFOMAS. I Congresso de Ciências Biomédicas Laboratoriais, Castelo Branco, Portugal, mai. 2016. Disponível em: $<$ www.researchgate.net/publication/303406474_IMUNOFENOTIPAGEM_NO_DIAGNOSTICO_DOS LINFOMAS>. Acesso em: 31 mar. 2018.

ARAÚJO, L. H. D. L. et al. Linfoma Não-Hodgkin de Alto Grau: Revisão de Literatura. Revista Brasileira de Cancerologia, [S.L], v. 54, n. 2, p. 175-183, jan. 2008. Disponível em:

<http://www.inca.gov.br/rbc/n_54/v02/pdf/revisao_5_pag_175a183.pdf>. Acesso em: 31 mar. 2018.

PALAVRAS-CHAVE: Linfoma, Não-Hodgkin, Neoplasias, Imunohistoquímica, Epidemiológico 


\title{
BREAST-Q: EXPECTATIVAS DE PACIENTES BRASILEIRAS QUANTO À RECONSTRUÇÃO MAMÁRIA
}

\author{
LUANA OLIVEIRA DE FARIA*; NATHALIA ALVES SANTOS; TAINARA RITA PEZZINI; IVANILDO \\ ARCHANGELO JUNIOR; LUCIANA CHAMONE AMARO; DANIELA FRANCESCATO VEIGA \\ UNIVÁS - Universidade do Vale do Sapucaí
}

INTRODUÇÃO: O câncer de mama é altamente prevalente no mundo e no Brasil. Apesar dos avanços terapêuticos, a mastectomia continua sendo a opção para muitas mulheres e a reconstrução mamária faz parte desse tratamento. Vários estudos demonstraram que a satisfação com os resultados da cirurgia é mais alta quando a paciente foi devidamente informada e quando o procedimento é consistente com suas expectativas, principalmente em relação à aparência, intensidade da dor e tempo de recuperação. Portanto, a avaliação de expectativas nas consultas pré-operatórias é importante para melhorar a compreensão sobre o tratamento e a satisfação com o atendimento prestado. O objetivo deste estudo foi avaliar as expectativas de pacientes com a reconstrução mamária. METODOLOGIA: Estudo multicêntrico e transversal em que foram selecionadas pacientes candidatas à reconstrução mamária, tanto imediata quanto tardia. Os dados foram coletados em dois centros brasileiros de referência no tratamento do câncer mamário. Foram incluídas mulheres maiores de 18 anos, submetidas a diferentes técnicas de reconstrução, como implantes, retalho do latíssimo do dorso (LD) ou retalho transverso do músculo reto abdominal (TRAM). No pré-operatório, realizou-se a autoaplicação assistida do módulo "Expectativas com a Reconstrução Mamária" do BREAST-Q@. Esse módulo, que foi traduzido e validado para uso no Brasil em 2018, é formado por 27 questões sobre quatro escalas de expectativas: Suporte prestado pela equipe médica, Dor, Enfrentamento e Aparência da mama. Além disso, o instrumento aborda temas como informação necessária, tomada de decisões, expectativas com relação às complicações, sensibilidade, reconstrução da papila mamária e cirurgia de revisão. Para todos os testes estatísticos, foi adotado um nível de significância de 5\%. RESULTADOS: Foram incluídas 123 pacientes. A maioria $(78,9 \%)$ era caucasiana, a idade mediana foi de 48 anos e o índice de massa corpórea (IMC) mediano de $26 \mathrm{Kg} / \mathrm{m}^{2}$. A maior parte seria submetida à reconstrução mamária tardia (65\%) e a técnica mais indicada foi reconstrução com implantes (65,9\%). Quanto às expectativas, as escalas de Enfrentamento

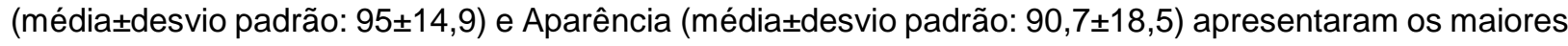
scores. Mais da metade das pacientes referiram querer saber de tudo e se envolver em todo o processo de tomada de decisões. Mulheres que realizaram quimioterapia apresentaram expectativa maior em relação ao apoio prestado pela equipe médica. No entanto, as expectativas dessas pacientes foram menores tanto em relação ao Enfrentamento quanto à Aparência das mamas. Foram encontradas associações relacionadas à técnica de reconstrução $(p=0,035)$, nível de escolaridade $(p=0,004)$, cor da pele $(p=0,013)$ e idade $(p=0,048)$. Com relação às escalas que abordavam expectativas após 10 anos da reconstrução mamária, $51,2 \%$ relataram não saber se seriam necessárias novas cirurgias nas mamas. CONSIDERAÇÕES FINAIS: As expectativas das pacientes foram altas, especialmente em relação ao Enfrentamento e à Aparência. Identificar as expectativas da paciente no momento da decisão cirúrgica pode prepará-las para a possibilidade de complicações e necessidade de novos procedimentos.

\section{REFERÊNCIAS}

Aguiar I de C, Veiga DF, Marques TF, Novo NF, Sabino Neto M, Ferreira LM. Patient-reported outcomes measured by BREAST-Q after implantbased breast reconstruction: a cross-sectional controlled study in Brazilian patients. Breast. 2017;31:22-5.

Zhong T, Hu J, Bagher S, O'neill AC, Beber B, Hofer SOP, et al. Decision regret following breast reconstruction: the role of self-efficacy and satisfaction with information in the preoperative period. Plast Reconstr Surg. 2013;132(5):724-34.

Tedesco D, Loerzel V. Breast reconstruction: impact of patient-centered, expectations-based education on women undergoing reconstructive surgery after mastectomy. Clin J Oncol Nurs. 2020 Apr 1;24(2):186-94.

PALAVRAS-CHAVE: Neoplasias da mama; Reconstrução da mama; Satisfação do paciente; Expectativa do paciente; Período pré-operatório. 


\title{
COMPOSIÇÃO FLORÍSTICA DE MATA CILIAR COMO SUBSÍDIO PARA RESTAURAÇÃO FLORESTAL EM POUSO ALEGRE - MG
}

\author{
DANILO AUGUSTO DA SILVA*; PABLO JOSÉ REZENDE MOURA; VANESSA DA FONTOURA \\ CUSTÓDIO MONTEIRO; FARLEY SOARES BRAZ; VANESSA DA FONTOURA CUSTÓDIO MONTEIRO \\ UNIVÁS - Universidade do Vale do Sapucaí
}

INTRODUÇÃO: Durante o desenvolvimento da humanidade, as atividades antrópicas têm intensificado a conversão dos ambientes naturais para o desenvolvimento de diversas praticas produtivas. Essas mudanças provocam a fragmentação dos habitats, alterando assim a qualidade ambiental. Da área total original da Mata Atlântica, estima-se que apenas $11,7 \%$ esteja preservada em remanescentes florestais. O levantamento florístico consiste em uma importante ferramenta para inventário florestal de vegetação natural, além de subsidiar projetos de conservação e recuperação da vegetação. Diante disso, objetivouse realizar um levantamento florístico em um remanescente de Floresta Estacional Semidecidual de Mata Atlântica localizado no município de Pouso Alegre, sul de Minas Gerais. METODOLOGIA: O local de estudo se encontra aproximadamente a $800 \mathrm{~m}$ de altitude, com relevo ondulado a fortemente ondulado. O solo é do tipo latossolo vermelho-amarelo distrófico e o clima da região é caracterizado como Cwa subtropical úmido. A vegetação foi avaliada de agosto de 2020 a dezembro de 2020 através do método de caminhamento, que consiste na descrição sumária da área amostrada e listagem das espécies encontradas à medida em que o pesquisador caminha lentamente em linha reta. Foram amostrados todos os indivíduos arbóreos que apresentaram estruturas reprodutivas e diâmetro a altura do peito (DAP) igual ou superior a $5 \mathrm{~cm}$. O material botânico foi herborizado para ser depositado no herbário da Univás. As espécies foram identificadas com 0 auxílio de chaves taxonômicas e bibliografias especializadas. RESULTADOS/DESENVOLVIMENTO: Foram identificadas 23 espécies de 15 famílias distintas (Anacardiaceae, Araliaceae, Arecaceae, Burseraceae, Erythroxylaceae, Euphorbiaceae, Fabaceae, Lauraceae, Magnoliaceae, Meliaceae, Myrtaceae, Primulaceae, Solanaceae, Urticaceae e Verbenaceae). As famílias Euphorbiaceae, Fabaceae e Meliaceae predominaram, com três espécies em cada: Alchornea grandulosa, Croton urucurana, Sebastiania commersoniana (Euphorbiaceae); Inga marginata, Inga sessilis, Erythrina falcata (Fabaceae); Cedrela odorata, Trichilia sp., Guarea kunthiana (Meliaceae). CONSIDERAÇÕES FINAIS: Através do presente trabalho foi possível identificar a predominância de espécies pioneiras, secundárias iniciais e secundárias tardias, sendo portanto um ambiente com altas perturbações ecológicas. A metodologia de caminhamento foi suficiente para listar as espécies do local, sendo amostradas todas que apresentavam estruturas reprodutivas e também as que não apresentavam, mas que são espécies de fácil reconhecimento. Desta forma, a lista gerada poderá futuramente fomentar e agregar em projetos que visem à recuperação e conservação da vegetação no município de Pouso Alegre e na região sul de Minas Gerais, visto que um levantamento florístico conspícuo é imprescindível em qualquer projeto relacionado à flora.

\section{REFERÊNCIAS}

CARDOSO-LEITE, E.; RODRIGUES, R. R. Fitossociologia e caracterização sucessional de um fragmento de Floresta Estacional no Sudeste do Brasil. Revista Árvore, v.32, n.3, p.583-595, 2008.

DARONCO, C.; MELO, A. C. G.; DURIGAN, G. Ecossistema em restauração versus ecossistema de referência: estudo de caso da comunidade vegetal de mata ciliar em região de Cerrado, Assis, SP, Brasil. Hoehnea, v. 40, n. 3, p. 485-498, set. 2013.

WIVALDO, J. N. S; MOREIRA, E. O; SILVA, J. J. C. Políticas públicas e gestão ambiental para conservação dos recursos hídricos: Reflexões sobre a crise hídrica em Minas Gerais. Revista de Discentes de Ciência Política da UFSCAR, v.6, n.3, p. 54-66, 2018.

PALAVRAS-CHAVE: Conservação; Levantamento; Remanescentes; Vegetação. 


\title{
CONDIÇÕES DE SAÚDE DE ACADEMICOS DE ENFERMAGEM DURANTE A PANDEMIA DE COVID-19
}

\author{
JESSICA FERNANDA SOUZA MACHADO, RITA DE CÁSSIA PEREIRA; \\ UNIVÁS - Universidade do Vale do Sapucaí
}

INTRODUÇÃO: A China registrou, em dezembro de 2019, uma nova pneumonia, denominada de Covid19. Esse vírus é altamente transmissível e espalhou-se rapidamente pelo mundo, levando a Organização Mundial da Saúde (OMS) a declarar estado de pandemia, em março de 2020, o que exigiu de todos os países medidas de saúde pública emergenciais e de interesse internacional. No Brasil, diversas medidas foram adotadas pelos estados e municípios, como o fechamento de escolas e comércios não essenciais. Geralmente, a repercussão clínica e comportamental dessa obrigação implica mudanças no estilo de vida e pode afetar a saúde mental dos cidadãos. Pesquisas realizadas têm reportado prevalências elevadas de depressão e ansiedade no conjunto da população estudada. Com relação às repercussões na vida acadêmica, os desdobramentos da pandemia também se tornaram foco da atenção, por considerar o risco de infecção de estudantes com participação no enfrentamento da epidemia, a ruptura da rotina de estudos, o adiamento das tarefas e atividades acadêmicas e o atraso no cronograma dos cursos, repercutindo nos planos do futuro profissional e na busca pela independência. MÉTODO: Trata-se de um estudo quantitativo do tipo descritivo. Os participantes do estudo foram acadêmicos do $2^{\circ}, 4^{\circ}, 6^{\circ}, 8^{\circ}$ e $10^{\circ}$ período, regularmente matriculados no curso de Enfermagem da Universidade do Vale do Sapucaí, de Pouso Alegre- MG. A amostra foi composta por 60 alunos. A amostragem foi do tipo intencional ou proposital. No presente estudo foram utilizados 02 instrumentos, sendo eles: um questionário sociodemográfico e um contendo dados relacionados a condição de saúde dos universitários. Os dados foram coletados por meio de questionário online (Google Formulários). RESULTADOS: O trabalho mostrou que 95\% dos respondentes eram do sexo feminino, 61,6\% com idade entre 18 e 25 anos, 91,7\% praticantes de alguma religião, $66,7 \%$ não possui filhos, $66,7 \%$ são solteiros. $81,7 \%$ não possui doença crônica, $95 \%$ não são tabagistas, $90 \%$ não são etilistas, $66,3 \%$ mudaram hábitos alimentares durante pandemia, $48,3 \%$ tiveram ganho ponderal, 93,3\% acessam redes sociais para obter dados sobre a pandemia, $51,6 \%$ utilizam as redes sociais por mais de duas horas diárias, 16,7\% tiveram perdas familiares por COVID-19, 23,3\% tiveram COVID-19, 50\% procuram ajuda de um profissional de saúde, 11,7\% aumentaram o uso de drogas ilícitas, 21,7\% aumentaram o número de horas trabalhadas. Em relação ao uso de psicotrópicos, 23,3 \% utilizaram o medicamento, $10 \%$ iniciaram o uso durante a pandemia. Quando questionados sobre o motivo do uso, $11,7 \%$ relataram ter sido por motivo de ansiedade e $6,7 \%$ por depressão. CONSIDERAÇÕES FINAIS: A pesquisa mostrou a importância do cuidado com preservação da saúde mental dos acadêmicos durante a pandemia de COVID -19, devendo está ser considerada prioritária para os gestores e dirigentes dos serviços.

\section{REFERÊNCIAS}

BONITA, R.; BEAGLEHOLE, R.; KJELLSTRÖM, T. Epidemiologia básica. 2.ed. São Paulo: Grupo Editorial Nacional, 2010.

BRASIL. Ministério da Saúde. Fundação Oswaldo Cruz. Saúde mental e atenção psicossocial na pandemia COVID-19: a quarentena na COVID-19- orientações e estratégias de cuidado, Rio de Janeiro: FIOCRUZ, 2020. 2021.

SENHORAS, E. M.; PAZ, A. C. O. Educação no século XXI: tecnologias: volume 31. [E-book]. Belo Horizonte: Poisson, 2019. doi: 10.36229/978-85-7042-139-5.

PALAVRAS-CHAVE: Pandemia. COVID-19. Acadêmicos de Enfermagem. Saúde Mental 


\title{
CONHECIMENTO DAS DIFICULDADES ENCONTRADA PELA ENFERMEIRA NA ASSISTÊNCIA A GESTANTE FRENTE ÀS CONDIÇÕES SOCIAIS
}

\author{
BRUNA VICTÓRIA DE GOUVEIA MARQUES*; MARIA CRISTINA PORTO E SILVA \\ UNIVÁS - Universidade do Vale do Sapucaí
}

INTRODUÇÃO: O pré-natal é o período em que deve ocorrer o acompanhamento do desenvolvimento fetal, sendo associado ao bom estado de saúde da mulher, para que assim a evolução da gestação possa acontecer em um meio tranquilo e saudável. O nível social tende a interferir nessa evolução, podendo assim ocasionar riscos na saúde da mãe e do feto. O estudo teve como objetivo conhecer as dificuldades encontradas pelos enfermeiros sobre a influência da condição social e econômica na assistência de enfermagem à gestante. METODOLOGIA: Esta pesquisa teve sua base teórico-metodológica fundamentada nos princípios da pesquisa qualitativa, pois favorece 0 aprofundamento relativo aos significados, crenças e valores das pessoas, atribuindo significados específicos as suas ações e relações humanas. A pesquisa foi realizada com enfermeiras que atuavam na Estratégia Saúde da Família (ESF), que acompanhavam o pré-natal de baixo risco de áreas em condições sociais desfavoráveis. Os dados foram obtidos por meio de um questionário semiestruturado. Houve entrevistas na quais, após a aprovação pelo Comitê de Ética e autorização dos participantes, foram gravadas e transcritas. RESULTADOS: Após a análise dos discursos emergiram as seguintes unidades de significados: Impacto da baixa escolaridade na adesão ao cuidado pré natal; Dificuldade para realização de exames no pré natal; A falta de uma adequada nutrição; Falta de apoio familiar e do companheiro; A presença das drogas ilícitas na vida da gestante, Gestações Anteriores influenciando a gestação atual. CONCLUSÃO: É evidente o papel de extrema relevância que a enfermagem possui no atendimento a essas gestantes, sendo de suma importância que os enfermeiros responsáveis pelo pré-natal tenham conhecimento sobre como as questões socioeconômicas podem afetar um individuo em sua percepção de cuidado e saúde, e possam assim, traçar estratégias que sejam mais adequadas e afetivas, aumentando a chance dessas gestantes a darem continuidade ao longo de todo o cuidado pré-natal.

\section{REFERÊNCIAS}

ANVERSA, E. T. R.; BASTOS, G. A. N.; NUNES, L. N.; PIZZOL, T. S. D. Qualidade do processo da assistência pré-natal: unidades básicas de saúde e unidades de Estratégia Saúde da Família em município no Sul do Brasil. Caderno de Saúde Pública, Rio de Janeiro, v. 28, n. 4, p. 789-800, Abr. 2012.

BACKES, D. S.; BACKES, M. S.; ERDMANN, A. L.; BÜSCHER, A.; SALAZAR-MAYA, A. M.

Significado da prática social do enfermeiro com e a partir do sistema Único de Saúde brasileiro. Aquichan. Chia, Colômbia, v. 14, n. 4, p. 560-570, Dez. 2014.

BARATIERI, T.; CAZETTA, V.; MARCON S. S. Reincidência Gestacional na Adolescência: percepções da jovem mãe. Ciência, Cuidado e Saúde. [S. I.], v. 10, n. 1, p. 19

PALAVRAS-CHAVE: Gestação; Pré-natal; Dificuldades na gestação; Desafios da enfermagem; Problemas socioeconômicos. 
UNIVÁs | 2021

\title{
CORRELAÇÃO ENTRE A RELAÇÃO CINTURA-QUADRIL E OS VALORES DA PRESSÃO ARTERIAL EM ESTUDANTES DE MEDICINA
}

\author{
GUSTAVO PAIVA AZEVEDO*; LUIZ GIOVANNI TEIXEIRA RIGATO; GUSTAVO ALBERTO LEMES \\ SANTOS; LIVIA COUTO MELO; MARINA VILLELA FREIRE; PAULO ROBERTO MAIA; SILVIA MARA \\ TASSO \\ UNIVÁS - Universidade do Vale do Sapucaí
}

Introdução: No Brasil, o excesso de peso é um importante distúrbio nutricional. A deposição e o acúmulo de gordura corporal costuma ter início durante a infância e a adolescência, perdurando na fase adulta jovem e oferecendo risco para surgimento de outras comorbidades relacionadas. As populações modernas têm adotado hábitos alimentares prejudiciais à saúde, dando preferência a alimentos processados, ricos em açúcar, sódio e gorduras. Tudo isso, aliado à redução da atividade física e do lazer, pode gerar alterações no estado nutricional e na pressão arterial. Os acadêmicos de medicina, por sua vez, são mais vulneráveis à condutas de risco para a saúde. O estresse gerado pelo meio acadêmico, como o grande número de aulas semanais, avaliações e atividades extracurriculares, faz com que o estudante utilize seu tempo livre em atividades menos exaustivas como assistir televisão ou navegar na internet. Nesse viés, toda essa carga estressante, aliada à falta de atividade física pode refletir em doenças do aparelho circulatório. Diante disso, o objetivo deste estudo foi avaliar a existência de correlação entre a relação cintura-quadril (RCQ) e os valores da pressão arterial em estudantes de Medicina, já que, em médio prazo, ações de promoção de saúde sobre essa população de universitários podem exemplificar e impactar toda a população atendidas por eles no futuro. Metodologia: estudo será do tipo observacional, individual e transversal, no qual foram avaliados estudantes do primeiro ao sexto ano de medicina matriculados no ano de 2021 na Universidade do Vale do Sapucaí. Para convocar os estudantes foi elaborado um questionário sociodemográfico adaptado para a plataforma "Google Forms". Dos estudantes que aceitaram participar do estudo foram coletados os seguintes dados: peso, altura, circunferência da cintura, circunferência do quadril e pressão arterial. Aqueles que realizaram algum esforço antes da coleta dos dados foram convidados a ficar em repouso por no mínimo 5 minutos antes da aferição da pressão arterial. Posteriormente foi calculado o índice de massa corporal (IMC) e a RCQ. Dos 62 alunos que responderam ao questionário, 40 compareceram para a coleta dos dados. O nível de significância utilizado como critério de aceitação ou rejeição nos testes estatísticos foi de $5 \%(p<0,05)$. Essa pesquisa seguiu as determinações da RESOLUÇÃO № 466, DE 12 DE DEZEMBRO DE 2012, do Conselho Nacional de Saúde (CNS) e foi aprovada pelo Comitê de Ética e Pesquisa da UNIVÁS no dia 31/05/2021 № do parecer: 4.760.551. Resultados: para classificação da pressão arterial foi utilizada a diretriz da sociedade brasileira de cardiologia. $5 \%$ dos alunos foram classificados com hipertensão estágio $1,52,5 \%$ com pressão normal limítrofe e 42,5\% com pressão normal. Existiu uma maior prevalência entre o sexo masculino de alunos com a pressão arterial alterada. Observou-se também que a classificação da pressão arterial aumenta quando há elevação do peso, do IMC, e da RCQ. Considerações Finais: a análise da correlação entre a $\mathrm{RCQ}$ e os valores da pressão arterial em estudantes de medicina mostrou que o sexo masculino possuiu medidas de pressão mais alteradas e as variáveis peso, IMC e RCQ demonstraram influenciar diretamente nos valores da pressão arterial dos estudantes.

\section{REFERÊNCIAS}

SANTOS, Darci Gilson; CUNHA, Jéssica Camila Viana da; PINTO, João Luís Costa; et al. Avaliação de Fatores de Risco e Prevalência da Hipertensão Arterial Sistêmica Entre os Acadêmicos do Primeiro e Oitavo Períodos da Faculdade de Medicina de Barbacena. Revista Interdisciplinar de Estudos Experimentais - Animais e Humanos Interdisciplinary Journal Of Experimental Studies, n. 1, p. 29-36, 2018. JANSSEN, Ian; KATZMARZYK, Peter T; ROSS, Robert. Waist circumference and not body mass index explains obesity-related health risk. The American Journal Of Clinical Nutrition, n. 3, p.379-384, 2004.

PALAVRAS-CHAVE: Índice de massa corporal; Razão cintura quadril; Obesidade. 


\title{
CORRELAÇÃO ENTRE ALONGAMENTO E MOBILIZAÇÃO NA MELHORA DA AMPLITUDE ARTICULAR DE PRATICANTES DE MUSCULAÇÃO
}

\author{
LUANA APARECIDA DOS SANTOS*; SARAH DE PAULA PINTO; DIEGO GUIMARÃES OPENHEIMER; \\ RICARDO DA SILVA ALVES \\ UNIVÁS - Universidade do Vale do Sapucaí
}

Introdução: O treinamento resistido melhora a aptidão musculoesquelética, aumento de força e massa muscular, resistência a fadiga, velocidade, potência, agilidade, equilíbrio, promove bem-estar físico e mental. No entanto ele corre em amplitudes parciais, embora ela seja considerada necessária para que o indivíduo consiga um torque muscular maior, esse padrão pode gerar encurtamentos e restringir os movimentos articulares, devido as altas demandas imposta as estruturas corporais. O presente estudo teve como objetivo correlacionar alongamento convencional e mobilização articular com aumentos na amplitude de movimentos de praticantes de musculação. Método: Trata-se de um ensaio clínico, controlado, randomizado e duplo cego. Foram avaliados indivíduos adultos, praticantes de musculação na academia, de ambos os sexos, com idade Media \pm desvio padrão, GI $30.88 \pm 1.79$ e GC $33.42 \pm 3.32$ anos. Os grupos foram aleatoriamente divididos em: Grupo intervenção, que recebeu a mobilização com movimento (MWM) de tornozelo em um único atendimento e Grupo controle, que recebeu protocolos de alongamentos convencional para musculos do tornozelo. Todos os voluntários foram avaliados pelos instrumentos: Y test, Lung teste, Step down test e Leg lateral reach test. Resultados: Os resultados obtidos demostram que ambas as técnicas aumentaram a amplitude de movimento, (Lung test direito GInt = 7,05\%; G- Con= 4,72\%; Lung teste esquerdo G-Int 11,92\%; G-Con 6,47\%, Y-teste esquerdo; G-Int = 5,60\%; G-Con = 4,80\%; Y-teste direito G-Int 8,11\%, G-Con=10,82\%).. Entretanto quando analisado a porcentagem entre os grupos, a mobilização demonstrou maiores incrementos de forma imediata, comparada ao alongamento, na melhora da amplitude articular. Conclui-se que ambas as técnicas podem ser utilizadas, no entanto as MWM, se mostram mais efetivas em uma única sessão.

\section{REFERÊNCIAS}

Alves TGG, Sousa EC, Sousa RS, et al. Exercícios resistidos melhoram a qualidade de vida em idosos: Estudo qualitativo. Revista Brasileira de Prescrição e Fisiologia do Exercício, São Paulo. v.12. n.73. p.205212. Mar./Abril. 2018.

Lima FV, Pereira DG, Diniz RCR, Santiago DCG, et a. Efeito da amplitude de movimento no número máximo de repetições no exercício supino livre. Rev. bras. Educ. Fís. Esporte, São Paulo, v.26, n.4, p.571 79, out./dez. 2012.

20- Willy RW, Hoglund LT, Barton C J, et al. Patellofemoral Pain Clinical Practice Guidelines Linked to the International Classification of Functioning, Disability and Health From the Academy of Orthopaedic Physical Therapy of the Americ

PALAVRAS-CHAVE: Treino resistido, equilíbrio, mobilidade e alongamento 


\title{
DESENVOLVIMENTO DE ALGORITMO E APLICATIVO SOBRE CUIDADOS PÓS-OPERATÓRIOS EM RECONSTRUÇÃO MAMÁRIA
}

\author{
IARA PAIVA GERÔNIMO*; EVELYNE BORGES DE MATTOS ANDRADE; DRA. DANIELA \\ FRANCESCATO VEIGA \\ UNIVÁS - Universidade do Vale do Sapucaí
}

INTRODUÇÃO: O câncer de mama é o segundo tipo de câncer mais frequente em mulheres, atrás apenas do câncer de pele não melanoma. A reconstrução mamária faz parte do tratamento do câncer de mama e, como toda cirurgia, necessita de cuidados gerais e específicos no pós-operatório, que garantirão uma recuperação satisfatória. Atualmente, os aplicativos de dispositivos móveis estão sendo usados também como meio de informações para cuidados em saúde. Frequentemente, os cuidados com o sítio operatório são motivos de dúvida e receio por parte das pacientes. Dessa maneira, o desenvolvimento de um aplicativo que oriente e auxilie as pacientes nos cuidados pós-operatórios da reconstrução mamária poderá colaborar na redução de complicações e na obtenção de bons resultados. O objetivo deste trabalho foi desenvolver e avaliar a confiabilidade de um algoritmo, posteriormente transformado em um aplicativo, para auxiliar pacientes nos cuidados pós-operatórios da reconstrução mamária. METODOLOGIA: Foi realizada uma ampla revisão da literatura sobre cuidados pós-operatórios em reconstrução mamária para embasar o desenvolvimento do algoritmo. Para a validação, foi utilizada a técnica de Delphi. Vinte cirurgiões plásticos foram convidados a atuar como juízes, e avaliaram e sugeriram modificações, se necessário. RESULTADOS: Os cirurgiões julgaram o algoritmo confiável e capaz de auxiliar as pacientes, sendo obtido um valor de 0,77 na análise pelo Alfa de Cronbach. Também foi realizado o cálculo do Índice de Validade de Conteúdo (IVC), obtendo-se IVC de $94,74 \%$ quanto à sequência de informações; de $94,74 \%$ quanto à facilidade de entendimento; de $94,74 \%$ quanto à linguagem e IVC de $89,47 \%$ quanto à pertinência do conteúdo, resultando em um IVC global de 93,42\%, o que representa alta concordância dos juízes em relação ao algoritmo. Foi, então, desenvolvido o aplicativo "MAMA pós-op®", já registrado no Instituto Nacional de Propriedade Industrial (BR512020002917-5). CONSIDERAÇÕES FINAIS: A reconstrução mamária tem impacto positivo em diferentes aspectos da qualidade de vida da mulher, contribuindo para a melhora da autoestima, do funcionamento físico, da saúde mental, da capacidade para o trabalho e da saúde sexual. As informações sobre os cuidados pós-cirúrgicos são fornecidas as pacientes nas consultas antes da cirurgia, no momento da alta hospitalar e nas consultas subsequentes. No entanto, é comum surgirem dúvidas que, na maioria das vezes, são sanadas através de meios não confiáveis, como a internet ou a opinião de terceiros. O avanço e a difusão da tecnologia permitiu que a telemedicina se tornasse uma alternativa de fácil acesso para conectar o paciente à equipe de saúde, contribuindo para esclarecer dúvidas, evitar deslocamentos desnecessários ao pronto-socorro, reconhecer sinais e sintomas de complicações e facilitar o cuidado. Esse tipo de tecnologia é particularmente útil em tempos de isolamento social imposto pela pandemia COVID-19. O aplicativo desenvolvido e validado é uma fonte segura e confiável de informações e tem o potencial de auxiliar na recuperação pós-operatória adequada e de reduzir complicações e custos do tratamento.

\section{REFERÊNCIAS}

Fontes KP, Veiga DF, et al. Physical activity, functional ability, and quality of life after breast cancer surgery . J Plast Reconstr Aesthet Surg . 2019 Mar;72(3):394 400

Janis JE, Harrisson B, Khansa I. Evidence Based Strategies to Reduce Postoperative Complications in Plastic Surgery . 2016 Jan; Plast Reconstr Surg 137:351 360

WHO: World Health Organization. Cancer country profiles 2020. Global Profile. Available on : https://www.who. cancer/country profiles/Global_Cancer_Profile_2020.

PALAVRAS-CHAVE: Câncer de mama; reconstrução mamária; cuidados pós-operatórios; aplicativos móveis 


\title{
DESVELANDO A REPRODUÇÃO ASSISTIDA PELO SISTEMA ÚNICO DE SAÚDE
}

\author{
THAYNÁ VASCONCELOS DA SILVA*; FERNANDA RIBEIRO BORGES \\ UNIVÁS - Universidade do Vale do Sapucaí
}

INTRODUÇÃO As Técnicas de Reprodução Assistida (TRAs) são recursos terapêuticos que visam a possível gestação de casais que possuem dificuldade para o processo de gestação natural. Consoante a esta dificuldade, a infertilidade constitui um problema de Saúde Pública. Sendo assim, o Sistema Único de Saúde (SUS), através de leis e portarias dispõe a realização desta terapêutica, tornando possível a efetuação de um sonho de vida do casal de qualquer aquisição econômica. METODOLOGIA Trata-se de uma revisão integrativa da literatura realizada na Base de Dados Literatura Latino-americana e do Caribe em Ciências da Saúde (LILACS), Banco de Dados em Enfermagem (BDENF) e Biblioteca Eletrônica Scientific Electronic Library Online (SCIELO) no período de 2011 a 2021. RESULTADOS/DESENVOLVIMENTO Inicialmente, foram encontrados um total de 178 artigos científicos. Após a leitura dos títulos e dos resumos, foram excluídas 160 publicações científicas que: não abordavam a temática, eram artigos duplicados ou não estavam disponíveis na íntegra. Foram realizadas leituras na íntegra de 18 artigos. Destes, foram excluídos 15, uma vez que os estudos não abordavam a realização das técnicas de reprodução assistida pelo SUS. Assim, obteve-se uma amostra final de 3 publicações que trazem as evidências da reprodução assistida pelo SUS. CONSIDERAÇÕES FINAIS Pelos artigos encontrados há necessidade de intervenções por meio de políticas públicas devido à dificuldade de acesso a este tipo de tratamento. Em segunda análise, tais intervenções devem garantir o custeio integral em todo ciclo terapêutico respeitando os direitos reprodutivos e assistência psicológica, potencializando a aderência ao tratamento. Ademais, é necessária a capacitação dos profissionais de saúde que atuam no SUS, essencialmente na atenção primária para encaminhamentos aos níveis de maior complexidade para efetuação da TRA. Nestes víeis vale ressaltar que os artigos científicos referentes ao tema estão escassos, o que aponta a necessidade de ampliar o debate acerca deste assunto.

\section{REFERÊNCIAS}

DE ALENCAR GRANGEIRO, Yasmim et al. REPRODUÇÃO HUMANA ASSISTIDA NO BRASIL: UMA ANÁLISE EPIDEMIOLÓGICA. Revista Interfaces: Saúde, Humanas e Tecnologia, v. 8, n. 1, p. 437444, 2020.

Dias AA, Moura ERF, Nogueira PSF, Coutinho JFV, Oriá MOB. Estratégia educativa voltada para enfermeiros sobre atenção básica à infertilidade: estudo de intervenção. Rev Gaúcha Enferm., Porto Alegre (RS) 2012 jun;33(2):69-77.

FÉLIS, Keila Cristina; DE ALMEIDA, Rogério José. Perspectiva de casais em relação à infertilidade e reprodução assistida: uma revisão sistemática. Reprodução \& Climatério, v. 31, n. 2, p. 105-111, 2016.

PALAVRAS-CHAVE: Técnicas de Reprodução Assistida; Sistema Único de Saúde; Planejamento Familiar; Infertilidade. 


\title{
DISPENSAÇÃO DE MEDICAMENTOS EM AMBULATÓRIO OCUPACIONAL DE UMA EMPRESA DE PARAISÓPOLIS - MG
}

\author{
JOSIANE ALINE RIBEIRO DE CARVALHO*; JAQUELINE JÓICE MUNIZ \\ UNIVÁS - Universidade do Vale do Sapucaí
}

INTRODUÇÃO: Avaliar as dificuldades que agravam a saúde dos colaboradores em uma empresa é fundamental para o bem-estar dos funcionários e para a garantia de lucros para a mesma, tendo em vista que uma pessoa consegue ser mais efetiva em suas atividades quando está em boas condições físicas e psicológicas. Por essa razão, o acompanhamento e oferta de assistência médica aos funcionários são de suma importância no ambiente fabril (CHIAVENATO, 2010). Os medicamentos isentos de prescrição (MIP) são geralmente dispensados no ambulatório ocupacional, visando proporcionar alívio para sintomas leves, que podem surgir por situações vivenciadas no cotidiano dentro das empresas, seja por condições de segurança e ergonomia ou por estresses (BUSANELLO et al, 2017). OBJETIVO: identificar MIP requeridos no ambulatório ocupacional de uma empresa e se a procura tem relação com condições e ambiente de trabalho. METODOLOGIA: Realizou-se um levantamento dos MIP dispensados no ambulatório ocupacional na empresa Apitiv, multinacional de sistema de distribuição e cabos para veículos leves, pesados e máquinas, em Paraisópolis - MG, no período de setembro a dezembro de 2019, utilizando um formulário preenchido pelo próprio funcionário no momento da dispensação do medicamento. RESULTADOS: Foi observado que dos 1300 funcionários da empresa, 36\% fizeram solicitação de MIP no ambulatório ocupacional da empresa Apitiv em um período de 4 meses. Desses, foram selecionados 100 formulários para análise, sendo que a maioria dos participantes era do sexo masculino (66\%), na faixa etária de 18 a 28 anos de idade (42\%) e, também, a maioria (91\%) não relatou doença crônica. Somente $15 \%$ dos participantes da pesquisa relacionaram a causa da procura do MIP à sua função exercida na empresa e os MIP mais solicitados foram analgésicos (34\%), principalmente para dores de cabeça, seguido por relaxante muscular (18\%). CONCLUSÃO: O presente estudo identificou que, apesar de atividades realizadas na empresa serem motivos de poucas solicitações de MIP no ambulatório ocupacional, os analgésicos são os MIP mais solicitados, revelando assim que ainda há necessidade de avaliação de potenciais ambientes de trabalho desconfortáveis para os funcionários.

\section{REFERÊNCIAS}

BUSANELLO, C.; GOMES, E.; GALINA, K, J.; JUNIOR, J, S, G.; PROVASI, M.; HASHIMOTO, M, S, M.; HOFFOMANN, R, A, G. Farmácia com manipulação. Guia da Profissão farmacêutica. $1^{a}$ ed. Paraná: CRF-PR. 2017.

CHIAVENATO, I. Gestão de pessoas. 3ª ed. Rio de Janeiro: Elsevier, 2010.

PALAVRAS-CHAVE: Medicamentos isentos de prescrição; dispensação; assistência ambulatorial; saúde ocupacional; empresas. 


\title{
EFEITO AGUDO DA MOBILIZAÇÃO COM MOVIMENTO EM PACIENTES COM DOR LOMBAR
}

\author{
TAYLA MARIA FRAGA CAMARGO*; MARCELO RENATO MASSAHUD JUNIOR ; RICARDO DA SILVA \\ ALVES \\ UNIVÁS - Universidade do Vale do Sapucaí
}

Atualmente, a dor lombar é considerado uma disfunção musculoesquelética, considerado problema de saúde pública que interfere nas atividades de vida diária. Além disso, ocorre limitações do movimento do tronco, presença de dores e desconforto. Nesse sentido, as terapias manuais tem contribuído de forma imediata para melhora da amplitude de movimento (ADM) e redução da dor. O objetivo deste estudo, foi avaliar o efeito imediato da mobilização articular com movimento no alívio de dor e mobilidade da coluna lombar. Métodos: Tratou-se de um ensaio clínico randomizado e controlado, com 30 indivíduos de 18 a 60 anos, de ambos os sexos, que apresentam dor lombar. Os voluntários foram divididos aleatoriamente em dois grupos: Grupo Intervenção (GINT) (Idade= Media \pm desvio padrão; feminino= 86,66\%; masculino= $13,34 \%)$, receberam a intervenção por mobilização articular com deslizamentos apofisários naturais mantidos (MWM- SNAGs); Grupo Controle (GCONT) (Idade= Media \pm desvio padrão feminino= 66,66\%; masculino $=33,34 \%$ ), que receberam uma mobilização articular placebo. Todos os voluntários foram avaliados quanto à da percepção de dor por meio da escala numérica de dor (EVN), a mobilidade da coluna lombar por meio do teste modificado de Schober (TMS) e avaliação da dor neuropática e nociceptiva por meio do questionário DN4. Resultados: No GINT houve aumentos significativos para flexão lombar (pré= $81,21 \pm 15,23^{\circ}$; pós $=90,00 \pm 19,62^{\circ}, p=<0,05$ ), aumento da mobilidade da coluna lombar no TMS (pré= GINT 15,33 $\pm 1,05$ pós $=$ GINT 16,0 $\pm 1,02, p=<0,05$ ) e redução significativa da percepção de dor pela EVN (GINT: pré= 5,33 $\pm 2,26$; pós $=1,47 \pm 2,61=p<0,05$; GCONT: pré= 4,07 $\pm 2,34$; pós $=2,20 \pm 1,93, p$ $<0,05)$. Para as demais variáveis não foram encontradas diferenças. Conclusão: $A$ intervenção com MWM-SNAG promoveu melhora da amplitude de movimento e mobilidade em flexão da coluna lombar, associada com redução da dor em indivíduos com dor lombar.

\section{REFERÊNCIAS}

HARTVIGSEN, J. et al. What low back pain is and why we need to pay attention. The Lancet, v. 391, n. 10137, p. 2356-2367, 2018.

HIDALGO, Benjamin et al. Short-term effects of Mulligan mobilization with movement on pain, disability, and kinematic spinal movements in patients with nonspecific low back pain: a randomized placebocontrolled trial. Journal of manipulative and physiological therapeutics, v. 38, n. 6, p. 365-374, 2015.

STATHOPOULOS, N.; DIMITRIADIS, Z.; KOUMANTAKIS, G. A. Effectiveness of Mulligan's mobilization with movement techniques on pain and disability of peripheral joints: a systematic review with metaanalysis between 2008\&\#10291; 2017. Physiotherapy, v. 105, n. 1, p. 1-9

PALAVRAS-CHAVE: Lombalgia, dor lombar, mobilização articular, terapia manual, dn4. 


\title{
EFEITO DA INTERVENÇÃO FISIOTERAPÊUTICA NA HÉRNIA DE DISCO LOMBAR: REVISÃO DE LITERATURA
}

\author{
ADRIELLE DANDARA RIBEIRO RAMOS*; LUCAS DE OLIVEIRA MACHADO; RICARDO CUNHA \\ BERNARDES \\ UNIVÁS - Universidade do Vale do Sapucaí
}

\begin{abstract}
A Hérnia de Disco Lombar (HDL), se refere a um deslocamento dos componentes do disco intervertebral, é um dos distúrbios degenerativos espinhais mais comuns e a principal causa de lombalgia e ciatalgia. Apenas $84 \%$ das pessoas sentem dor nas costas em algum momento de suas vidas. À medida que o envelhecimento e a degeneração evoluem, o núcleo passa a ser a principal parte afetada, tornando-se mais fibrótico e pouco elástico. Se manifesta no estágio inicial comum da doença degenerativa do disco, o que significa que o disco intervertebral não pode acomodar o núcleo pulposo. O objetivo dessa revisão sistemática de literatura, foi realizar uma análise preliminar da eficácia das principais intervenções fisioterapêuticas utilizadas no tratamento da hérnia de disco, e discutir as evidências que apresentam maior relevância clínica na prática fisioterapêutica. Para intervenção baseada em exercícios nos pacientes com hérnia de disco lombar, e comprovar a eficácia das intervenções fisioterapêuticas, realizando uma consulta a base eletrônica de dados SCIELO, PUBMED, PEDRO e utilizando as palavras-chave como lumbar spine, herniated disc, disc degenerations, physiotherapeutic interventions. Para os critérios de inclusão adotaram-se apenas ensaios controlados randomizados, revisões sistemáticas e meta-análise por tratamento fisioterapêutico e intervenção baseada em exercícios e classificação maior ou igual a 7/10 na escala Physiotherapy Evidence Datebase. Foram encontrados na busca 113 ensaios clínicos randomizados, com 57 artigos selecionados por títulos relacionados ao tema. Após o processo de seleção e avaliação dos artigos, 11 estudos foram selecionados para discussão. Desses, ensaios clínicos randomizados abrangeram exercícios baseados em terapia manual como: Terapia manipulativa da coluna vertebral, estabilização, mobilização espinhal, TENS, laser, quiropraxia, método McKenzie. Como resultados, podemos observar em todos os estudos incluídos na revisão, que as técnicas de fisioterapia utilizadas para tratar a hérnia de disco intervertebral têm mostrado melhorias significativas e resultados positivos, prolongando em muitos casos e eliminando a necessidade de recorrer a procedimentos cirúrgicos. Portanto, o tratamento conservador é uma estratégia eficaz e uma intervenção baseada em exercícios envolvendo fatores de origem ou do ponto de ligação locais a hernia de disco lombar, promovendo alívio da dor e melhora da função em indivíduos com hérnia de disco lombar.
\end{abstract}

\section{REFERÊNCIAS}

Kimb, Suha et all. O efeito da estabilização lombar e exercícios de caminhada em dor lombar crônica, Medicina: junho 2019 - Volume 98 - Edição 26 - p e16173.

Vining, Robert et al. "Efeitos do Cuidado Quiroprático sobre força, equilíbrio e resistência no pessoal militar dos EUA com dor lombar: um julgamento controlado randomizado." Journal of alternative and complementar medicine (Nova York, Nova lorque) vol. 26,7 (2020): 592-601.

$\mathrm{Xu}$, Jinhai et all. A randomized controlled study for the treatment of middle-aged and old-aged lumbar disc herniation by Shis spine balance manipulation combined with bone and muscle guidance, Medicine: December 18, 2020 - Volume 99 - Issue 51 - p e23812.

PALAVRAS-CHAVE: Coluna lombar, Hérnia de disco, Degenerações discais, Intervenções fisioterapêuticas. 


\title{
EFEITOS DA EXPOSIÇÃO À LUZ DE DISPOSITIVOS ELETRÔNICOS NO CICLO CIRCADIANO
}

\author{
GUSTAVO JUNHO TOLEDO*; MATEUS GOMES POLO; VINICIUS FONSECA BERNARDES; \\ GUILHERME MIRANDA BÓCOLI; JOSÉ DIAS DA SILVA NETO \\ UNIVÁS - Universidade do Vale do Sapucaí
}

Introdução: Basicamente, o ritmo circadiano é o relógio interno de 24 horas que nossos corpos seguem. Ele é responsável por controlar os a interposição dos padrões de sono e vigília, além de muitos outros processos dentro do corpo. Nos adultos saudáveis, esse padrão promove picos mais altos de energia no meio da manhã e no final da tarde. Durante as primeiras horas da madrugada e no início da tarde, o corpo atinge níveis mais baixos de energia. Este ciclo pode variar dependendo da idade, saúde e estilo de vida que o paciente adota. A luz desempenha um papel fundamental durante a regulação do ritmo circadiano. Uma vez que os olhos captam a luz do sol, um sinal é enviado ao hipotálamo de que é hora de ficar alerta. Se os olhos não forem expostos à luz por um longo período de tempo, o cérebro interpreta que é para desencadear a liberação de melatonina. Estudos certamente sugerem que a luz azul pode suprimir a liberação de melatonina à noite, tornando mais difícil conseguir dormir . Nesta revisão, resumimos o conhecimento atual dos efeitos da luz azul na regulação da função fisiológica e os efeitos da exposição à luz azul na saúde ocular. Finalmente, discutimos os dados disponíveis para determinar se a exposição de longo prazo à luz azul é segura ou adicionais são necessários estudos para compreender totalmente os efeitos da luz azul exposição na saúde ocular. Objetivo: Determinar os efeitos da luz azul de dispositivos eletrônicos no ritmo circadiano humano, delineando possíveis consequências positivas e negativas à saúde decorrentes dessa exposição na produção de melatonina. Métodos: realizou-se revisão de literatura nas bases de dados vinculadas à saúde, publicados em Inglês, Português e Espanhol. Inicialmente, as palavras chave foram vinculadas aos Descritores em Ciências da Saúde (DECS) e ao Medical Subject Headings (MeSH): vocabulário controlado da National Library of Medicine (NLM), utilizado para indexação de artigos para o PubMed. Utilizou-se a Biblioteca Virtual em Saúde (BVS), que reúne 12 bases de dados da área de saúde. Também, o PubMed, portal da Biblioteca Nacional de Medicina dos Estados Unidos, que inclui referências da base Medline e outros jornais ligados às ciências biológicas de artigos biomédicos. Utilizou-se a biblioteca eletrônica Scientific Electronic Library Online (SciELO), que disponibiliza diversas coleções de periódicos científicos e livros em diversas áreas do conhecimento, incluindo a área da Saúde; como também as fontes de evidências primárias: Medline via Ovid, Embase, Lilacs, Scopus e Web of Science. Para classificar o nível de evidência dos estudos selecionados, foram utilizadas as categorias da Agency for Healthcare Research and Quality (AHRQ-2016). A pesquisa foi desenhada para focar em dois conceitos principais: luz e ritmo circadiano. Assim, foram escolhidos os termos de busca relacionados à luz ("exposição à luz" OU "luz artificial") e os relacionados ao ritmo circadiano (circadiano E melatonina OU "sono REM"). Os termos foram pesquisados \&\#8203;\&\#8203;nos títulos, resumos e palavras-chave dos artigos. Conclusão: Existem fortes indícios que sugerem a interferência da luz azul na produção de melatonina pelo corpo, afetando diretamente a forma como o ciclo circadiano se expressa no organismo. Estudos também apontam um aumento na frequência de eventos cardiovasculares e doenças psiquiátricas, como depressão e bipolaridade, em pacientes expostos à luz de dispositivos eletrônicos antes do sono.

\section{REFERÊNCIAS}

ALBERNAZ XAVIER, E. et al. O papel da melatonina na fisiologia normal e patológica (a melatonina na fisiologia). Revista de Medicina e Saúde de Brasília, v. 8, n. 1, 2019.

TÄHKÄMÖ, L. et al. Systematic review of light exposure impact on human circadian rhythm. Chronobiology international, v. 36, n. 2, p. 151-170, 2019.

WAHL, S. et al. The inner clock-Blue light sets the human rhythm. Journal of biophotonics, v. 12, n. 12, 2019.

PALAVRAS-CHAVE: Melatonina; Sono; Luz azul. 


\title{
ELABORAÇÃO E VALIDAÇÃO DE UMA CARTILHA DE ORIENTAÇÕES PARA CUIDADORES DE PACIENTES PORTADORES DE ESCLEROSE LATERAL AMIOTRÓFICA
}

\author{
MARIA EDUARDA CALIXTO COVELO*; BRUNA LEONEL CARLOS \\ UNIVÁS - Universidade do Vale do Sapucaí
}

Introdução: A Esclerose Lateral Amiotrófica (ELA) se trata de uma doença do neurônio motor degenerativa e progressiva, caracterizada por afetar os neurônios motores superiores e inferiores de maneira irreversível. Tal doença causa espasticidade e atrofia do sistema muscular, flacidez, fasciculação e fraqueza muscular. Tais alterações acarretam em uma sequência de complicações, como disartria, disfagia e enfraquecimento dos músculos respiratórios. Devido às limitações em sua capacidade funcional, a partir de certo estágio da doença, o portador da ELA se torna dependente do cuidador para caminhar, se alimentar, realizar a atividades de higiene pessoal, administração de medicamentos, entre outros. Dependências essas que podem se tornar menor com as práticas corretas exercidas pelo cuidador. Objetivo: Deste modo, este estudo terá o objetivo de desenvolver uma cartilha, destinada a cuidadores de pacientes com ELA, com o intuito de apresentar aos mesmos esclarecimentos sobre a ELA e cuidados que devem ser tomados no dia a dia do indivíduo para facilitar suas atividades, prevenir deformidades e melhorar a qualidade de vida. Além disso, será realizado, também, a validação da cartilha por meio de um questionário de avaliação respondido por fisioterapeutas e pelos cuidadores Metodologia: Sendo assim, será feito em três etapas: primeiramente será realizada a revisão de literatura para coleta de informações para a elaboração da cartilha. Em seguida, será confeccionada a cartilha de modo virtual e adicionado fotos reproduzindo as posições e movimentos corretos. E por fim, a cartilha será enviada para fisioterapeutas e cuidadores, pré-selecionados, que avaliaram a mesma por meio de um questionário. Resultados parciais: Até o momento, a cartilha foi elaborada e distribuída apenas para fisioterapeutas, de acordo com as respostas dos questionários de validação a cartilha está sendo ajustada para ser reenviada.

\section{REFERÊNCIAS}

ANDERSEN, P. et al. EFNS guidelines on the clinical management of amyotrophic lateral sclerosis (MALS) - Revised reporto f na EFNS task forc. European Journal of Neurology. v. 19, p. 360-375. 2012.

CHEN, A. MITSUMOTO, H. The Role of Exercise in Amyotrophic Lateral Sclerosis. Physical Medicine and Rehabilitation Clinics of North America. v. 19, n. 3, p. 545-557. 2008.

JONES, H. et al. Dysphagia in Rare Conditions: An Encyclopedia. San Diego, CA: Plural Publishing, 2010.

PALAVRAS-CHAVE: esclerose lateral amiotrófica, doença do neurônio motor, reabilitação, orientações, cuidadores. 


\title{
ESPIRITUALIDADE E EDUCAÇÃO: EM DEFESA DE UMA PEDAGOGIA HOLÍSTICA
}

\author{
RAQUEL DAMASCENDO DIAS MATEO*; ROGÉRIO LOBO SÁBER \\ UNIVÁS - Universidade do Vale do Sapucaí
}

Introdução: Os processos educacionais precisam adequar-se às dificuldades particulares dos alunos envolvidos, tentando atender ao máximo suas limitações e necessidades. Dessa maneira, a Pedagogia deve humanizar sua práxis, tendo em vista que os participantes são seres humanos que, para além da teoria da sala de aula, carecem de empatia, afeto e cuidado. Desenvolvimento: Para mediar e sustentar essa prática afetiva e o ato de educar, a espiritualidade é uma dimensão da existência que não pode ser desconsiderada pelas intervenções educacionais, já que a educação precisa afetar o íntimo do ser humano para que seja efetiva, autêntica. Ao promover significação dos processos, uma tal educação é capaz de promover a autonomia dos aprendizes. A pesquisa refletiu sobre a importância de a dimensão espiritual ser priorizada por práticas pedagógicas holísticas e confirmou a hipótese de que uma práxis pensada para a contemporaneidade não pode relegar tal aliança a um segundo plano. Metodologia: Por meio de recenseamento bibliográfico, o trabalho (a) agrupou as principais características do que se entende por espiritualidade, assinalando o desenvolvimento histórico do conceito; (b) demarcou a diferença entre religião e espiritualidade, elevando esta última a um patamar universal, pertencente a todo ser humano; e (c) analisou possíveis aproximações entre os princípios da espiritualidade e os princípios de uma educação que se compromete com a formação integral do educando e com experiências educacionais humanizadas. Considerações finais: A hipótese de trabalho levantada foi a existência de uma firme relação entre as dimensões espiritual, afetiva e cognitiva nos processos pedagógicos. $O$ mapeamento bibliográfico realizado permitiu confirmar que a espiritualidade é uma dimensão da vida humana indispensável ao ambiente educacional porque transcende o entorno escolar e traz a importância do olhar humano e afetivo, contribuindo para o processo de aprendizagem do aluno e para a manutenção de saudáveis e construtivas relações interpessoais. Foi possível nomear então elementos essenciais pertencentes tanto à espiritualidade quanto à educação, tais como amor, afetividade, empatia e compreensão. A reflexão desenvolvida a respeito deles confirmou o reforçado vínculo existente/necessário entre educação e espiritualidade.

\section{REFERÊNCIAS}

COTTINGHAM, John. A dimensão espiritual: religião, filosofia e valor humano. 2. ed. São Paulo: Edições Loyola, 2008.

MO SUNG, Jung. Educar para reencantar a vida: Pedagogia e espiritualidade. São Paulo: Reflexão, 2012. SECONDIN, Bruno. Espiritualidade em diálogo: Novos cenários da experiência espiritual. São Paulo: Paulinas, 2002.

PALAVRAS-CHAVE: Espiritualidade; Pedagogia; Educação; Religião; Afeto. 


\title{
ESTRATÉGIA PARA IDENTIFICAÇÃO DE BIOFILMES IN VITRO
}

\author{
JOÃO VITOR DE SOUSA TOLEDO*; RODRIGO MACHADO PEREIRA; GUSTAVO BRUNELLI VALLIM; \\ LIVIA ROCHA MARTINS; LUIZ FRANCISLEY DE PAIVA; DIBA MARIA SEBBA TOSTA DE SOUZA \\ UNIVÁS - Universidade do Vale do Sapucaí
}

INTRODUÇÃO: Biofilmes são comunidades de microrganismos que vivem aderidos a uma superfície e envoltos numa complexa mistura de compostos tais como proteínas, polissacáridos e DNA extracelular. Sua formação representa modo protegido de crescimento que torna as células bacterianas menos suscetíveis não só a antimicrobianos, como também ao sistema imune. Os microrganismos do biofilme em ferida crônica não cicatrizante podem promover resposta hiper inflamatória, ser prejudicial ao hospedeiro, promover hipóxia tecidual localizada reduzindo à disponibilidade de oxigênio necessário a cicatrização (CAETANO, 2018; TORTORA; FUNKE; CASE, 2012). Assim, o objetivo deste estudo é avaliar o desempenho de corantes naturais na coloração de biofilmes microbianos. METODOLOGIA: Trata-se de um estudo experimental in vitro, exploratório, analítico, longitudinal e prospectivo, realizado no Laboratório de Pesquisas Básicas - UNIVÁS. Foram analisados os corantes naturais de Curcuma, Hibisco, Urucum e o padrão positivo Cristal Violeta $0,1 \%$. Os microrganismos utilizados foram: Escherichia coli ATCC8739, Staphylococcus aureus ATCC6538, Pseudomonas aeruginosa ATCC9027 e Salmonella typhimurium ATCC14028. Após cultura de 24 horas em meio Agar Mueller-Hinton, foi preparada uma suspensão ajustada ao tubo 0,5 da escala de McFarland que em seguida foi diluída 1:20 e depois 1:10 em meio caldo Mueller-Hinton de forma a conter $5 \times 105 \mathrm{UFC} / \mathrm{mL}$. Foi dispensado $1 \mathrm{~mL}$ da suspensão em tubos eppendorf que foram identificados e incubados a $35 \stackrel{\circ}{\circ} \mathrm{C}$ por 24 horas. Após esse período, o inoculo foi removido e os tubos lavados $3 \mathrm{X}$ e deixado para secar por 1 hora. Em seguida, foram dispensados em cada tubo 1200 $\mu \mathrm{L}$ dos corantes e incubados por 15 minutos. Passado esse tempo, os corantes foram removidos e os tubos lavados $3 \mathrm{X}$ e deixados para secar. Após essa etapa foi adicionado em cada tubo, $2000 \mu \mathrm{L}$ de Ácido Acético a $30 \%$ e incubado em temperatura ambiente por 15 minutos. Em seguida, a solução resultante foi transferida para um cubeta e realizou-se a leitura em espectrofotômetro (KASVI K37-VIS) em comprimento de onda de $570 \mathrm{~nm}$ (cristal violeta), $413 \mathrm{~nm}$ (Urucum) $419 \mathrm{~nm}$ (Curcuma) e $520 \mathrm{~nm}$ (Hibisco). As amostras foram classificadas segundo Stepanovic et al. Os isolados foram classificados em quatro categorias: Não aderente se DOi \&\#8804; DOc; fracamente aderente (+) se DOc < DOi \&\#8804; 2 x DOc; moderadamente aderente (++) se 2 x DOc < DOi \&\#8804; 4 x DOc; ou fortemente aderente (+++) se 4 x DOc < DOi. Os resultados das análises dos corantes naturais foram comparados o corante padrão cristal violeta. RESULTADO: Com exceção da Salmonella typhimurium, todos os microrganismos formaram biofilmes. Utilizando o cristal violeta foi classificado como fortemente aderente a cepa de Pseudomonas aeruginosa e de moderadamente aderentes as cepas de S. aureus e E. coli. Utilizando o corante de Hibisco, P. aeruginosa também foi classificada como fortemente aderente, entretanto, possuem valores de DO muito inferior quando comparados com o cristal violeta. Os corantes de Urucum e Curcuma não coraram biofilme. CONCLUSÃO: O corante de Hibisco foi capaz de corar biofilme, entretanto, a sua baixa DO quando comparado com a DO do controle positivo sugere que o corante só é capaz de corar biofilme se este estiver em excesso. Os corantes Curcuma e Urucum não coram biofilme.

\section{REFERÊNCIAS}

CAETANO, A. C. L. Biofilmes e Antimicrobianos. 2018. 66 f. Tese (Mestrado em Ciências Farmacêuticas) - Faculdade Ciências da Saúde, Universidade Fernando Pessoa, Porto, 2018.

STEPANOVIC, S.; VUKOVIC, D.; DAKIC, I.; SAVIC, B.; SVABIC-VLAHOVIC, M. J Microbiol Methods. 2000; v.40, n.2, p.175-179.

TORTORA, G. J.; FUNKE, B. R.; CASE, C. L. Microbiologia. 10. ed. Porto Alegre: Artmed, 2012.

PALAVRAS-CHAVE: Matriz Extracelular de Substâncias Poliméricas; Fatores de virulências; Corantes. 


\title{
ESTRESSE E QUALIDADE DE VIDA EM ESTUDANTES DE MEDICINA NO CONTEXTO DA COVID-19
}

\author{
GUSTAVO PAIVA AZEVEDO*; GABRIEL CARNEIRO BRANDÃO DE MELO; ANTÔNIO HOMERO \\ ROCHA DE TOLEDO; JOSÉ DIAS DA SILVA NETO \\ UNIVÁS - Universidade do Vale do Sapucaí
}

Introdução: a emergente pandemia pelo novo coronavírus (COVID-19) tem causado relevantes problemas de saúde pública e danos socioeconômicos em todo o mundo, o que causou o fechamento de mais de 160 países e afetou mais de $87 \%$ da população estudantil mundial. Nesse contexto, a aprendizagem online foi introduzida para ajustar o ensino às novas realidades. Entretanto, a longa duração da quarentena, a perda da liberdade, o medo da doença, a frustração, o tédio, a desinformação entre diversos outros fatores estressores emergiram da crise e propiciaram o desenvolvimento de sintomas de estresse na população. Os estudantes de Medicina, em razão da alta demanda dos estudos acadêmicos, enfrentam mais fatores de estresse do que a população geral, fato que reflete em outros domínios da vida dessa população, dentre os quais a falta de lazer, $\mathrm{o}$ isolamento social e o estresse permanente derivado da exaustão emocional, os torna suscetíveis a transtornos psicológicos. Tais fatores podem interferir no rendimento acadêmico e na qualidade de vida geral dessa população. Diante disso, o objetivo deste estudo é avaliar o estresse e a qualidade de vida em estudantes de Medicina durante a pandemia por COVID-19. Metodologia: estudo descritivo, qualitativo, do tipo transversal, no qual foram avaliados estudantes de Medicina do primeiro ao quinto ano da Universidade do Vale do Sapucaí (UNIVÁS), através de questionários disponibilizados em ambiente virtual. Foi aplicada uma adaptação para o ambiente universitário do instrumento de avaliação de qualidade de vida The World Health Organization Quality of Life - WHOQOL-bref. Essa pesquisa seguiu as determinações da RESOLUÇÃO No 466, DE 12 DE DEZEMBRO DE 2012, do Conselho Nacional de Saúde (CNS) e foi aprovada pelo Comitê de Ética e Pesquisa da UNIVÁS no dia 17/12/2020 № do parecer: 4.472.220. Resultados: o sexo masculino demonstrou melhor avaliação das facetas dos domínios do WHOQOL-bref quando comparado ao sexo feminino. Considerações Finais: a análise do estresse e da qualidade de vida dos estudantes de medicina do $1^{\circ}$ ao $5^{\circ}$ ano durante a pandemia COVID-19 demonstrou que o sexo masculino possui menor carga de estresse e maior qualidade de vida quando comparado ao sexo feminino. Além disso, a sobrecarga de estresse a que esses estudantes estão sujeitos mostrou interferência negativa no sono e no desempenho geral para as atividades diárias.

\section{REFERÊNCIAS}

ARAÚJO, Francisco Jonathan de Oliveira; LIMA, Ligia Samara Abrantes de; CIDADE, Pedro Ivo Martins; et al. Impact Of Sars-Cov-2 And Its Reverberation In Global Higher Education And Mental Health. Psychiatry Research, v. 288, p. 112977, 2020.

MEO, Sultan Ayoub; ABUKHALAF, Dr Abdulelah Adnan; ALOMAR, Ali Abdullah; et al. COVID-19 Pandemic: Impact of Quarantine on Medical Students, Mental Wellbeing and Learning Behaviors. Pakistan Journal Of Medical Sciences, v. 36, p. 43-48, 2020.

SOLIS, Ana C.; LOTUFO-NETO, Francisco. Predictors of quality of life in Brazilian medical students: a systematic review and meta-analysis. Brazilian Journal Of Psychiatry, n. 6, p. 556-567, 2019.

PALAVRAS-CHAVE: Estresse; Qualidade de vida; Estudantes de medicina; COVID-19. 


\title{
ESTUDO HISTOLÓGICO DA PELE DE TRUTA ARCO-ÍRIS (ONCORHYNCHUS MYKISS).
}

\author{
MAYRA FARIA GOULART*; ANA CAROLINA SOARES; LUCAS BRAGA DE ANDRADE; GABRIELLA \\ LUDOVICO FRAGA; LUIZ FRANCISLEY DE PAIVA; WELLINGTON DELFINO; RODRIGO MACHADO \\ PEREIRA \\ UNIVÁS - Universidade do Vale do Sapucaí
}

INTRODUÇÃO: A truta (Oncorhynchus mykiss) é um peixe de escamas que vive em água doce, em temperatura aproximada de $12^{\circ} \mathrm{C}$, mas também podendo sobreviver até $25^{\circ} \mathrm{C}$. É encontrada em regiões da América e na Europa, onde alcança um cultivo maior. Além de reproduzir em ambientes naturais, possui a capacidade de se reproduzir em tanques para criadouro e proporciona alto valor nutricional e biológico (AMARAL,2007). OBJETIVO: O objetivo desse estudo é avaliar e descrever as estruturas histológicas da pele da truta para fins científicos e tecnológicos. METODOLOGIA: Peles de truta foram adquiridas do criadouro e frigorífico da cidade de São Bento Sapucaí-Mirim. Os animais foram cultivados em tanque para fins comerciais, alimentados com ração comercial e abatidos, pesando aproximadamente 350 gramas. As peles limpas foram fixadas em formalina 10\% por no mínimo 24 horas, clivadas em fragmentos menores e acondicionadas em cassetes plásticos para o processamento histológico. As peças foram desidratadas em série alcoólica crescente, clarificadas em xilol, impregnadas e incluídas em parafina. Os blocos foram seccionados em micrótomo rotativo a $4 \mu \mathrm{m}$., e os cortes foram distendidos em lâminas limpas. Para análise histológica geral das estruturas, realizou-se a técnica de coloração por hematoxilina de Harris e eosina alcoólica. Para destaque de estruturas secretoras de muco, utilizou-se a coloração por azul de toluidina. As lâminas foram avaliadas sob microscópio óptico. Fotomicrografias foram feitas por meio de câmara acoplada a ocular. RESULTADOS: Na epiderme foi observada a presença de um epitélio estratificado, com células basais intensamente coradas e glândulas secretoras de muco. As células mucosas foram destacadas pela coloração com azul de toluidina. Na interface com a derme, ocorre a presença de células pigmentadas (melanócitos) com coloração escura característica. Na derme, observouse a presença de fibras colágenas com espessuras pouco variadas, dispostas paralelamente, integrando a estrutura de um tecido conjuntivo denso. CONSIDERAÇÕES FINAIS: Os resultados demonstram que a pele de truta apresenta uma estrutura histológica característica, embora semelhantes a alguns outros peixes de água doce. A grande distribuição de glândulas na epiderme demonstra a grande capacidade secretora de muco na superfície da pele. A disposição de fibras colágenas como uma camada espessa na derme indica a possibilidade de utilização da pele de truta na oclusão de ferimentos cutâneos mediante as avaliações necessários.

\section{REFERÊNCIAS}

ALVES, Ana Paula Negreiros Nunes et al. Avaliação microscópica, estudo histoquímico e análise de propriedades tensiométricas da pele de tilapia do Nilo. 2015 Revista Brasileira de Queimaduras, Limeira, v. 14, n. 3, p. 203-210, jul./ago./set. 2015.

AMARAL, Gisele Ferreira. Análise do segmento de trutas: abordagens de cadeia produtiva e turismo rural. 2007. 118 f. Dissertação (Mestrado em Ciências Sociais em Desenvolvimento, Agricultura e Sociedade) Instituto de Ciências Humanas e Sociais, Universidade Federal Rural do Rio de Janeiro, Seropédica - RJ, 2007.

CONCEA. "Diretrizes da Prática de Eutanásia do Conselho Nacional de Controle de Experimentação Animal-CONCEA." (2013).

PALAVRAS-CHAVE: Estrutura histológica, epiderme, fibras colágenas, melanócitos. 
UNIVÁs | 2021

\title{
EXAME DE SUFICIÊNCIA DO CONSELHO FEDERAL DE CONTABILIDADE: OBSERVAÇÕES DOS ALUNOS DO CURSO DE CIÊNCIAS CONTÁBEIS
}

\author{
ALINE MOREIRA CAMPOS*; GEOVANY ROSA PIRES \\ UNIVÁS - Universidade do Vale do Sapucaí
}

INTRODUÇÃO: Este estudo tem por objetivo principal investigar se os alunos do último ano do curso de Ciências Contábeis da Universidade desconhecem as exigências do Conselho Federal de Contabilidade no que diz respeito ao exercício da profissão. As práticas contábeis brasileiras sofreram grandes mudanças no início do século XXI, onde houve uma convergência das normas internacionais de contabilidade, dessa maneira houve uma harmonização das práticas contábeis para que ocorresse uma maior transparência bem como uma normatização uniforme entre as diversas interpretações contábeis pelo mundo. Considerando as inúmeras mudanças na economia do país, bem como as ocorridas na gestão das organizações fica evidente cada vez mais a procura do mercado por profissionais com conhecimentos consolidados, essa lógica não é diferente para o profissional da contabilidade. O mercado privado procura por profissionais que contam com um amplo conjunto de competências, de forma que o profissional contábil trabalhe não somente como um técnico, mas também um parceiro nos negócios. Há inúmeros estudos que envolvem os principais motivos para uma má formação profissional e alguns motivos estão relacionados a formação acadêmica. Cabe ressaltar que em paralelo à preocupação quanto a qualidade dos profissionais que estão se inserindo no mercado há uma preocupação do Ministério da Educação com relação a qualidade do nível do ensino superior em Ciências Contábeis. Cabe ressaltar que o Conselho Federal de Contabilidade (CFC) e os Conselhos Regionais de Contabilidade (CRC) têm como objetivo fundamental, garantir que os profissionais da área contábil estejam capacitados a exercer suas funções junto à sociedade. METODOLOGIA: A metodologia de pesquisa será bibliográfica e exploratória com abrangência histórica para contextualizar a educação profissional contábil do Brasil. RESULTADOS/DESENVOLVIMENTO: A avaliação do desempenho dos estudantes do curso de graduação de Ciências Contábeis será realizada por meio do Exame Nacional de Desempenho dos Estudantes(ENADE,2021), entretanto para o profissional contábil poder exercer suas funções ele deverá ser aprovado no exame de suficiência do Conselho Federal de Contabilidade, sua obrigatoriedade foi conceituada pela Resolução CFC n.o 1.486/2015, onde esse exame visa comprovar a obtenção de conhecimentos médios, consoante os conteúdos programáticos desenvolvidos pelo curso de Ciências Contábeis, dessa forma, o respectivo exame trouxe para o ambiente acadêmico o desafio da melhoria na qualidade do ensino. No que diz respeito aos resultados da pesquisa verificou-se que dos 10 alunos que responderam, nenhum aluno possui formação técnica em contabilidade, apenas 1 alunos possui formação superior em tecnologia de Recursos Humanos. $80 \%$ estão trabalhando na área contábil, $10 \%$ na área financeira e $10 \%$ na área administrativa. Sobre os programas promovidos pelo Conselho Federal de Contabilidade todos os alunos já ouviram falar sobre o programa de educação continuada. CONCLUSÃO: Pode-se concluir que o objetivo da pesquisa foi alcançado, foi possível verificar que os alunos estão cientes sobre as normas exigidas pela legislação profissional, bem como da relevância da sua formação profissional e acadêmica. Foi possível identificar que os conteúdos abordados ao longo da graduação são os mesmo que são cobrados no exame de suficiência.

\section{REFERÊNCIAS}

CONSELHO FEDERAL DE CONTABILIDADE. Resolução CFC 1.486 DE 15.05.2015. Disponível em:<http://www.normaslegais.com.br/legislacao/resolucao-cfc-1486-2015.htm>. Acesso em: 10/09/2021
BRASIL.
Exame Nacional
de Desempenho dos
Estudantes.
Disponívelem:

<https://www.gov.br/inep/pt-br/areas-de-atuacao/avaliacao-e-exames-educacionais/enade> Acesso em: $14 / 09 / 2021$

PALAVRAS-CHAVE: Exame de suficiência. Contabilidade. Ensino. 


\title{
FATORES DA PERSONALIDADE E A EVASÃO E PERMANÊNCIA NO ENSINO SUPERIOR
}

\author{
PRISCILA ARAÚJO HART*; LARIANA PAULA PINTO \\ UNIVÁS - Universidade do Vale do Sapucaí
}

INTRODUÇÃO: Devido ao aumento do ingresso no ensino superior, entender as variáveis que podem ajudar ou dificultar o processo de adaptação do indivíduo na graduação e evitar a evasão, faz-se importante para que instituição e aluno possam desenvolver ações que beneficiem essa adaptação e a manutenção do bem-estar do estudante. Portanto, entender as características da personalidade que colaboram para isso e como elas se correlacionam com os motivos para evadir, torna-se fundamental. Uma forma de descrever essas características é através da teoria do Big Five, que parte do princípio de que as características psicológicas que moldam o comportamento e atitudes são relativamente estáveis. O seu papel não é delimitar a personalidade em dimensões específicas, mas sim avaliar a suas posições entre cinco fatores: Abertura, Conscienciosidade, Extroversão, Amabilidade e Neuroticismo. Devido a posição da personalidade dentro desses cinco fatores, algumas pessoas podem estar mais propensas a lidar melhor com situações negativas e de exigências, estando mais preparadas do que outras para os desafios cotidianos (NUNES, ZANON \& HUTZ, 2018). METODOLOGIA: A pesquisa teve uma amostra de 115 estudantes de graduação que responderam um questionário sociodemográfico e duas escalas que avaliam a personalidade e motivos para a evasão da graduação. A avaliação dos resultados encontrados foi feita através de recursos estatísticos descritivos e inferenciais. Para isso, foi realizada a correlação de Pearson entre os fatores da personalidade do Inventário dos Cinco Grandes Fatores da Personalidade (IGFP-5) com as esferas que compõem a Escala de Motivos de Evasão do Ensino Superior (M-ES). Podese verificar que algumas correlações se mostraram significativas estatisticamente, enquanto outras não obtiverem o mesmo nível. E, também, comparação de médias, através do teste $t$ de Student. RESULTADOS: Foram encontradas correlações fracas e negativas, ou seja, enquanto uma variável está presente em um nível maior, a outra estará rebaixada, no seguinte item fator Conscienciosidade com Motivos Relacionados ao Desempenho Acadêmico. Correlações positivas, ou seja, quanto mais forte uma variável a outra também será, e de magnitude fraca, foram encontradas nos seguintes itens: fator Abertura com Motivos Institucionais. Fator Neuroticismo com Motivos Interpessoais, Motivos Relacionados ao Desempenho Acadêmico, Motivos Institucionais e com a soma total das esferas da M-ES. Quando feita a comparação de médias através do teste $t$ de Student para avaliar se havia diferença entre grupos de acordo com o gênero, ano inicial e final e se o indivíduo havia cursado graduação anterior, foram encontradas diferenças significativas do Gênero e o Fator Neuroticismo, tendo o feminino uma média maior que o masculino indicando uma tendência a maior sofrimento emocional. Já com o grupo de indivíduos que já estiveram em uma graduação anterior ou não, encontrou-se diferenças significativas com dois fatores: Abertura e Conscienciosidade, o grupo que já cursou obtendo médias maiores aos demais no fator Abertura e menores em Conscienciosidade. CONSIDERAÇÕES FINAIS: além de permitir a aquisição de conhecimento sobre a temática, foi possível encontrar resultados que apoiam as hipóteses levantadas, reforçando a importância de elaborar ações que promovam a boa adaptação do aluno na instituição, reduzindo as chances de evasão. Porém, faz-se necessário novas pesquisas para ampliação dos dados encontrados.

\section{REFERÊNCIAS}

AMBIEL, R. A. M. M-ES: Escala de Motivos de Evasão do Ensino Superior. São Paulo: Hogrefe, 2017. ANDRADE, J. M. Evidências de Validade do Inventário dos Cinco Grandes Fatores de Personalidade para o Brasil. 2008. (Tese de doutorado, Universidade de Brasília: Instituto de Psicologia , Brasília - DF, 2008). Recuperado de: https://repositorio.unb.br/handle/10482/1751

NUNES, C. H. S., ZANON, C., \& HUTZ, C. S. Avaliação da Personalidade a partir de teorias fatoriais da personalidade. In C. S. HUTZ, D. R. BANDEIRA \& C. M. TRENTINI. Avaliação psicológica da inteligência e da personalidade. Porto Alegre: Artmed, 2018. (pp. 217-231).

PALAVRAS-CHAVE: Personalidade; Evasão do Ensino Superior; Bem-estar 


\title{
FIGURAÇÕES DA INFÂNCIA NA LITERATURA GÓTICA: UMA LEITURA PSICANALÍTICA DA OBRA "THE TURN OF THE SCREW" (1898), DE HENRY JAMES
}

\author{
RAPHAELA BIANCA SILVA DE SOUZA*; ROGÉRIO LOBO SÁBER \\ UNIVÁS - Universidade do Vale do Sapucaí
}

Introdução: No repositório das manifestações literárias góticas, o tema da infância fomenta análise ambígua porquanto objeto de uma oposição fundamental entre as concepções iluminista e romântica. Para os iluministas, a criança é uma criatura relegada a segundo plano devido a sua inexperiência de vida, embora os românticos a julguem como detentora de uma "sabedoria metafísica superior" (CAVALLARO, 2002, p. 150) e se mostrem inconformados e nostálgicos com a efemeridade da puerícia, cuja liberdade é substituída pelas obrigações da vida adulta. Desenvolvimento: Como desdobramento dessa cosmovisão romântica, também é frequente que os textos góticos promovam figurações da infância que priorizam a criança como agente promotor de medo, responsável pelo estabelecimento de tensões no núcleo familiar, fobias e embates entre gerações. Tais representações estéticas subvertem visões idealizadas sobre a infância e nos chamam a atenção para tendências perversas protagonizadas por crianças. Complementa essa ambiguidade representacional a concepção de que as crianças ameaçam a estabilidade da ordem da civilização, já que possuem vínculo com o primitivo, com o estágio primevo humano em que não existem amarras (CAVALLARO, 2002, p. 135). Elas geram ansiedade nos adultos porque representam o "Outro não civilizado" (CAVALLARO, 2002, p. 160) e, portanto, devem ser exiladas, literal ou figurativamente. Instala-se, portanto, choque de poderes entre o mundo infantil e o mundo adulto porque este não aceita a conexão que as crianças possuem com o sublime, o caos e a enargeia. Metodologia: O verbete "Gothic Fairy-Tale", redigido por Lucie Armitt (1998), estende-nos importante pista teórica ao comentar sobre a existência de atmosfera e de elementos góticos em versões tradicionais de contos de fadas, como em "Hansel e Gretel". A autora assinala que a leitura da trajetória das crianças presentes nos textos pode ser mais bem aprofundada a partir do recurso à crítica psicanalítica. Por essa razão, a pesquisa recorreu ao inventário freudiano como referencial crítico-metodológico para análise das figuras infantis em torno das quais se concentra a trama da novela inglesa The Turn of the Screw, publicado em 1898 por Henry James. Considerações finais: A literatura escrita em modo gótico prioriza representações estéticas que subvertem constructos sociais e formas predominantes de percepção da realidade, possibilitando que acompanhemos a trajetória de personagens que participam de eventos geradores de medo e de claustrofobia. Embora obras pertencentes à linhagem do texto gótico inaugural The Castle of Otranto (1764) representem a criança como vítima da decadência moral dos pais, outros textos - como The Turn of the Screw - invertem a posição de vítima e questionam a aparente inocência e vulnerabilidade dos rebentos. As ações friamente concebidas e executadas pelas crianças denunciam as perversões do sadismo e masoquismo, associadas por Freud a figuras infantis. Essa é a possibilidade de leitura reservada pela pesquisa a esse canônico texto da literatura de terror, ainda que pela própria estrutura narratológica, responsável pela existência de vozes narrativas não fidedignas, a crítica não tenha permissão para cristalizar única possibilidade exegética.

\section{REFERÊNCIAS}

ARMITT, Lucie. "Gothic fairy-tale". In: MULVEY-ROBERTS, Marie (ed.). The handbook to Gothic literature. Basingstoke: Macmillan Press, 1998, pp. 268-269.

CAVALLARO, Dani. The gothic vision: three centuries of horror, terror and fear. London: Continuum, 2002. FREUD, Sigmund. Três ensaios sobre a teoria da sexualidade, análise fragmentária de uma histeria ("O caso Dora") e outros textos: 1901-1905. Tradução Paulo César de Souza. São Paulo: Companhia das Letras, 2016. (Obras Completas, vol. 6).

PALAVRAS-CHAVE: Literatura gótica. Crítica psicanalítica. Figurações da infância. 
UNIVÁs | 2021

\title{
FIGURAÇÕES E DINÂMICA DA VIOLÊNCIA EM LIGHT IN AUGUST(1932), DE WILLIAM FAULKNER: INTERPRETAÇÕES BIOÉTICAS
}

\author{
JOÃO MATHEUS VILHENA DOS SANTOS*; STEPHANY VITÓRIA COSTA GONÇALVES; ROGÉRIO \\ LOBO SÁBER \\ UNIVÁS - Universidade do Vale do Sapucaí
}

Introdução: Os ideais bioéticos se resumem ao conjunto de preceitos morais e éticos que regem e defendem a vida humana. Indispensáveis à nossa sociedade contemporânea, sua relevância tem sido (re)afirmada pelos avanços socioantropológicos, filosóficos e científicos. Pela perspectiva bioética, o ser humano deve ser valorizado independentemente de quaisquer variáveis, sejam elas étnicas, sociais, econômicas ou ideológicas. Discussões no campo da bioética implicam reflexão e deliberação a respeito de temas considerados frequentemente tabus em nossa sociedade, dentre os quais se destacam a eutanásia, o aborto, a eugenia e o racismo. O reconhecimento, a exposição e a discussão desses temas e de outros que sigam na mesma direção correspondem a tarefas de difícil execução, principalmente quando a criação de espaços para o livre exercício do pensamento se vê interceptada por diretrizes ideológicas e/ou outras barreiras socioculturais. Desenvolvimento: Partimos da hipótese de que a aproximação a tais questões de complexo manuseio encontra, nas artes, um veículo facilitador, dado o potencial de encenação das obras estéticas. A figuratividade é elemento-base das obras literárias, cinematográficas e afins, e contribui para a exposição de temas que, embora tendam a gerar polêmica, podem ser mais amplamente compreendidos à luz das teorias bioéticas. A experiência estética viabiliza 0 acesso a tópicos tabus, bem como estimula o desenvolvimento do senso crítico e a ampliação das habilidades intelectivas. Ao mobilizar tanto a imaginação quanto o uso lógico da razão, a narratividade literária coloca em cena as inclinações sublimes e abjetas da natureza humana, assim como nos interpela a analisar configurações sociais que se norteiam pela dinâmica da violência. Metodologia: Partindo dessa premissa, analisamos o romance Light in August (1932), do escritor estadunidense William Faulkner, à luz das teorias bioéticas agrupadas para o enquadramento conceptual da pesquisa. $O$ mapeamento dos fundamentos bioéticos buscou concentrar-se em fontes teóricas que assinalassem o vínculo existente entre a bioética e a literatura. Dentre os tópicos de especial interesse ao domínio do conhecimento selecionado, recortamos o tema do racismo, que pode ser lido como um dos motivos nucleares do romance faulkneriano. Aos fundamentos teóricos de bioética somou-se pertinente aparato teóricometodológico da crítica literária. Considerações finais: A obra literária, lida à luz das teorias bioéticas selecionadas, permitiu-nos a aproximação e a compreensão mais ampla da questão do racismo. Embora esse romance de 1932 se ambiente na sociedade sulista estadunidense, é possível reafirmar a perenidade do tema posto em cena, uma vez que casos recorrentes de racismo são reportados frequentemente pela mídia, em diversas localidades. A leitura pela perspectiva bioética nos chama a atenção às mazelas vivenciadas por Joe Christmas, protagonista que se torna vítima do preconceito racial de uma sociedade limitada geográfica e ideologicamente. De identidade mestiça, o personagem habita um entrelugar e sua jornada existencial, permeada de atos violentos, nos interpela a refletir sobre a dignidade da vida humana — pressuposto inalienável do domínio bioético.

\section{REFERÊNCIAS}

DOWNIE, R. S.; MACNAUGHTON, Jane. Bioethics and the Humanities: Attitudes and Perceptions. Abingdon: Routledge-Cavendish, 2007.

KUHSE, Helga; SINGER, Peter. (Ed.). A Companion to Bioethics. 2nd edition. Chichester: Wiley-Blackwell, 2009.

MORATALLA, Tomás Domingo. Bioética y Cine: de la Narración a la Deliberación. Madrid: San Pablo, 2011.

PALAVRAS-CHAVE: Bioética. Arte. Literatura Estadunidense. Racismo. William Faulkner. 


\title{
FRATURA DE ACETÁBULO: COMPARAÇÃO DO RESULTADO FUNCIONAL ENTRE AS VIAS DE STOPPA E ILIOINGUINAL; REVISÃO SISTEMÁTICA DE LITERATURA
}

\author{
MATEUS GOMES POLO*; GUSTAVO JUNHO TOLEDO; ANA CAROLINA MONÇÃO BASSO; VINICIUS \\ FONSECA BERNARDES; DIÓGENES RODRIGES MACHADO \\ UNIVÁS - Universidade do Vale do Sapucaí
}

Introdução: As fraturas do acetábulo ocorrem principalmente em adultos jovens como resultado de traumas de alta velocidade $(1,2,3)$. Abordagens ilioinguinal e femoral têm sido utilizadas com sucesso por muitos anos. A maioria dos cirurgiões seleciona a abordagem cirúrgica de acordo com sua própria experiência, mas mesmo para essas lesões graves a morbidade mínima deve ser direcionada e, nesse ponto de vista, há poucos estudos comparando a abordagem de Stoppa e a abordagem ilioinguinal sobre eficiência e segurança, bem como a qualidade dos resultados pós-operatórios $(4,5)$. Objetivo: $O$ objetivo do estudo é revisar as indicações, a qualidade da redução, os resultados iniciais e as complicações do uso dessas abordagens anteriores para reconstrução de fraturas do acetábulo. Metodologia: As palavras chave foram vinculadas aos Descritores em Ciências da Saúde (DECS) e Medical Subject Headings (MeSH). Utilizou-se as bases de dados em saúde para a pesquisa: Biblioteca Virtual em Saúde (BVS), PubMed e outros jornais ligados às ciências biológicas. Incluiu-se artigos originais disponíveis nas bases eletrônicas, publicados e indexados nas referidas bases de dados, no período entre 2014 a 2021. Foram excluídos artigos:com falta de clareza dos resumos das etapas do conteúdo; artigos que abordam vias diferentes das propostas; abordagem cirúrgica percutânea. Resultados: Comparando os 4 níveis de Matta, a diferença na qualidade da redução entre as vias de Stoppa e llioinguinal não foi significativa. Portanto, sugere que o sucesso cirúrgico não está relacionado com a via utilizada $(6,7)$. Independentemente da via de acesso utilizada, prevalece as taxas de redução excelente e boa com médias $43,02 \%$ e $48,09 \%$ dos pacientes avaliando o procedimento cirúrgico. O resultado clínico após a redução aberta e fixação interna da fratura acetabular é fortemente influenciada pela qualidade da redução anatômica. Apenas 21 pacientes tiveram perda de redução durante o primeiro ano de seguimento. Isso indica a estabilidade da fixação alcançada $(8,9)$. Demonstra-se que as taxas de redução anatômica das fraturas acetabulares obtidas pela abordagem llioinguinal foram semelhantes às alcançadas pela abordagem de Stoppa (10). Conclusão: Conclui-se que tanto a abordagem cirúrgica de Stoppa como a ilioinguinal podem oferecer benefícios aos cirurgiões que precisam tratar de fraturas de acetábulo pela via anterior, sendo que as taxas de redução são resultados da experiência do cirurgião responsável.

\section{REFERÊNCIAS}

Isaacson MJ, Taylor BC, French BG, Poka A. Treatment of Acetabulum Fractures Through the Modified Stoppa Approach: Strategies and Outcomes. Clin Orthop Relat Res. 2014;472(11):3345-52.

JUDET R, JUDET J, LETOURNEL E. Fractures of the Acetabulum: Classification and Surgical Approaches for Open Reduction. Preliminary Report. J Bone Joint Surg Am. 1964;46:1615-46.

Clinic-al OF. THE LONG-TERM RESULTS OF LOW-FRICTION A PRIMARY ARTHROPLASTY INTERVENTION * Alphabetical. J Bone Jt Surg. 1972;54:61-76.

PALAVRAS-CHAVE: Stoppa; Ilioinguinal; Fratura; Acetábulo 


\section{GEL DESBRIDANTE PARA FERIDAS CRÔNICAS, PRODUZIDO COM A CASCA VERDE DA BANANA.}

MAYCON CRISTIAN GOMES DE PAULA*; YUJI ATARASHI TAVARES; BRUNA DE CÁSSIA SOUSA; ISADORA ANDRÉ DE CAMARGO PACHECO; DÊNIA AMÉLIA NOVATO CASTELLI VON ATZINGEN; ADRIANA RODRIGUES DOS ANJOS MENDONÇA

UNIVÁS - Universidade do Vale do Sapucaí

Introdução: As doenças crônicas não transmissíveis são as principais causas de mortalidade no Brasil, representando $72,6 \%$ do total de óbitos registrados. Desse total, $47,9 \%$ estão relacionados às doenças cardiovasculares e ao Diabetes mellitus. As duas condições são as principais causadoras de doença vascular periférica- feridas crônicas e úlceras-que precedem $85 \%$ das amputações não-traumáticas de membros inferiores. A prevalência desse desfecho pode ser reduzida pela profilaxia de complicações, principalmente pela higienização e desbridamento do local. Estudos prévios demonstraram a capacidade de cicatrização e ação anti-inflamatória da casca da banana verde da espécie Musa sapientum. Objetivo: Avaliar a ação desbridante do gel contendo $10 \%$ da casca da banana verde, em úlceras crônicas. Métodos: Estudo clínico, longitudinal, com amostragem por conveniência. Realizado no Núcleo de Assistência e Ensino de Enfermagem do Hospital das Clínicas Samuel Libânio. Os pacientes receberam o tratamento por 4 semanas com Colagenase 0,6 U/g (grupo controle) ou Gel a 10\% da casca verde da banana verde (grupo estudo). As úlceras crônicas foram avaliadas semanalmente (no $7^{\circ}, 14^{\circ}$ e $21^{\circ}$ dia de tratamento) e documentadas por fotografia com padrão pré-estabelecido. A avaliação da área de desbridamento foi realizada de acordo com o aspecto e quantidade (muita, média pequena e ausente) de tecido necrótico da lesão. Resultados: Dentre os 20 pacientes que cumpriram o período da pesquisa, 11 foram alocados no grupo de estudo e 9 no grupo controle. Houve prevalência de pacientes do sexo masculino e com feridas do tipo úlcera venosa em ambos os grupos. A média de idade foi 67 e 64 anos nos grupos estudo e controle respectivamente. Comparando as avaliações das áreas de desbridamento entre os grupos controle e estudo nos 3 períodos não foi observada diferença estatística ( $p=0,239 ; 0,291 ; 0,776)$. Quando analisada a evolução da área da lesão dentro do mesmo grupo, foi observada melhora significante $(p=0,025)$ no grupo estudo entre a primeira e a terceira coleta. Conclusão: o Gel contendo $10 \%$ da casca da banana verde apresentou ação desbridante em úlceras crônicas.

\section{REFERÊNCIAS}

VON ATZINGEN, Dênia Amélia Novato Castelli et al. Repair of surgical wounds in rats using a 10\% unripe Musa sapientum peel gel. Acta Cirúrgica Brasileira, São Paulo, v. 30, n. 9, p.591, set. 2015.Disponível em:http://www.scielo.br/scielo.php?script=sci_arttext\&pid=S0102-86502015000900586\&lng=en\&nrm=iso BOLLIGER, F. P. Levantamento Sistemático da Produção Agrícola, 2013. Disponível em: file://C:/Users/Usu\%C3\%A1rio/Downloads/Ispa_201308.pdf. 3-POWERS, Jennifer G et al. Wound healing and treating wounds: Chronic wound care and management. Journal of the American Academy of Dermatology, Elsevier, v. 74, n. 4, p. 607, abr. 2016.

PALAVRAS-CHAVE: Desbridamento; Musa sapientum; Cicatrização; Úlcera venosa 


\section{GEL FITOTERÁPICO PARA O TRATAMENTO DE MELASMAS}

LUCAS MENDES NUNES*; DÊNIA AMÉLIA NOVATO CASTELLI VON ATZINGEN; JAQUELINE JOICE MUNIZ; RAFAELA FERNANDA OLIVEIRA DE VILAS BOAS; ADRIANA RODRIGUES DOS ANJOS MENDONÇA

UNIVÁS - Universidade do Vale do Sapucaí

Introdução: Melasmas são condições caracterizadas pelo surgimento de manchas escuras e com formatos irregulares e bem definidos na pele, principalmente no rosto. Seu tratamento pode ser feito a partir de medicamentos tópicos e procedimentos para o clareamento, como peelings, lasers e luzes. A terapêutica existente permite, todavia, que o problema seja tratado, mas não curado, por se tratar de uma doença crônica. A ressurgência, bem como a não efetividade dos procedimentos supracitados ainda são frequentes. Uma possível opção seria o uso de fitoterápicos e plantas medicinais, reconhecidas como alternativa viável de tratamento pela Organização Mundial de Saúde. Objetivo: avaliar produto fitoterápico para o tratamento do Melasma. Métodos: Estudo clínico, triplo-cego, randomizado. 74 pacientes do sexo feminino com Melasma, foram recrutadas e alocadas em dois grupos: grupo 1 realizou tratamento com filtro solar (30FPS) mais placebo, e grupo 2 utilizou o filtro solar (30 FPS) mais o produto fitoterápico. O sigilo de alocação ficou sob responsabilidade da Farmacêutica que manipulou os produtos.Todas as pacientes foram orientadas a utilizá-los duas vezes ao dia. A avaliação foi realizada 90 dias após o tratamento, através do Instrumento de análise do índice de área e gravidade do melasma (MASI). A análise estatística foi realizada através do Teste de Mann-Whitney. Resultados: ocorreram 34 perdas ou desistências. Das 40 pacientes participantes, 19 pertenciam ao grupo 1 e 21 ao grupo 2. Não houve diferença entre $1^{\underline{a}}$ e $2^{\underline{a}}$ avaliação para o grupo 1 , sendo valor de $p=0,113$. Houve diferença entre $1^{\underline{a}}$ e $2^{\underline{a}}$ avaliação para o grupo 2 , sendo mediana da $2^{\underline{a}}$ avaliação maior que mediana da $1^{\underline{a}}$ avaliação e valor de $\mathrm{p}=0,000$. A mediana da diferença $\mathrm{G} 2$ ( $2^{\underline{a}}$ avaliação - $1^{\underline{a}}$ avaliação) foi maior que a mediana da diferença G1 (2 $2^{\underline{a}}$ avaliação - 1aa avaliação), valor de $p=0,000$. Conclusão: o produto fitoterápico desenvolvido foi capaz de reduzir a gravidade do melasma.

\section{REFERÊNCIAS}

ERTAM I, ÖZKAPU T, AKÇAY Y, SOZMEN EY, ÜNAL I. Antioxidant activity in melasma. Turkderm-Turk Arch Dermatol Venereology. 2018.

HANDEL AC, MIOT LDB, MIOT HA. Melasma: a clinical and epidemiological review. An Bras Dermatol. 2014.

CANTELLI M, FERILLO M, DONNARUMMA M, EMANUELE E, FABBROCINI G. A new proprietary gel containing glabridin, andrographolide, and apolactoferrin improves the appearance of epidermal melasma in adult women: A 6-month pilot, uncontrolled open-label study. J Cosmet Dermatol. 2019.

PALAVRAS-CHAVE: Melasma. Fitoterapia. Protetor solar. Dermatologia. Pele. 


\title{
HPV: REPERCUSSÃO NA VIDA DA MULHER
}

\author{
VITÓRIA SILVÉRIO COELHO*; MARIA CRISTINA PORTO E SILVA \\ UNIVÁS - Universidade do Vale do Sapucaí
}

A infecção pelo Papilomavírus Humano (HPV) enquadra-se como um problema de saúde pública, sendo considerada a Infecção Sexualmente Transmissível (IST) mais comum. O aumento nas taxas vem ocorrendo tendo em vista a mudança comportamental nas práticas sexuais na sociedade, sendo transmitidas através de contato sexual (oral, vaginal e anal) sem o uso do preservativo. Ainda podendo ocorrer na forma de transmissão vertical durante a gestação, parto e através da amamentação (INCA, 2013). Portanto o estudo teve como objetivo identificar os sentimentos envolvidos na descoberta da infecção pelo HPV e apontar os impactos na vida da mulher após descoberta da infecção pelo HPV. Tratase de um estudo do tipo descritivo e transversal, com sua base teórico-metodológica fundamentada nos princípios da pesquisa qualitativa cujo os dados foram analisados segunda a inspiração fenomenológica. A população do estudo foram mulheres que apresentaram no último resultado do exame Papanicolau a presença do HPV. Os dados foram obtidos por meio de entrevistas semiestruturadas que, após aprovação pelo comitê de ética e autorização dos participantes, foram gravadas e dirigidas por um roteiro constituído pela questão norteadora elaborada pela pesquisadora. Foram identificadas nove unidades de significados com os seguintes temas: a repercussão na vida das participantes, a importância da esperança após a descoberta do HPV, as incertezas da paciente diante do HPV, a doença desconhecida, o diagnóstico de HPV como fato inesperado, apontar os impactos após a descoberta da infecção, o impacto do diagnóstico no relacionamento, confusão de pensamentos acerca do diagnóstico, angústia causada pelo resultado HPV, alarmado com as próximas relações, sem reação sobre o resultado do Papanicolau. O comportamento sexual está ligado ao crescimento do diagnóstico de papiloma vírus humano tendo em vista que mudanças nos hábitos, como utilização do preservativo durante a relação sexual mesmo que parceiro fixo, se fazem necessárias para que haja uma sexualidade segura, evitando a infecção sexualmente transmissível. Políticas públicas devem ser implementadas com ações preventivas para doença, na qual os custos para os gestores na prevenção do câncer de colo do útero são financeiramente mais econômicos do que o tratamento.

\section{REFERÊNCIAS}

BORSATTO, Alessandra Zanei; VIDAL, Maria Luiza Bernardo; ROCHA, Renata Carla Nencetti Pereira. Vacina contra o HPV e a Prevenção do Câncer do Colo do Útero: Subsídios para a Prática. Rev. bras. cancerol, 2011. p. 67-74.

BRASIL, MINISTÉRIO DA SAÚDE. Nota Informativa Conjunta no 01/2015 CGNPNI/DEVIT/DST/AIDS/SVS/MS, que dispõe sobre alteração de faixa etária e do intervalo de doses da vacina HPV para mulheres de nove a 26 anos de idade HIV positivas. Disponível em: $<$ http://www.aids.gov.br>. Acesso em 12 de agosto de 2017.

BRASIL, MINISTÉRIO DA SAÚDE. Protocolo clinico e diretrizes terapêuticas: Relatório de recomendação. Ultima atualização em 2015. Disponível em: <http://conitec.go

PALAVRAS-CHAVE: Papilomavírus humano. Atenção Básica. Saúde da Mulher 


\title{
INFLUENCIA DA ANSIEDADE NO COMPORTAMENTO ALIMENTAR DOS UNIVERSITÁRIOS DA REDE DE ENSINO PRIVADO DOS CURSOS DE ENFERMAGEM E NUTRIÇÃO
}

\author{
LILIANE APARECIDA PEREIRA*; LILIANE APARECIDA PEREIRA; ANA CAROLINA BRASIL E \\ BERNARDES \\ UNIVÁS - Universidade do Vale do Sapucaí
}

Introdução: Tendo em vista que ato de se alimentar é crucial para a sobrevivência humana, podendo ser influenciado por diversos fatores, pesquisa-se sobre a influência da ansiedade no comportamento alimentar dos universitários de ensino privado dos curso de enfermagem e nutrição. Objetivo: A fim de avaliar como a ansiedade influencia no comportamento alimentar, especificamente nas escolhas, frequências e quantidades alimentares em universitários. Para tanto, é necessário conhecer se há um nível de ansiedade presente nos graduandos, identificar se o comportamento alimentar é influenciado pelo estado emocional e identificar se há alterações nas escolhas, frequência e quantidades ingeridas quando se está ansioso. Métodos: Um estudo com 61 estudantes do curso de Nutrição e Enfermagem, sendo uma pesquisa observacional de natureza quantitativa, delineamento transversal analítico, através da aplicação do Questionário Holandês de Comportamento Alimentar(QHCA), socioeconômico e questões sobre ansiedade e alimentação, que foram estruturados através do Google Forms $\circledast$ e enviados aos grupos do estudo. Resultados: Observou-se 40,97\% $(n=25)$ da amostra refere que as vezes se sente ansioso e $85,25 \%$ ( $n=52)$ que o aumento da ansiedade aumentou/iniciou após o começo da graduação, referindose a frequência quando os estudantes estão ansiosos desejo de comer, apresenta-se frequentemente $26,39 \%(n=10)$ e $14,75 \%(n=9)$ muito frequentemente. Ao comparar as três subescalas do QHCA (emocional, restrita e externa) observou-se que a externa sobressaiu sobre as demais. Discussão: A pesquisa apontou uma prevalência relevante de ansiedade nos graduandos, podendo ser decorrente da demanda acadêmica, quanto à identificação sobre as possíveis alterações alimentares, referentes a aumento da ingestão quando se está ansioso, nota-se um aumento na ingestão. Conclusão: Conclui-se após análise do estudo, um nível de ansiedade presente nos graduandos, apontando uma relação entre a ansiedade e a alimentação. A frequência que ocorre o consumo alimentar diante da ansiedade, variouse de uma, média a alta em relação a metade dos participantes da pesquisa e a ingestão externa é mais influência no comportamento alimentar, contudo, fatores emocionais mostram influenciar no comportamento alimentar em certa ocasiões.

\section{REFERÊNCIAS}

ALBERGARIA, Rita et al. Questionário Holandês do Comportamento Alimentar: validação e exploração em adultos com obesidade. Psicologia, Saúde \& Doenças, Lisboa, v.19, n.1, p. 144-150, 2018. Disponívelem:<https://www.researchgate.net/profile/RitaAlbergaria2/publication/324547402 DUTCH_EA TING_BEHAVIOR_QUESTIONNAIRE_VALIDATION_AND_EXPLOITATION_IN_ADULTS_WITH_OBES ITY/links/5ad75ddf458515c60f5735f8/DUTCH-EATING-BEHAVIOR-QUESTIONNAIRE-

VALIDATIONAND-EXPLOITAT ION-IN-ADULTS-WITH-OBESITY.pdf >. Acesso em: 28 Maio 2021. AMERICAN PSYCHIATRIC ASSOCIATON (APA). (2014). Manual diagnóstico e estatístico de transtornos mentais: DSM-5 [Recurso eletrônico]. (5 ${ }^{\mathrm{a}}$ ed,; M. I. C. Nascimento, Trad.). Port

PALAVRAS-CHAVE: Palavras-chave: Comportamento alimentar. Influencia. Ansiedade. 


\title{
LEVANTAMENTO PARASITOLÓGICO DAS AVES SILVESTRES EM MANTENEDOURO DE FAUNA NO MUNICÍPIO DE POUSO ALEGRE, MINAS GERAIS
}

\author{
STHEFANIE CAROLINE RODRIGUES DE LIMA*; ANA BÁRBARA BARROS; SÁVIA PERINA PORTILHO \\ FALCI \\ UNIVÁS - Universidade do Vale do Sapucaí
}

INTRODUÇÃO: Diagnósticos coproparasitológicos são importantes ferramentas que possibilitam a análise da intensidade das infecções, na qual viabiliza verificar a possibilidade de transmissão entre seres de uma mesma comunidade, e até mesmo avaliar condições sanitárias a que estão submetidas e o impacto das ações de controle. (SNAK et al, 2017). A pesquisa da diversidade parasitológica em animas silvestres é considerada um indicador da boa saúde dos ecossistemas, pois irá refletir a filogenia e as chances que permitem a interação entre hospedeiros e parasitas e, com isso, as ameaças evolutivas em ambos. (SANTANA, MESQUITA E FILHO, 2014). Os animais silvestres vêm tomando um gradual interesse como a escolha de animais de estimação. Dentre estes o preferido são as aves, onde possuem maior interação e companheirismo, os mais prediletos são os psitacídeos já que os mesmos são animais vocais, inteligentes e com habilidades de imitar sons humanos. Afora os benefícios que essa correlação oferece, por serem animais silvestres, estes representam grandes fatores de risco à saúde pública por poderem abrigar microrganismos patogênicos que podem ser transmitidos a humanos e outros animais domésticos. (TRINDADE E FIGUEIRA< 2017). Os psitacídeos são caracterizados pelo seu temperamento, coloração de penas, sua habilidade em poder imitar sons da voz humana e seu companheirismo. OBJETIVO: Dessa forma, o presente projeto com o intuito de contribuir para o meio científico e conhecimento de parasitas locais, se justifica na importância de coletar e analisar prevalência de parasitos intestinais presentes nas fezes de aves silvestres em mantenedouro de fauna, verificando o grau de risco para os animais e qual a probabilidade dessas zoonoses serem prosperadas para a comunidade local. METODOLOGIA: Foi feita a coleta com o método de procura nos recintos, onde era coletado todo o material de forma fresca para a análise. Após a coleta, o material era identificado e transportado para a Universidade do Vale do Sapucaí, sendo analisados no laboratório. Para a análise parasitológica, foi utilizado os métodos de Flutuação espontânea ou Método de Willis e pelo método de sedimentação espontânea ou Método de Hoffman, Pons e Janer. As análises foram fotografadas e descritas. Após a obtenção de todas as coletas será feito uma análise estatística. RESULTADOS/DESENVOLVIMENTO: Os resultados são obtidos de maneira parcial. Os recintos foram demarcados de acordo com a característica de cada ave que habita o local, em seguida, foi feita uma tabela contendo a quantidade de cada animal e foto dos mesmos. Após a obtenção dos dados, através de revisão bibliográfica, pesquisou-se quais parasitas poderiam ser encontrados em psitacídeos. Foram feitas duas coletas de amostras de fezes frescas, utilizando-se o método de procura ativa. As fezes foram analisadas pelos métodos de Wills e HPJ. Foram encontrados até o momento larva de Strongyloides stercoralis, e cistos de Entamoeba histolytica. CONSIDERAÇÕES FINAIS: O projeto colabora científica e socialmente tendo em vista que as análises parasitológicas contribuirão para melhoria na vida destes animais silvestres e possibilitarão a prevenção de transmissão destes parasitas para a comunidade local.

\section{REFERÊNCIAS}

BRANDÃO ML, CHAME M, CORDEIRO JLP, CHAVES SAM. Diversidade de helmintos intestinais em mamíferos silvestres e domésticos na Caatinga do Parque Nacional Serra da Capivara, Sudeste do Piauí, Brasil. Rev. Bras. Parasitol. Vet., Jaboticabal, v. 18, supl. 1, p. 19-28, dez. 2009.

COSTA IA, COELHO CD, BUENO C, FERREIRA I, FREIRE RB. Ocorrência de parasitos gastrintestinais em aves silvestres no município de Seropédira, Rio de Janeiro, Brasil. Ci. Anim. Bras., Goiânia. V. 11, n.4, p 914-922, out/dez. 2010.

SANTOS PMS, SILVA SGN, FONSECA CF, OLIVEIRA JB. Parasitos de aves e mamíferos silvestres em cativeiro no estado de Pernambuco. Pesq. Vet. Bras, setembro 2015

PALAVRAS-CHAVE: Aves silvestres; parasita; levantamento; cativeiro. 


\title{
MANUAL FISIOTERAPÊUTICO PARA GESTANTES E PUÉRPERAS: PREVENINDO A INCONTINÊNCIA URINÁRIA
}

\author{
RAFAELA FERREIRA NOGUEIRA*; SARA PEIXOTO ROSA; JONAS ISAC DA ROSA \\ UNIVÁS - Universidade do Vale do Sapucaí
}

Incontinência Urinária (IU) é definida pela Sociedade Internacional de Continência (ICS) como a queixa de qualquer perda involuntária de urina. A prevalência da IU varia entre 23 a $67 \%$ na gestação e 6 a $29 \%$ no pós-parto (PALMA, 2009). O aumento da prevalência durante a gravidez se dá pelo aumento de estresse sobre o assoalho pélvico e no puerpério está muito relacionada aos fatores de risco obstétricos, dentre eles: parto vaginal, uso ou não de fórceps, episiotomia e peso do recém-nascido. Além disso, no período gravídico há um aumento significativo nas concentrações de diversos hormônios, dentre eles, estão a progesterona e a relaxina. A primeira está intimamente ligada ao relaxamento da musculatura lisa e a segunda é a responsável pela diminuição do tônus e força da musculatura do assoalho pélvico (MAP), o que também contribui para a perda urinária durante essa fase. Dessa forma, a gestação atrelada ao parto pode afetar na funcionalidade da MAP e outras estruturas que dão suporte a ela, dando origem as disfunções do assoalho pélvico. O treinamento da MAP, é considerado o tratamento mais relevante, referente à melhoria das escalas de qualidade de vida $(Q V)$ específica da incontinência (MORONI, 2016). O manual fisioterapêutico para gestantes e puérperas: prevenindo a incontinência urinária tem como alvo, implementar métodos e técnicas diferentes, concomitantemente explícitos, para bom entendimento e resolução de suas usuárias, que estarão sozinhas em suas residências. Objetivo: Desenvolver, validar e legitimar um manual fisioterapêutico para gestantes e puérperas: prevenindo a incontinência urinária. Método: Estudo em produção de pesquisa do tipo metodológica, com o uso de revisão sistemática de literatura. Para a elaboração do manual realizou-se uma revisão junto às bases de dados das Ciências da Saúde, como PubMed, SciELO, Medline, PeDRO, Google Acadêmico, além de consultas bibliográficas em livros e teses da área dos últimos 10 anos. Foram contatados, através de e-mail e WhasApp, 30 profissionais, para apreciação e validação do manual. Para análise estatística serão utilizados: Índice de validade de conteúdo de cada item avaliado; para validação será utilizado: Teste de alfa de Cronbach (a $>0,7$ ). O manual auxiliará mulheres gestantes e/ou puérperas, embora não afaste a importância da avaliação funcional do assoalho pélvico, a prevenir a incontinência urinária decorrente da gestação. Além disso, servirá como assistência fisioterapêutica básica, beneficiando mulheres carentes e leigas.

\section{REFERÊNCIAS}

MORONI, Rafael Mendes et al. Tratamento conservador da incontinência urinária de esforço: uma revisão sistemática com meta-análise de ensaios clínicos randomizados. Rev. Bras. Ginecol. Obstet.

, Rio de Janeiro, v. 38, n. 2, pág. 97-111, fevereiro de 2016.

MARTINS, Leticia et al. Prevalência da incontinência urinária em gestantes e puérperas em maternidades públicas. Fisioterapia Brasil, vol. 11, número 5, p. 334- 339, setembro/ outubro, 2010. BARACHO, Elza. Fisioterapia aplicada à saúde da mulher/Elza Baracho. - 6. ed. - Rio de Janeiro: Guanabara Koogan, 2018.

PALAVRAS-CHAVE: Incontinência urinária; Manual; Musculatura do assoalho pélvico; Gestante; Prevenção. 


\title{
MANUAL PARA ORIENTAR O PROFISSIONAL DA SAÚDE NO TRATAMENTO DE ÚLCERA VENOSA
}

\author{
MATHEUS MARTINS PEREIRA*; GERALDO MAGELA SALOMÉ \\ UNIVÁS - Universidade do Vale do Sapucaí
}

Introdução: As úlceras de pernas são consideradas um problema de saúde pública de abrangência mundial, responsáveis por significativos índices de morbidade e mortalidade. Trata-se de uma lesão encontrada abaixo do joelho em qualquer extensão da perna, sendo classificada como ferida crônica, ou seja, uma ferida que se apresenta estagnada por um período de seis semanas ou mais, o que requer uma estruturada intervenção multiprofissional (KELECHI et al., 2020; MEDEIROS et al., 2016; OLIVEIRA et al., 2016). Desta forma, a elaboração de um manual que contenha dados sobre o que é úlcera venosa, como ocorre, seus fatores etiológicos e, principalmente, o tratamento através da cobertura primaria e a terapia compressivo, apresenta significante relevância científica e social, especialmente no ambiente hospitalar, ambulatorial e Estratégia Saúde da Família, pois traz inúmeros efeitos e benefícios à saúde deste grupo de profissionais e pacientes, reduzindo diretamente as complicações e promovendo mais rápido a cicatrização, além de benefícios aos gestores, com menos afastamentos de seus profissionais, redução dos custos com tratamentos, exames e perícias. Objetivo: Construir e validar um manual para profissionais da saúde relacionado ao tratamento da úlcera venosa. Métodos: A pesquisa foi desenvolvida nos meses de junho a setembro de 2021, seguindo as etapas: diagnóstico situacional; revisão da literatura junto às principais bases de dados de Ciências da Saúde; seleção e fichamento do conteúdo; elaboração dos textos; criação das ilustrações; diagramação do manual. Resultados: A versão final do manual "Terapia compressiva: Tratamento úlcera venosa" contém 49 páginas, incluindo a capa, contracapa com a ficha catalográfica, lista de ilustrações, lista de quadros, sumário, prefácio, apresentação, quatro capítulos (Definição de ulcera venosa, Característica de ulcera Venosa, Cobertura utilizada no tratamento de ferida, Terapia compressiva, Índice tornozelo braço e referências bibliográficas), em tamanho padrão de formatação com $21 \mathrm{~cm}$ de altura por $15 \mathrm{~cm}$ de largura. Cada página conta com, no máximo, até cinco ilustrações, totalizando 39 ilustrações. Considerações finais: Após revisão interativa da literatura, foi possível construir manual "Terapia compressiva: tratamento de úlcera venosa", que oferece fundamentação teórica e prática aos profissionais de saúde e contribui para compreensão dos tipos e técnica de terapia compressiva e coberturas primarias utilizados no tratamento da úlcera venosa, que oferece fundamentação teórica e prática aos profissionais de saúde possa realizar uma avaliação do indivíduo com úlcera venosa sistematiza, individualizada e personalizada. Quando este procedimento é realizado corretamente o profissional estará prestando uma assistência com mínimo risco possível, sem danos, uma assistência segura e com qualidade.

\section{REFERÊNCIAS}

Benevides JL, Coutinho JFV, Pascoal LC, Joventino ES, Martins MC, Gubert FA, et al. Development and validation of educational technology for venous ulcer care. Rev Esc Enferm USP. 2016;50(2):306-312. DOI: http://dx.doi.org/10.1590/S0080-623420160000200018.

Pontes BCD, Salomé GM. Booklet on the use of personal protective equipment during the COVID-19 pandemic: preventing facial skin injurie. Fisioter. Mov., 2021, v. 34, e34111 DOI: 10.1590/fm.2021.34111.

PALAVRAS-CHAVE: Úlcera Venosa; Ferimentos e lesões. Terapia compressiva; Bandagem elástica; Bota De Unna. 


\title{
MASTOFAUNA EM FRAGMENTO DE MATA ATLÂNTICA, PORÇÃO SUL DE MINAS GERAIS
}

\author{
ALYSON JOSÉ GONÇALVES DOS SANTOS*; TADEU GOMES DE OLIVEIRA; ALEXANDRE MARTINS \\ COSTA LOPES; ANA BARBARA BARROS
}

UNIVÁS - Universidade do Vale do Sapucaí

INTRODUÇÃO: A Mata Atlântica é um bioma muito variado em seu relevo, com relação a sua diversidade biológica e índices de ameaça, a Mata Atlântica, foi dada como um dos hotspots mundiais, ou seja, uma área que apresenta grande diversidade ecológica portanto uma área importante na qual deve-se manter a biodiversidade. A degradação da Mata Atlântica e a defaunação tem como principal causa atividades antrópicas, levando a extinção local das espécies. Em especial, a classe Mammalia, aparecem dentre os animais mais sujeitos a extinção local em áreas fragmentadas, por necessitarem de uma ampla área de distribuição geográfica, apresentam pouca densidade e de modo direto são acometidos a atividades antrópicas, ainda, estudos realizados afirmam que o Brasil possui a maior abundância de mamíferos de toda região neo-tropical, com cerca de $13 \%$ da mastofauna mundial. A caracterização de uma comunidade de mamíferos, além de fornecer uma ideia melhor da importância biológica da área, fornece subsídios para avaliar o status de conservação das espécies, o que possibilita o desenvolvimento de planos de conservação e manejo da biodiversidade da mastofaunistica. OBJETIVO: Diante disso, com o objetivo de contribuir para o conhecimento da biodiversidade local, este trabalho tem como propósito, inventariar a fauna de mamíferos de médio e grande porte, ocorrentes no Parque Natural Professor Fernando Afonso Bonillo, afim de atualizar a lista de espécies da unidade de conservação, e assim poder estabelecer estratégias de conservação para a fauna de mamíferos no local. METODOLOGIA: Foram implantadas 2 transectos de amostragem lineares dentro do parque. Ao longo de cada transecto foram determinados pontos de amostragem georreferenciados definidos como pontos estratégicos para captura fotográfica dos animais, esses pontos eram preestabelecidos mediante a fatores físicos e biológicos que poderiam influenciar a ocorrência dos mamíferos no local, tais como, latrinas, pontos de forrageio, tocas, trilhas de fauna e locais de dessedentação. Foram colocadas 3 armadilhas fotográficas do modelo Bushnell, dentro de cada transecto. Mediante aos fatores que influenciariam os registros, não foi estabelecido uma metragem fixa de uma câmera a outra, somente levando em consideração os fatores de influência, mas, sendo respeitado um limite mínimo para que não houvesse uma taxa influente de sobreposição de espécies já registradas. As armadilhas eram checadas em um intervalo de 30 dias. RESULTADOS/DESENVOLVIMENTO: Foram registradas 24 espécies de mamíferos na área de estudo distribuídas em 6 ordens e 15 famílias, sendo 20 espécies de mamíferos de médio e grande porte e 4 de pequenos mamíferos. Destas, 20 espécies foram registradas por armadilhas fotográficas, seis por contato visual e uma espécie foi registrada por vocalização. A maior abundância foi da ordem Carnivora, com $42 \%$ da representatividade dos registros, seguida de Rodentia com $21 \%$, Cingulata com $18 \%$, Primates e Didelphimorphia com 8\%. CONSIDERAÇÕES FINAIS. O conhecimento sobre a diversidade de espécies em Unidades de Conservação ou outras áreas contínuas é fundamental para tomadas de decisões e elaboração de propostas conservacionistas, bem como para o entendimento de padrões ecológicos e de distribuição das espécies Os resultados obtidos, principalmente com relação à presença de espécies raras ou ameaçadas, atestam a importância da área de estudo para a conservação destas espécies.

\section{REFERÊNCIAS}

BÔLLA, Daniela Aparecida S. et al. Mastofauna terrestre do sul de Santa Catarina: mamíferos de médio e grande porte e voadores. Tecnologia e Ambiente, v. 23, p. 61-78, 2017.

CHEREM, J. J.; ALTHOFF, Sérgio Luiz. Mamíferos de uma área de ecótono entre floresta estacional decidual e floresta ombrófila mista no estado de Santa Catarina, sul do Brasil. Boletim da Sociedade Brasileira de Mastozoologia, v. 84, p. 1-11, 2019.

GRAIPEL, M. E. et al. Características associadas ao risco de extinção nos mamíferos terrestres da Mata Atlântica. Oecologia Australis, Florianópolis. v. 20, n. 1, p. 81-108. Jan. 2016.

PALAVRAS-CHAVE: Conservação; Mastofauna; Mata Atlântica; 


\title{
MULTISENSE NO EXAME NEUROLÓGICO PERIFÉRICO EM DIABÉTICOS
}

\author{
MARIA VITÓRIA SOUZA ROSA*; BEATRIZ BERTOLACCINI MARTÍNEZ; BRUNO TAVARES VALE; \\ BRUNO TAVARES VALE; BEATRIZ BERTOLACCINI MARTÍNEZ \\ UNIVÁS - Universidade do Vale do Sapucaí
}

INTRODUÇÃO: Polineuropatia periférica (PNP) é uma das principais complicações crônicas do diabetes mellitus (DM) e representa a principal causa de amputação não traumática de membros inferiores (MMII). Neste contexto, o exame neurológico periférico (ENP) é importante na prevenção desta complicação. O método tradicional para a realização do ENP se dá com quatro aparelhos distintos: monofilamento, para avaliação da sensibilidade protetora; diapasão na pesquisa da sensibilidade vibratória; martelo, para a sensibilidade reflexa e tubo de vidro com água, para sensibilidade térmica. O Multisense foi um aparelho desenvolvido no Mestrado Profissional em Ciências Aplicadas à Saúde (MPCAS) da UNIVÁS, com o objetivo de juntar os quatro aparelhos em um único, para otimizar o ENP. O seu pedido de patente encontra-se registrado no Instituto Nacional da Propriedade Industrial (INPI) sob o no BR 102019012541 1. OBJETIVO: Comparar o Multisense ao método convencional no ENP em pacientes diabéticos. MÉTODOS: Pesquisa aprovada pelo Comitê de Ética em Pesquisa da UNIVÁS sob parecer CAAE 91923018.8.0000.5102. Estudo primário do tipo teste diagnóstico, realizado no período de janeiro de 2019 a dezembro de 2020 no Centro Municipal de educação em Diabetes (CEMED) e na Unidade de Atenção Primária São João (UNIVÁS). Foram critérios de inclusão: ter 18 anos ou mais; ser portador de DM tipo 1 ou 2, independente do tempo; não apresentar lesões ou amputações em membros inferiores; assinar o Termo de Consentimento Livre e Esclarecido. Os pacientes foram submetidos, simultaneamente, aos exames com o Multisense e o método convencional e os resultados foram comparados entre si. Para as características dos participantes foi realizada estatística descritiva. Os resultados dos escores dos exames foram analisados através da concordância e confiabilidade por meio do cálculo do coeficiente de Kappa $(\mathrm{Kp})$ : valores de $\mathrm{Kp}>$ que 0,80 caracterizaram excelente concordância, entre 0,60 e 0,79 indicam alta concordância, entre 0,40 e 0,59 média concordância e abaixo de 0,39 baixa concordância. Os resultados dos tempos de exames foram expressos através de média \pm desvio padrão e foi utilizado o Teste de Student para a comparação. Foi adotado $p<0,05$ para a rejeição da hipótese de nulidade. Para a análise estatística utilizou-se o software Statistical Package for the Social Sciences (SPSS). RESULTADOS: 49,2\% dos participantes eram do sexo feminino; a mediana de idade foi de 67 anos (mínimo 44 anos e máximo 86 anos); $91,7 \%$ dos participantes tinham 10 ou mais anos de DM. O teste $\mathrm{Kp}$ demonstrou concordância maior do que 0,80 em todos os testes de pesquisa de sensibilidade. O tempo de exame, em minutos, com - Multisense foi menor do que com o método convencional $(1,5 \pm 0,3$ vs $5,2 \pm 0,3 ; p<0,0001)$. CONCLUSÃO: Houve concordância e confiabilidade nos testes realizados com o Multisense, comparados ao método convencional. O tempo de exame com o Multisense foi menor do que o tempo do método convencional

\section{REFERÊNCIAS}

Pop-Busui R, Boulton AJ, Feldman EL, Bril V, Freeman R, Malik RA et al. Diabetic neuropathy: a position statement by the American Diabetes Association. Diabetes Care. 2017;40(1):136-54.

Truini A, Cruccu G. How diagnostic tests help to disentangle the mechanisms underlying neuropathic pain symptoms in painful neuropathies. Pain. 2016;157(Suppl 1):S53-9.

PALAVRAS-CHAVE: neuropatias diabéticas, exame neurológico, técnicas e procedimentos diagnósticos, patentes, inovação tecnológica 


\title{
NÍVEL DE ATIVIDADE FÍSICA, ESTADO NUTRICIONAL E SÍNDROME METABÓLICA EM POLICIAIS MILITARES DE POUSO ALEGRE - MG
}

\author{
GABRIELLY APARECIDA SILVEIRA REZENDE*; CAMILA BLANCO GUIMARÃES \\ UNIVÁS - Universidade do Vale do Sapucaí
}

Introdução: O presente estudo consistiu na análise do estado nutricional dos policiais militares de uma cidade do Sul de Minas Gerais - MG, bem como sua correlação com os hábitos alimentares dos mesmos e seus níveis de atividade física. Além de verificar ainda parâmetros de síndrome metabólica, possivelmente presentes nestes policiais. Objetivos: Investigou aspectos relacionados à qualidade de vida, associadas ao nível de atividade física, estado nutricional e síndrome metabólica dos policiais militares de uma cidade do Sul de Minas Gerais - MG. Metodologia: A pesquisa foi de campo, descritiva, transversal e quantitativa, avaliada através dos questionários socioeconômico e Internacional de atividade física, fez-se a aplicação do dia alimentar habitual e do cálculo energético, bem como a distribuição de macronutrientes das dietas para avaliar o consumo ingerido por eles. Foram empregadas as medidas antropométricas peso, estatura e circunferências. A amostra foi obtida por policiais militares utilizando todas as categorias, de ambos os sexos, com idade maior ou igual 18 anos e menor de 60 anos de idade e que assinaram o Termo de Consentimento Livre e Esclarecido. Resultados: Foi possível observar que $34,15 \%$ comiam fora de casa uma vez por semana; $60,97 \%$ faziam o uso de bebidas alcoólicas; $70,73 \%$ dos participantes da pesquisa relataram ausência de patologia; $17,07 \%$ dos policiais militares estavam muito ativos de acordo com o critério $A ; 24,39 \%$ apresentaram-se ativos de acordo com o critério A; e $14,63 \%$ estavam irregularmente ativo de acordo com o critério B; pôde-se observar que 43,91\% consumiam mais carboidrato, seguido de proteína e o lipídeo com menor quantidade; em relação ao consumo de calorias de acordo com a taxa metabólica basal, foi possível observar que 39,02\% consumiam valores inferiores ao recomendado segundo Harris-Benedict, e $60,98 \%$ dos participantes da pesquisa consumiam valores superiores ao recomendado; $24,39 \%$ dos indivíduos pesquisados encontravam-se com o IMC adequado, $65,85 \%$ estavam com sobrepeso e $9,76 \%$ possui obesidade grau I. Com relação ao risco de desenvolver doenças cardiovasculares, $51,22 \%$ encontravam-se com baixo risco; 39,02\% estavam com risco moderado; $7,32 \%$ apresentaram alto risco e 2,44\% encontrava-se em risco muito alto; ao avaliar o risco de complicações metabólicas por meio da circunferência abdominal (CA), foi observado que $43,91 \%$ encontravam-se sem risco; $17,07 \%$ com risco médio; $24,39 \%$ com risco alto e $14,36 \%$ com risco altíssimo; Conclusão: Os participantes apresentaram fatores que podem comprometer sua saúde, podendo estar relacionado a isso a significativa porcentagem de sobrepeso, indicando que todos os PMs apresentaram risco de desenvolver doenças cardiovasculares, mesmo sendo a maior porcentagem considerada de baixo risco. O risco de complicações metabólicas através da circunferência abdominal foi elevado. Os hábitos alimentares da maioria dos PMs quanto aos macronutrientes foi de encontro com o recomendado pelas DRIs, em relação ao consumo de calorias a maioria dos PMs consumiam valores superiores aos recomendados, ressalta-se que não foi calculado o fator de atividade desses profissionais. O percentual de PMs muito ativos e ativos foi maior que o percentual de PMs irregularmente ativos. A maioria dos PMs muito ativos apresentaram baixo risco de desenvolver doenças e sem risco para complicações metabólicas.

\section{REFERÊNCIAS}

BARBOSA, Y. L. B. Qualidade de vida e nível de atividade física de policiais militares ativos e sedentários:

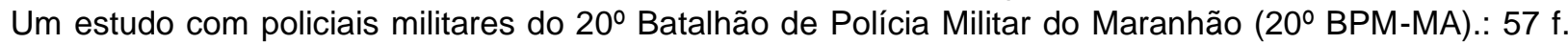
Monografia - Universidade Federal do Maranhão, São Luís, 2019.

CAETANO, H. B. S.; CAETANO, C. I.; LÓPEZ-GIL, J. F.; CAVICHIOLLI, F. R.; PAULO, A. C. Ingestão de lipídios e risco à saúde baseado em diferentes indicadores antropométricos em policiais militares de Curitiba, Paraná. Revista Ciência em Saúde, v. 9, n. 4, p. 21-27, 2019.

PALAVRAS-CHAVE: Policiais Militares. Estado Nutricional. Atividade física. Síndrome metabólica. 


\title{
O CAMAROTE DAS PRINCESAS: A LEGITIMAÇÃO VISUAL DO LUGAR DA MULHER NA COROAÇÃO DE DOM PEDRO II DE MANUEL DE ARAÚJO PORTO-ALEGRE
}

\author{
JÚLIA KLEHM FERMINO*; RAFAEL LAZZAROTTO SIMIONI \\ Faculdade de Direito do Sul de Minas - FDSM/ UNIVÁS - Universidade do Vale do Sapucaí
}

INTRODUÇÃO: Este trabalho analisa a relação entre arte, direito e o lugar da mulher na pintura da Coroação de Dom Pedro II (1845), de Manoel de Araújo Porto-Alegre. Isoladas em um camarote privativo, a pintura dialoga com a tradição figurativa dos cerimoniais políticos do século $\mathrm{XIX}$, nos quais o espaço para a presença da mulher no cenário político é de distanciamento e contemplação passiva. Passados quase duzentos anos, os camarotes privativos dos cerimoniais do Império continuam a simbolizar o espaço de exceção situado entre a oikos e a polis, sob o qual se pode pensar na (im)presença da mulher nos espaços políticos do Estado brasileiro. METODOLOGIA: Como metodologia, utilizamos a forma de observação de segunda ordem, desenvolvida no âmbito da teoria dos sistemas sociais autopoiéticos de Niklas Luhmann. O conceito de forma permite entender e reconstruir o sentido como diferença entre identidade e diferença. Uma unidade analítica autológica, que oportuniza a observação das formas pictóricas como formas de comunicação baseadas em presenças e ausências, em formas indicadas e suprimidas que, exatamente por isso, permitem entender a imagem não apenas pelo que ela mostra, mas também pelo que ela, sob as margens do seu enquadramento, cuidadosamente esconde. RESULTADOS/DESENVOLVIMENTO: Foi realizada uma interpretação jurídica das relações iconográficas pensadas por Porto-Alegre para a pintura da Coroação de Dom Pedro II, especialmente a partir do diálogo entre ela e as pinturas da Coroação de Dom Pedro I e da Aclamação de Dom João VI, ambas do seu professor, Jean-Baptiste Debret. Essa reconstrução visual dos espaços de ocupação da mulher na arte política da primeira metade do século XIX permitiu discutir, sob uma perspectiva jurídica, a forma contemporânea dos camarotes imperiais. CONCLUSÃO: O camarote das princesas do Império do Brasil permanece no contexto político das atuais democracias constitucionais. No caso da política do Brasil contemporâneo, a obrigatoriedade de mulheres, através das chamadas cotas de gênero, revela a violência simbólica da sua (im)presença nesse meio: estão lá, mas suas ideias são menosprezadas; figuram no cenário político, mas suas vozes são pouco ouvidas. Os camarotes privativos da oikos sobrevivem nos espaços políticos dos Estados contemporâneos, inclusive nas democracias constitucionais.

\section{REFERÊNCIAS}

HOOKS, Bell. O feminismo é para todo mundo: políticas arrebatadoras. Rio de Janeiro: Rosa dos Tempos, 2018.

LERNER, Gerda. A criação do patriarcado: história da opressão das mulheres pelos homens. São Paulo: Cultrix, 2019.

LUHMANN, Niklas. El arte de la sociedad. Tradução de Javier Torres Nafarrate. México: Herder Editorial e Universidad lberoamericana, 2005.

PALAVRAS-CHAVE: Arte; Direito; Manuel de Araújo Porto-Alegre; Feminismo; Igualdade. 


\title{
O MANUAL “METODOLOGIA DA MATEMÁTICA” DE IRENE DE ALBUQUERQUE (1954): UM ESTUDO DA ARITMÉTICA
}

\author{
ELANIA KELLY DE ARAUJO SOUSA*; ELANIA KELLY DE ARAÚJO SOUSA; ROSIMEIRE APARECIDA \\ SOARES BORGES; ROSIMEIRE APARECIDA SOARES BORGES \\ UNIVÁS - Universidade do Vale do Sapucaí
}

A professora Irene de Albuquerque nasceu no Rio de Janeiro, no ano de 1915, e deixou marcas de sua atuação profissional, no período de 1940 a 1960, como professora na escola primária e na Escola Normal no Instituto de Educação do Distrito Federal, além de ser autora de livros que foram relevantes para a formação dos docentes. Esta pesquisa teve como objetivo analisar as contribuições dessa educadora, como uma expert, para a constituição dos saberes docentes relativos à disciplina matemática, com foco na formação profissional do professor que ensinava essa disciplina. Trata-se de um estudo histórico que teve como referencial teórico-metodológico estudos recentes que abordam saberes profissionais docentes, dentre os quais, Hofstetter e Schneuwly (2017), para quem o saber a ensinar constitui-se no objeto empregado no trabalho do professor e o saber para ensinar transforma esse objeto em ensinável, podendo ser utilizado como instrumento de trabalho docente. A conceituação de expert está fundamentada em Almeida e Valente (2019), segundo os quais, é a expertise reconhecida de um personagem que o eleva à condição de expert, e, essa elevação contribui para o desenvolvimento da própria expertise, em relação à produção de novos saberes que são legitimados pelas funções e cargos exercidos por esse expert. Como fontes essenciais deste estudo foram eleitos o manual "Metodologia da Matemática", de 1954, de autoria dessa professora, bem como estudos que investigaram suas contribuições como elementos constituintes para e a educação. Como resultados, as análises do referido manual mostraram que são diversificadas as orientações apresentadas por essa autora, sobre conteúdos matemáticos e metodologias de ensino, saberes para ensinar Matemática, que esses alunos da escola Normal deveriam estudar para uma futura atuação como professores da escola primária. As análises dos estudos sobre as contribuições dessa professora para a educação, possibilitam afirmar que ela se destacou nesse período, por sua expertise, por meio de suas ações, pelos saberes específicos adquiridos em sua experiência como decente e pelos saberes científicos que adquiriu em seus estudos no Brasil e nos Estados Unidos da América, o que possibilitou-lhe atuar em palestras e comissões de ensino, conceder entrevistas, e o assessoramento em órgãos oficiais, além de coordenação de cursos de formação de professores. Entende-se assim, que a atuação dessa professora em diversas funções e suas orientações veiculadas para os professores e alunos normalistas, por meio das obras que publicou, revelaram que suas ações são características de uma expert, no que tange à constituição de saberes objetivados, que resultam da integração dos saberes a ensinar, provenientes da ciência de referência, com os saberes para ensinar, que têm seu lugar no campo profissional. Desta maneira, entende-se que a expertise de Irene de Albuquerque foi sendo constituída no campo pedagógico, e contribuiu para a matemática por meio da objetivação dos saberes dessa disciplina, haja vista que os saberes produzidos por experts se decantam e são reelaborados pelo fato de deterem aspectos próprios do ofício de ser professor.

\section{REFERÊNCIAS}

ALBUQUERQUE, Irene de. Metodologia da matemática. 1 ed. Rio de Janeiro: Editora Conquista, 1954. ALMEIDA, André Francisco de; VALENTE, Wagner Rodrigues. R. Os experts e a produção de saberes para docência: primeiros estudos do acervo Lydia Lamparelli. Linhas Críticas, Brasília, v. 25, p.318-332, 2019. Disponível em: https://periodicos.unb.br/index.php/linhascriticas/article/view/23109. Acesso em: 7 out. 2021. HOFSTETTER, Rita; SCHNEUWLY, Bernard. Saberes: um tema central para as profissões do ensino e da formação. In: HOFSTETTER, Rita; VALENTE, Wagner Rodrigues (org.). Saberes em (trans)formação: tema central da formação de professores. 1 ed. São Paulo: Editora Livraria da Física.

PALAVRAS-CHAVE: Irene de Albuquerque; Expert; Manual de didática; Saberes objetivados; Formação de professores. 


\title{
O QUE A DEPRESSÃO E O SUICÍDIO (C)FALAM ATARVÉS DA PSICANÁLISE E A CANÇÃO "DESCONSTRUÇÃO" DE TIAGO IORC
}

\author{
BRUNA KITÉRIA MOREIRA PAIVA*; ATÍLIO CATOSSO SALLES \\ UNIVÁS - Universidade do Vale do Sapucaí
}

INTRODUÇÃO:O suicídio conforme encontramos no Ministério da Saúde (2009) é um "fenômeno complexo, multifacetado e de múltiplas determinações, que pode afetar indivíduos de diferentes origens, classes sociais, idades, orientações sexuais e identidades de gênero". Para Durkheim (1897/2000) diz que os aspectos que explicam o suicídio não estão necessariamente localizados no individuo, e sim na sociedade.E quando Kehl (2015) afirma que a depressão também torna-se um sintoma social contemporâneo que de converge para um mal-estar histórico como a histeria foi para a sociedade européia no século XXI, representando hoje uma das principais maneiras de adoecimento e sofrimento humano que podem ainda levar ao comportamento suicida. Desta forma, a pesquisa traz a discussão o suicídio e a depressão como fenômenos sociais e não só um ato individual de responsabilidade do sujeito, utilizando da análise e reflexão com embasamento na teoria Psicanalítica em correlação com a canção popular brasileira "Desconstrução" do autor e cantor Tiago lorc. Se mostrando relevante a partir dos altos índices de diagnósticos de depressão e comportamentos suicidas que ferem e demandam ações políticas, em que se precisa promover meios de fala, de abertura, oportunidades de debate para produção de reflexões críticas e assertivas.METODOLOGIA:É desenvolvido um estudo de abordagem qualitativa, de natureza aplicada, explicativa e procedimento bibliográfico, tendo a abordagem psicanalítica como embasamento de reflexão e compreensão que norteia a pesquisa nas suas proposições, interpretações e análises dos resultados na correlacionando com a canção popular brasileira "Desconstrução" do autor e cantor Tiago lorc, como uma ferramenta proeminente e fecunda para falar abertamente do que por vezes tenta-se esconder ou calar na voz do outro sobre a depressão e o suicídio. RESULTADOS/DESENVOLVIMENTO: Segundo Lacan (1962-1963/2005) a partir da perspectiva freudiana que traz o suicídio articulado aos conceitos de ato psicanalítico, angústia e de objeto, contribui quando fala do ato suicida como a sobreposição do gozo da morte contra o desejo de saber, como único ato humano que pode classificar como bem-sucedido contestando o ato falho. Não é suficiente só falar sobre o suicídio, contudo é essencial discutir com seriedade suas causas, trazendo à tona o que a tempo Marx (1846/2006, p. 44) já exortava "A classificação das diferentes causas do suicídio deveria ser a classificação dos próprios defeitos de nossa sociedade". CONSIDERAÇÕES FINAIS:O indivíduo e o sujeito do ato e comportamento suicida, muitas vezes sem voz a priori e posteriori, no que tange seu sofrimento, necessita que existam reflexões e questionamentos sobre sua responsabilidade única do fato, trazendo a realidade à responsabilidade compartilhada também no social. A contribuição da pesquisa apresenta para a sociedade como um todo, a discussão da questão de saúde pública da depressão e suicídio como fenômenos sociais e não como transtorno mental e desequilíbrio emocional somente. Assim como demonstrado na canção, percebe-se como o sujeito por vezes sofre isoladamente, assumindo para si toda a responsabilidade do comportamento e ato suicida, sem espaços para falar de si, dizer de si e ainda desconsiderando a possibilidade de luta compartilhada e ajuda eficaz de políticas públicas, já que como se discute, o sujeito se vê sem outras opções de saída àquilo que a própria sociedade o impõe e exige como norma de vida ou de morte.

\section{REFERÊNCIAS}

KEHL, M. R. O tempo e o cão, a atualidade das depressões. $2^{\mathrm{a}}$ ed., São Paulo, Boitempo, 2015. LACAN, J. (2005). O seminário, livro 10: a angústia. Rio de Janeiro, RJ: Jorge Zahar. (Obra original publicado em 1962-1963)

MARX, K. (2006). Sobre o suicídio (R. Enderle \& F. Fontanella, trad.). São Paulo, SP: Boitempo. (Obra original publicado em 1846)

PALAVRAS-CHAVE: Depressão, Suicídio, Psicanálise, Canção Desconstrução 


\title{
XVIII Congresso de Iniciação Científica
}

UNIVÁs | 2021

\section{OS DIGITAL INFLUENCERS E O (SEU) DISCURSO DE MODA NO YOUTUBE}

\author{
LUARA ELISA SIMÕES OLIVEIRA*; ATILIO CATOSSO SALLES \\ UNIVÁS - Universidade do Vale do Sapucaí
}

INTRODUÇÃO: Na perspectiva da Análise de Discurso, analisamos o funcionamento do discurso de moda por posições sujeito Digital Influencer no YouTube. Foi problematizado como a palavra 'Digital Influencer' vem sendo significada e como são colocados em evidência determinados sentidos de "moda" a serem seguidos, de modo que questionamos: Como são produzidos os sentidos de 'moda' e os efeitos de sentido produzidos pelos Digital Influencer? O presente Projeto de Iniciação Científica teve como objetivo compreender como se constituem os discursos dos Digital Influencer e como alguns sentidos e não outros, de moda, produzidos na posição sujeito Digital Influencer se inscrevem na discursividade do Youtube enquanto uma referência a ser seguida. O termo Digital Influencer tem sido usado para definir o "usuário" que alcança um grande número de seguidores de qualquer rede social (Facebook, YouTube, Twitter, blogs, Instagram) e passa a ser seguido não apenas com visualizações, mas com fortes identificações com as suas posições. METODOLOGIA: A perspectiva teórico-metodológica que fundamenta essa Pesquisa de Iniciação Científica é a Análise de Discurso, fundada por Michel Pêcheux (1969) na França e por Eni Orlandi (1983) no Brasil. Fazendo uso da metodologia qualitativa e descritiva, baseando-se em um levantamento bibliográfico de qualidade e fazendo uso de material de vídeos publicados no YouTube, por Digital Influencers, foi possível desenvolver uma análise sobre o tema. DESENVOLVIMENTO: Segundo Orlandi (2012), a língua é o lugar material em que se realizam os efeitos de sentido, ou seja, a língua é a materialidade específica do discurso e o discurso é a materialidade específica da ideologia (Pêcheux, 1988). Tendo como base os estudos sobre a língua e seus efeitos de sentido, que a Análise de Discurso nos possibilita, foi possível analisar como alguns discursos de moda e não outros, conseguem chamar a atenção dos espectadores, fazendo com que os mesmos atribuam aquele estilo de moda e passam a seguir continuamente os discursos proferidos pelos Digital Influencers. CONCLUSÃO: Há um processo de produção de sentidos determinado pelo próprio modo de produção de um vídeo a ser postado (montagem de roteiro, de assunto, da fala, da roupa e do carisma para chamar a atenção do público jovem), que vai desde o projeto de gravação até para além da adesão de seguidores no YouTube. Diante dessa problemática, com esta pesquisa foi possível compreender como a circulação de determinados sentidos de "moda" determinam as nossas relações sociais hoje, em especial, na fabricação de um "consenso" (Orlandi, 2010) por uma imagem de um Digital Influencer, impulsionada pelas evidências produzidas na mídia e por sentimento relacionado àquela imagem, na/pela ordem do digital.

\section{REFERÊNCIAS}

ADORNO, Guilherme. Discursos Sobre o Eu na Composição Autoral dos Vlogs. 2015. Tese (Doutorado em Linguística) - Tese (Doutorado em Linguística) - Instituto de Estudos da Linguagem. Universidade Estadual de Campinas.

ORLANDI, Eni de Lourdes Puccinelli. Discurso e Leitura. Campinas, SP: Cortez, [1988] 2011. ORLANDI, Eni de Lourdes Puccinelli. Discurso em Análise:- Sujeito, Sentido, Ideologia. 1. ed. Campinas: Pontes, 2012.

PALAVRAS-CHAVE: Análise de Discurso, Digital Influencers, Moda, Tecnologia, YouTube 


\title{
PADRONIZAÇÃO DO MÉTODO DE COLORAÇÃO HISTOQUÍMICA UTILIZANDO TANINOS OBTIDOS DE RESÍDUOS DA MADEIRA DE EUCALIPTO
}

\author{
SUZANA CRISTINA DA SILVA*; RODRIGO MACHADO PEREIRA \\ UNIVÁS - Universidade do Vale do Sapucaí
}

INTRODUÇÃO: Diversas estruturas das células e dos tecidos são pouco visíveis ao microscópio óptico pelas técnicas histológicas convencionais. Deste modo, são necessárias reações citoquímicas específicas, que geram pigmentos que se ligam às estruturas, tornando-as evidentes à microscopia de luz (Junqueira e Carneiro, 2013). A técnica centenária de Mayer foi desenvolvida utilizando ácido tânico e sais de ferro. Esta técnica consiste na capacidade de taninos se ligarem a proteínas, e posteriormente, serem evidenciados pelos íons férricos (Mayer, 1897). Em resultados anteriores, foi demonstrado o uso de taninos obtidos da madeira de eucalipto para reação histoquímica, que provavelmente, evidencia fibras elásticas (Silva e Pereira, 2019) OBJETIVO: Neste estudo, buscou-se padronizar o melhor método de obtenção de taninos de resíduos da madeira de eucalipto e aplicação em reação histoquímica para identificação de fibras elásticas. METODOLOGIA: Lascas e fragmentos obtidos do processamento da madeira de eucalipto foram secos e triturados. Para padronizar o melhor método de extração de taninos, diferentes solventes foram adotados: água destilada (A), solução de $\mathrm{Na} 2 \mathrm{CO} 3$ (B) e etanol $50 \%$ (C). A extração foi realizada com misturas de 30 gramas de pó de madeira e $300 \mathrm{ml}$ de solvente submetidas a aquecimento com refluxo, resfriadas e filtradas para obtenção dos extratos. $\mathrm{O} \mathrm{pH}, \mathrm{o}$ total de extrativos, $\mathrm{O}$ teor de fenóis totais (f) e a concentração de taninos (t) foi avaliada. Com base nestes resultados, o melhor extrato foi utilizado para reação histoquímica proposta. Cortes histológicos de órgãos de rato (pele,

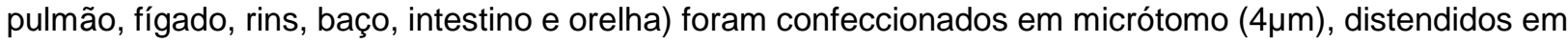
lâminas de microscopia, desparafinizados e hidratados (via xilol-álcool-água). Os cortes receberam o extrato de eucalipto (10 min.), foram lavados em água destilada (1 min.) e tratados com solução de cloreto férrico a 10\% (1 min.) para reação com os taninos. Foram contracorados com hematoxilina de Harris, hematoxilina-eosina ou simplesmente montados sem contracoloração. Os três tipos de colorações foram analisadas ao microscópio óptico explorando as estruturas evidenciadas. Como controle de coloração de fibras elásticas, também foram coradas lâminas pela técnica de Verhoeff. RESULTADOS: O método de extração alcalina em $\mathrm{Na} 2 \mathrm{CO} 3$ (B) obteve maior teor de extrativos sólidos $(7,58 \%, \mathrm{pH}=10,53)$, comparado às outras extrações ( $\mathrm{A}: 0,43 \%, \mathrm{pH}=3,82 ; \mathrm{C}: 1,06 \%, \mathrm{pH}=4,64)$. Porém, o extrato hidroetanólico (C) apresentou concentração superior de fenóis e taninos ( $f=6,044 \mathrm{mg} / \mathrm{mL}, t=1,124 \mathrm{mg} / \mathrm{mL}$ ) em relação aos demais $(A: f=2,726 \mathrm{mg} / \mathrm{mL}, t=0,668 \mathrm{mg} / \mathrm{mL} ; B: f=4,402 \mathrm{mg} / \mathrm{mL}, t=0,672 \mathrm{mg} / \mathrm{mL}$ ). Neste sentido, o extrato $\mathrm{C}$ foi eleito para a reação histoquímica. Pelas lâminas preparadas apenas com a reação, foi observado uma coloração acinzentada discreta da maioria das estruturas celulares e teciduais. Em cortes de pulmão, as lâminas elásticas de vasos arteriais apresentaram destaque acentuado (cinza escuro). Comparandose a mesma região em lâminas coradas por Verhoeff, foi possível comprovar a capacidade do método histoquímico proposto em destacar fibras elásticas. CONSIDERAÇÕES FINAIS: Contudo, foi comprovado que os taninos obtidos da madeira de eucalipto podem ser utilizados para realização de uma reação histoquímica que permite destacar fibras elásticas. Para tanto, a extração dos taninos em etanol $50 \%$ é o método mais eficiente.

\section{REFERÊNCIAS}

JUNQUEIRA, L. C.; CARNEIRO, J. Histologia Básica. 12 ed. Rio de Janeiro: Guanabara Koogan, 2013. MAYER, P. Über den Spiraldarm der Selachier. Mitt. Zool. Stat. Neapel, v. 12, p. 749-754, 1897. SILVA, S. C; PEREIRA, R. M. Desenvolvimento de metodo histoquimco para identificação de fibras elasticas. In: ANAIS ELETRONICOS DO XVI CONGRESSO DE INICIAÇÂO CIENTIFICA E V FEIRA

DE CIENCIAS E TECNOLOGIA DA UNIVAS, 2019, Pouso Alegre. Anais eletrônicos... Pouso Alegre: $8^{\circ}$ ed, 2019. $\quad$ p. $238 \quad-\quad$ 239. Disponível em:

https://www.univas.edu.br/docs/2018/pesquisa/iniciacaoCientifica/publicacoes/anais16.pdf. Acesso em: 12 out. 2021.

PALAVRAS-CHAVE: histoquímica, elastina, taninos, eucalipto. 


\title{
XVIII Congresso de Iniciação Científica
}

\section{PANCREATITE PTH DEPENDENTE}

\author{
ISABELLA STEPHANIE SIMÕES*; RUBIA PINHEIRO; JORGE LUIZ DE CARVALHO MELO \\ UNIVÁS - Universidade do Vale do Sapucaí
}

RESUMO: A pancreatite cuja etiologia é a Hipercalcemia não está dentre as mais frequentes, no entanto uma vez diagnosticada a causa de tal desordem metabólica, essa deve ser além de tratada com hidratação vigorosa, furosemida após hidratação e bifosnatos, tendo como opção terapêutica também glicocorticoides e até hemodiálise em casos selecionados. Deve-se ainda buscar compreender a etiologia precursora da hipercalcemia. INTRODUÇÃO: A grande maioria, $90 \%$ dos casos, de hipercalcemia, tem como causa Hiperparatireoidismo primário ou tumor maligno (Sindrome paraneoplasica). A malignidade gera ainda anemia e perda de peso associados. A historia clinica é uma ferramenta muito importante para auxiliar na distinção entre o hiperparatireoidismo primário e o tumor maligno com hipercalcemia associada. Para realizar o diagnostico diferencial entre essas duas comorbidades é necessário dosar o paratormonio sérico (PTH), no hiperparatireoidismo primário ele está normal ou aumentado, PTH dependente. Na doença maligna é definida como PTH independente. No entanto raramente o PTH pode estar elevado na malignidade, como em caso de Carcinoma de paratireoide. OBJETIVOS: Objetivo do presente trabalho é apresentar um caso clinico de uma pancreatite cuja etiologia se dá por hipercalcemia, essa secundária a provável Carcinoma de Paratireoide, atentando para seu diagnóstico. METODOLOGIA: Revisão de prontuário, entrevista com o paciente, registro de métodos diagnósticos e revisão de literatura. CASO CLINICO: Homem, 70 anos, com quadro de pancreatite aguda Baltazar e decorrente de Hipercalcemia (Ca 14,1), associado perda ponderal de $30 \mathrm{Kg}$ em 3 meses, doença renal cronica e anemia. Durante propedeutica complementar encontrada PTH 2.490 e nódulo em paratireoide. Realizada TC de torax que evidenciou derrame pleural bilateral, nódulos pulmonares de aspecto secundário, medindo cerca de $2,6 \mathrm{~cm}$ basal a direita. Após melhora clinica paciente recebe alta com pedido de Ressonância magnética e seguimento ambulatorial. CONCLUSÃO: Dentre as etiologias mais comuns de pancreatite aguda estão biliar e alcoolica, nessa ordem, porém uma vez descartas um leque de possibilidades se abre, dentre elas a Hipercalcemia, desordem metabólica cuja maioria dos casos se associa ao Hiperparatireoidismo primário ou tumores malignos. Como propedêutica complementar em vigência de hipercalcemia o próximo passo é ver se a desordem é PTH dependente ou independente. A maioria dos PTH dependentes se deve ao hiperparatireoidismo primário, no entanto o Carcinoma de paratireoide é um importante diagnóstico diferencial que deve ser recordado e buscado, para que possa haver intervenção o mais precocemente possível. Já que a hipercalcemia sintomática frequentemente se manifesta quando a doença já está avançada.

\section{REFERÊNCIAS}

MORIMITSU, Lilian K. et al. Carcinoma de paratiróide: características clínicas e anátomo-patológicas de cinco casos. Sociedade Brasileira de Endocrinologia e Metabologia, Scielo, 29 jun. 2001. DOI https://doi.org/10.1590/S0004-27302001000200006. Disponível em: https://www.scielo.br/j/abem/a/txrXTMvLP9DxWhqrJsB8wRg/?lang=pt. Acesso em: 8 maio 2021. PROSPERO, José Donato et al. Paratireóides: estrutura, funções e patologia. Acta Ortopédica Brasileira, Scielo, 2 jun. 2009. DOI https://doi.org/10.1590/S1413-78522009000200011. Disponível em: https://www.scielo.br/j/aob/a/zsqhCFNLbTsM6n5yXfhnSzf/?lang=pt\#. Acesso em: 15 maio 2021

PALAVRAS-CHAVE: Pancreatite, hipercalcemia, PTH 


\title{
PERCEPÇÃO DOS FAMÍLIARES DE DEPENDENTES QUIMICOS SOBRE O TRATAMENTO NO CENTRO DE ATENÇÃO PSICOSSOCIAL- CAPS AD
}

\author{
FERNANDA DE SOUZA NUNES; RITA DE CÁSSIA PEREIRA \\ UNIVÁS - Universidade do Vale do Sapucaí
}

INTRODUÇÃO: Tendo em vista que o modelo manicomial no Brasil foi superado a partir de políticas de saúde, por meio de discussões nas conferências de saúde mental que foram realizadas no decorrer dos anos, no qual o movimento sanitário e o governo reencontram-se com os movimentos sociais populares, inaugurando-se uma nova fase de participação social nas Políticas Públicas de Saúde. Os Centros de Atenção Psicossociais (CAPS) são serviços de atenção diária em saúde mental, de caráter substitutivo ao hospital psiquiátrico. Considerando a família parte essencial do tratamento, entendida a partir do ambiente em que vive e sendo este um espaço de construção de relações intrafamiliar e extrafamiliar, onde se dá a luta por melhores condições de vida, e reinserção na comunidade. A satisfação da família pode ser entendida como o resultado do atendimento que foi prestado, pois manifesta a visão global dessa atividade e está impregnada pelos valores pessoais e sociais, bem como pelas experiências individuais. Assim, pode-se inferir que o grau de satisfação e a mesma de uma família para a outra. OBJETIVO: conhecer a percepção das famílias atendidas pela equipe do CAPS AD sobre o serviço oferecido pela equipe. MÉTODO: Trata-se de um estudo de origem qualitativa do tipo transversal. Foi explorado para este estudo usuários do serviço CAPS AD do Município de Pouso Alegre-MG. Os participantes do estudo foram 10 usuários que utilizaram o serviço. A amostragem foi do tipo intencional ou proposital. No presente estudo foram utilizados um instrumento sócio demográfico e um roteiro de entrevista semi estruturada para os usuários do CAPS AD, elaborado com pergunta aberta relacionados com o tema: PERCEPÇÃO DOS FAMÍLIARES DE DEPENDENTES QUIMICOS SOBRE O TRATAMENTO NO CAPS- AD. As coletas de dados foram feitas na casa do usuário e no CAPS-AD. Análise dos dados: Os dados foram analisados de acordo com as diretrizes do Discurso do sujeito coletivo, que possibilitaram a visualização da percepção coletiva à medida que permitem captar o discurso que revela o modo como os indivíduos reais e concretos pensam e agem. Para análise dos discursos foram empregadas as seguintes figuras metodológicas: Idéia Central (IC), Expressões-chave (ECH) e Discurso do Sujeito Coletivo (DSC). Os resultados foram apresentados com a utilização da estatística descritiva, mostrarão as idéias centrais emergentes das expressões-chave que são oriundas das entrevistas gravadas. RESULTADO: A pesquisa mostrou a importância do serviço para os pacientes e familiares, que há uma satisfação enorme em poder contar com a disponibilidade dos profissionais que compõem a equipe, que buscam a melhoria da condição de saúde do paciente e família.

\section{REFERÊNCIAS}

Escola Anna NeryPrint version ISSN 1414-8145 Esc. Anna Nery vol.17 no. 2 Rio de Janeiro Apr./June 2013 https://doi.org/10.1590/S1414-81452013000200005. Acesso em 29 de março de 2021 https://www.researchgate.net/publication/287518728_Impacto_social_do_uso_abusivo_de_drogas_p ara_dependentes_quimicos_registrados_em_prontuarios/link/569e2d4308ae. Acesso em 29 de março de 2021

PALAVRAS-CHAVE: Percepção, Familiares, Dependentes Químicos, CAPS- AD 


\title{
XVIII Congresso de Iniciação Científica
}

\section{POTENCIAL ANTI-HISTAMÍNICO DE PRODUTO FITOTERÁPICO}

\author{
MARIA SYLVIA RENNÓ KALLÁS*; NAYANNE GOMES MARCIANO; RAFAELA PRADO GUIMARÃES; \\ ADRIANA RODRIGUES DOS ANJOS MENDONÇA \\ UNIVÁS - Universidade do Vale do Sapucaí
}

Introdução: As picadas de insetos representam um incômodo que ganha um espaço significativo nos países como Brasil. Tal problemática se justifica porque, em resposta a elas, uma reação é desencadeada pelo organismo. O corpo reconhece àquela agressão, e manifesta-se através de reação de hipersensibilidade tipo I, que corresponde a ativação de IgE ligado aos mastócitos e basófilos pelo antígeno, resultando em degranulação, e portanto, liberação de mediadores inflamatórios, a exemplo da histamina. Logo, ela permitiria uma vasodilatação que culminaria em eritema, formação de pápulas e prurido. Esforços foram despendidos para a produção de anti-histamínicos, cuja formulação se estendeu à área da fitoterapia. Através desse campo o desenvolvimento de produtos de fácil acesso e baratos tornase possível. A Eremanthus erythropappus é uma espécie de múltiplos usos, entretanto sua madeira é mais aplicada como moirão de cerca, pela sua durabilidade, e para a produção de óleo essencial que tem como principal componente um produto ativo obtido a partir da destilação do óleo de candeia bruto e muito utilizado em fabricação de medicamentos e cosméticos. Existe uma vasta literatura sobre a atividade biológica do óleo essencial de candeia, mas os estudos são insuficientes. Por fim, vale acrescentar a importância da avaliação clínica detalhada antes de iniciar qualquer tratamento. Objetivo: Desenvolver e avaliar o potencial anti-histamínico de uma pomada contendo o produto fitoterápico em sua formulação. Método: Estudo clínico, analítico, transversal e controlado. A amostra foi de 20 participantes. O método escolhido foi o Prick Test. $O$ antebraço de cada sujeito foi sensibilizado em quatro pontos $(A, B, C, D)$. Ponto A: controle positivo, sensibilizando-se com histamina, Ponto B: histamina e pomada com $0,5 \%$ de produto. Ponto C: histamina e pomada com $2,5 \%$ do elemento, Ponto D: histamina e pomada com $5 \%$ do fitoterápico. A pomada contendo o óleo em diferentes concentrações foi aplicada imediatamente após a sensibilização com a histamina. A leitura do teste foi realizada, em cada ponto, 15 minutos após a realização do procedimento. Os resultados foram analisados estatisticamente. Resultados/desenvolvimento: Analisando-se as médias das áreas formadas, $A=0,406 \mathrm{~cm}^{2}, B=0,2126 \mathrm{~cm}^{2}$, $\mathrm{C}=0,2016 \mathrm{~cm}^{2}$ e $\mathrm{D}=0,1915 \mathrm{~cm}^{2}$, nota-se redução de área do ponto controle para os demais, em $\mathrm{p}=0,727$, comprovando-se potencial anti-histamínico. Além disso, o gel que continha menor concentração do produto ativo, aplicado no ponto $B$, já foi suficiente para gerar o efeito, não divergindo, portanto, da efetividade das demais concentrações para o tamanho da amostra estudado. Considerações finais: $\mathrm{O}$ gel demonstrou potencial anti-histamínico.

\section{REFERÊNCIAS}

Aleluia CM, Procópio VC, Oliveira MTG, Furtado PGS, Giovannini JFG, Mendonça SMS. Fitoterápicos na odontologia: Medicines in dentist herbal. Rev Odontol São Paulo, 2015; 27(2):126-34. Disponível em: http://arquivos.cruzeirodosuleducacional.edu.br/principal/old/ revista_odontologia/pdf/maio_agosto_2015/Odonto_02_2015_126-134.pdf. Acesso em: 22 fev. 2021. Anvisa. Agência Nacional de Vigilância Sanitária. Resolução da diretoria colegiada- RDC № 26, de 13 de maio de 2014. Disponível em: http://saude.gov.br. Acesso em: 22 fev. 2021.

PALAVRAS-CHAVE: Anti-histamínico; fitoterapia; Candeia sp; óleo essencial; 


\section{PRÁTICAS INTEGRATIVAS E COMPLEMENTARES: AVALIAÇÃO DA AROMATERAPIA EM IDOSOS}

JÚLIA DE PAULA OLIVEIRA*; JÚLIA SIQUEIRA COSTA PAPI; JOSÉ VITOR DA SILVA; ADRIANA RODRIGUES DOS ANJOS MENDONÇA

UNIVÁS - Universidade do Vale do Sapucaí

INTRODUÇÃO: É comum em idosos a presença de sintomas de ansiedade e medo da morte. As Práticas Integrativas Complementares, que vem crescendo como opção terapêutica pelo mundo, em associação com o tratamento dito convencional, podem contribuir para o controle desses sentimentos, em especial a Aromaterapia, que pode ser utilizada no próprio ambiente residencial ou hospitalar. A Lavandula officinalis, uma das principais plantas para a extração e fabricação dos óleos essenciais, possui propriedades antissépticas, sedativas, digestivas, hipotensoras, analgésicas, aromáticas, purificantes, e contribui para alívio de náuseas, nervosismo, neurose cardíaca, paralisia, depressão, enxaqueca, insônia, tensão, entre outras. OBJETIVO: Avaliar a influência do uso do óleo de Lavandula officinalis sob os motivos para viver, em idosos. MÉTODOS: Estudo clínico, duplo-cego, com amostragem aleatória. Os participantes foram divididos em dois grupos, o controle utilizou apenas óleo de girassol, já o estudo utilizou óleo com Lavandula officinalis. Antes do início do tratamento, foi aplicado o Instrumento "Motivos para Viver". Após 1 e 2 meses de utilização do óleo, foram novamente avaliados. RESULTADOS: 5 pacientes fizeram parte do grupo estudo e 5 do grupo controle. Em ambos os grupos, houve predominância do sexo feminino, com idades entre 60 e 90 anos. Com o instrumento utilizado, foram comparadas as pontuações do início e do final do tratamento, obtendo-se uma média de diferença de pontos de cada grupo. No grupo estudo, houve um aumento de 7 pontos. No grupo controle, houve de 4,6 pontos. CONCLUSÃO: O uso do óleo com Lavandula officinalis demonstrou aumento significativo nos "Motivos para Viver" em idosos, podendo ser uma importante medida terapêutica não farmacológica na melhora da qualidade de vida dessa população.

\section{REFERÊNCIA}

MENUT, V. et al. Utilisation des médecines complémentaires et alternatives chez I

PALAVRAS-CHAVE: Práticas complementares e integrativas; Aromaterapia; Idoso; Lavandula. 


\section{PREDITORES DE DOR NA COLUNA LOMBAR EM UNIVERSITÁRIOS}

ANDRESSA BATISTA DO PATROCÍNIO SANTOS*; ANDRESSA BATISTA DO PATROCÍNIO SANTOS; TÁBATA CAROLINE TERRA VILELA; MARCELO RENATO MASSAHUD JUNIOR

UNIVÁS - Universidade do Vale do Sapucaí

Introdução:A dor lombar se caracteriza por ser osteomuscular, e ocorre na parte inferior da coluna vertebral. Com o passar dos anos e o acontecimento de doenças crônicas, consequentemente leva a um desgaste nos componentes de sustentação da coluna, alterando assim a anatomia e a fisiologia, levando, a morbidades variadas e à possibilidade de ocorrência de dor nas costas. Pelo fato de a dor lombar ser a principal responsável por grandes índices de faltas e incapacidades ao trabalho, gera um alto custo para a sociedade e para os sistemas de saúde dos países. Relata-se uma prevalência da dor em $29,3 \%$ universitários com idade de 18 a 29 anos. Objetivos: Conhecer as relações entre o estilo de vida, aptidão física, fatores biopsicossociais de universitários que apresentam ou não a dor lombar, e descobrir quais desses preditores acarreta a dor lombar, correlacionando os resultados com a literatura, e posteriormente atuar na prevenção. Metodologia: Aplicado pelo Google Forms os seguintes questionários: Questionário Nórdico de Sintomas Musculoesqueléticos e Questionário Psicossocial e de Hábitos de vida em 100 universitários da área da saúde como Fisioterapia, Enfermagem, Farmácia, Psicologia, Medicina e Nutrição da nossa instituição, Universidade do Vale do Sapucaí (UNIVÀS), Pouso Alegre-MG. Obtidos os resultados será comparado com outras buscas, como pesquisas na literatura de outros grupos como atletas, idosos etc., comparar os preditores para ver se estão relacionados. Discussão: Colhido os dados dos questionários ainda está sendo feito a correlação da literatura e das possíveis causas com os resultados obtidos, pretendo ter conclusão até dia 01/11/2021.

\section{REFERÊNCIAS}

ALFIERI, Fábio Marcon et al. PREVALÊNCIA DE DOR LOMBAR EM UNIVERSITÁRIOS DA SAÚDE E SUA RELAÇÃO COM ESTILO DE VIDA E NÍVEL DE ATIVIDADE FÍSICA. Revista Inspirar:

Movimento e Saúde, São Paulo, v. 11, p. 27-31, 17 dez. 2016.

MALTA, Deborah Carvalho et al. Fatores associados à dor crônica na coluna em adultos no Brasil. Revista de Saúde Pública: Revista de Saúde Pública, São Paulo, p. 1-12, 17 out. 2016. Semanal MORAIS, Markeyllanne Leocadio et al. Prevalência de dor lombar e fatores associados entre estudantes de fisioterapia. Brazilian Journal Of Pain, São Paulo, v. 1, jul/set. 2018.

PALAVRAS-CHAVE: Dor; Coluna Lombar; Preditores; Universitários 


\title{
PRESERVAÇÃO DA FERTILIDADE DE PACIENTES ONCOLÓGICAS: ABORDAGEM BIOÉTICA
}

\author{
ANA SOFIA FORTUNATO BORGES*; LYLIANA COUTINHO RESENDE BARBOSA; JOSÉ DIAS DA \\ SILVA NETO \\ UNIVÁS - Universidade do Vale do Sapucaí
}

INTRODUÇÃO:Diante do adiamento da decisão das mulheres pela gravidez, consequência de inúmeros fatores como sua inserção no mercado de trabalho e da possibilidade de concretização de uma carreira profissional; e da incidência cada vez mais frequente de câncer, principalmente de mama, em mulheres com a faixa etária concomitante a um possível desejo pela maternidade, estabelece-se uma problemática recorrente em ambos os fenômenos: a preservação da fertilidade em pacientes oncológicas, bem como as questões éticas envolvendo novas técnicas e o profissionalismo médico na tomada de decisões e informação da paciente. A partir de tais fatos e levantamentos, este trabalho visa à discussão acerca da ética médica diante das possibilidades da preservação da fertilidade de pacientes oncológicas, de forma a levantar estratégias que possam aumentar e difundir o mérito da manutenção e conservação de questões tão humanas e intrínsecas às mulheres em um momento de fragilidade, como a maternidade. $O$ objetivo do mesmo baseia-se na análise, de forma qualitativa, de percepções e embasamentos éticos de médicos acerca da preservação da fertilidade de pacientes oncológicas. METODOLOGIA: Esse estudo é uma pesquisa analítica, descritiva e qualitativa, com aprovação do Comitê de Ética da nossa instituição, em que foi enviado um questionário eletrônico a médicos oncologistas clínicos e cirúrgicos, ginecologistas, obstetras e radioterapeutas. O questionário constou de 9 questões de múltipla escolha que abordaram dados demográficos e conhecimentos gerais sobre a preservação da fertilidade de pacientes oncológicas e 4 questões dissertativas. RESULTADOS: Foram obtidas 15 respostas; $53,3 \%$ dos especialistas eram homens, $80 \%$ eram brancos, $93,34 \%$ entre 31 e 60 anos, $80 \%$ eram ginecologistas e obstetras, $73,3 \%$ se formou em instituição de ensino privada e $46,7 \%$ trabalha somente em hospitais privados. Em relação à abordagem da paciente oncológica a respeito da possibilidade de preservação de sua fertilidade e da frequência com que tais tratamentos de preservação são oferecidos, $53,3 \%$ relatam que sempre abordam suas pacientes sobre o tema e $33,3 \%$ relata que a possibilidade de tratamento sempre é oferecida às pacientes. $13,3 \%$ relatam que as suas pacientes nunca são abordadas sobre a possibilidade de preservação de sua fertilidade e $6,6 \%$ relatam que a possibilidade de tratamento nunca é oferecida às pacientes. Em relação às percepções e embasamentos éticos dos médicos sobre a preservação da fertilidade das pacientes, $66,6 \%$ refere como sendo de muita importância a possibilidade de se oferecer tratamentos de preservação da fertilidade para pacientes em idade fértil. Dentre as dificuldades encontradas em se lidar com o tema destacam-se a relativa urgência para início do tratamento oncológico da paciente, o alto custo dos procedimentos de preservação da fertilidade, a falta de orientação por parte dos profissionais e a dificuldade de se abordam a paciente em um momento de fragilidade. CONCLUSÃO: Embora o campo da oncofertilidade tenha evoluído significativamente, ainda existem falhas na orientação das pacientes oncológicas sobre a possibilidade de prejuízo de sua fertilidade e da possibilidade de preservação da mesma.

\section{REFERÊNCIAS}

INSTITUTO NACIONAL DE CANCER. Câncer de mama. Disponível em: $<$ https://www.inca.gov.br/tipos-de-cancer/cancer-de-mama>.

VILAR, L. M. G. DA S.; DUARTE, D. K. DE A.; LOPES, D. C. L.; SILVA, J. G. M. DA; SILVA, R. E. M.

N. E. Preservação da fertilidade em mulheres com câncer de ovário. Revista Brasileira de Inovação Tecnológica em Saúde - ISSN:2236-1103, v. 8, n. 1, p. 10, 14 nov. 2018.

RAMALHO DE CARVALHO, Bruno. Oncofertilidade: bases para a reflexão bioética. Oncofertilidade: bases para a reflexão bioética, Genesis Centro de Assistência em Reprodução Humana, Brasília, DF, Brasil, 21 set. 2018.

PALAVRAS-CHAVE: Preservação da fertilidade; medicina reprodutiva; mulher; ética médica. 
PRODUTO FITOTERÁPICO PARA TRATAMENDO DE ACNE EM PACIENTES JOVENS

\author{
RAFAELY TAYNARA RODRIGUES TORQUATO NUNES*; MARINA ARAÚJO RABELO; DANIELLE \\ APARECIDA FERREIRA DE OLIVEIRA MARRAFON; JAQUELINE JÓICE MUNIZ \\ UNIVÁS - Universidade do Vale do Sapucaí
}

Introdução: A acne vulgar é uma doença que acomete em geral face e tronco e pode acarretar cicatrizes permanentes quando não tratada da forma adequada. Dentre as diversas causas, encontra-se a bactéria Proprionibacterium acnes 1. Para tratamento da acne existem diversas opções de terapêutica, sendo que alguns fitocomésticos tem mostrado ação eficaz em reduzir proliferação de microorganismos e auxiliar na cicatrização das lesões 2 . O pó da casca de banana verde da espécie Musa sapientum demonstraram ações farmacológicas, como atividade anti-inflamatória, cicatrizante e antimicrobiana 3. O presente estudo teve como objetivo avaliar experimentalmente a ação de um fitocosmético à base de casca de banana verde no tratamento de acne em jovens. Metodologia: Trata-se de uma pesquisa de intervenção, do tipo ensaio clínico e amostragem por conveniência, aprovado pelo Comitê de Ética em Pesquisa (CEP) da Universidade do Vale do Sapucaí (UNIVAS) sobe o número de parecer 4.760 .508 , no qual foi aplicado o produto fitoterápico em pacientes entre 18 e 25 anos, com acne, do sexo feminino ou masculino, que assinaram o Termo de Consentimento Livre e Esclarecido e que apresentavam impacto na qualidade de vida, devido à presença da lesão. O fitocosmético foi aplicado nas lesões acneicas da face após teste epicutâneo que demonstrou a ausência de reação alérgica. A efetividade no tratamento das lesões acneicas na face está sendo avaliada, antes e após o uso do produto, por imagens fotográficas utilizando o programa Image J. Resultados: Até o presente momento, foi observado que os voluntários tiveram redução das lesões acneicas na face após o uso do produto. Considerações Finais: O fitoterápico a base de casca de banana tem mostrado reduzir lesões acneicas em face de voluntários jovens.

\title{
REFERÊNCIAS
}

Barros, A.B. Acne vulgar: aspectos gerais e atualizações no protocolo de tratamento. BWS Journal. 2020. 3: 1-13.

Araujo, M.S.O. Uso de fitocosméticos no tratamento da acne. ReBIS. 2020. 2 (3): 67-71.

Atzingen D.A.N.C.V.; Mendonça; A.R.A.; Filho,M.M.; Alvarenga,V.A.; Assis,V.A.; Penazzo, A.F.; Muzetti, J.H.; Rezende,T.S.Repairofsurgicalwoundsinratsusinga10\%unripeMusasapientumpeelgel.ActaCir. Bras. 2015. 30 (9): 586-92.

PALAVRAS-CHAVE: Acne, fitoterapia, banana e Musa sapientum. 


\title{
QUALIDADE DE VIDA DE PACIENTES COM DOENÇAS CARDIOVASCULARES EM TERAPIA COM ANTICOAGULANTES EM POUSO ALEGRE
}

\author{
MILENA BARBOSA DE ARAUJO*; ELIANA NACARATO VIANNA DE ANDRADE; SARA SANTOS \\ ARAUJO; AUGUSTO CASTELLI VON ATZINGEN \\ UNIVÁS - Universidade do Vale do Sapucaí
}

Introdução: A utilização da terapêutica com anticoagulantes é fundamental para prevenção de fenômenos tromboembólicos com relação a condições clínicas como fibrilação atrial, tromboembolismo venoso, portadores de próteses valvares cardíacas, insuficiência cardíaca congestiva, infarto agudo do miocárdio. Neste sentido, este trabalho teve como objetivo conhecer a relação entre a utilização da terapia com anticoagulantes orais e a qualidade de vida dos pacientes portadores de doenças cardiovasculares. Sobretudo, identificar qual o impacto na vida dos pacientes que utilizam a terapia com anticoagulantes, as mudanças no bem-estar, nas atividades cotidianas como trabalho, atividades diárias, hábitos e lazer. Metodologia: Trata-se de um estudo transversal, que foi realizado no Hospital das Clínicas de Samuel Libânio (HCSL), a população foi composta através dos critérios de inclusão: pacientes acompanhados nos ambulatórios de anticoagulação e cardiologia, com idade igual ou superior a 18 anos, de ambos os sexos, anticoagulados, que possuem síndromes de origem cardiogênica. Os participam foram incluídos de forma consecutivos. Os critérios de não inclusão foram definidos como não utilização de terapia com anticoagulantes, déficit cognitivo que impedisse a compreensão do estudo e aplicação dos questionários e, ausência de doença cardíaca. Por fim, resposta incompletas ou incorretas aos questionários, desistência do participante a qualquer momento da pesquisa foram considerados critérios de exclusão deste estudo. O questionário de qualidade de vida: A qualidade de vida foi aferida por meio do instrumento específico Duke Anticoagulation Satisfaction Scale (DASS). O DASS foi desenvolvido nos Estados Unidos da América (EUA) para avaliar a qualidade de vida e satisfação dos pacientes que tomam anticoagulantes orais, e os resultados obtidos com a versão original mostrava propriedades psicométricas adequadas. Resultados: A amostra constitui-se de 40 pacientes, acompanhados no ambulatório de anticoagulação, sendo $70 \%$ destes do sexo masculino e $30 \%$ do sexo feminino. Os acometimentos cardiovasculares mais comumente encontradas foram hipertensão arterial sistêmica e arritmias, presentes em $53,3 \%$ dos casos e 46,3\%, respectivamente. A droga mais utilizada entre os participantes do estudo é a Varfarina, $82,5 \%$. Quando questionados sobre os impactos sobre seus tratamentos, diante da pandemia do COVID-19, cerca de $20 \%$ encontrou maior dificuldade em realiza-lo, e 56,7\% dos participantes apresentava receio em sair de casa como principal fator estressor. Em relação as respostas do questionário padronizado notaram-se uma boa aceitação da terapia, com baixo impacto negativo sobretudo nas atividades diárias, alimentação e posologia e manutenção do tratamento. $70 \%$ da amostra compreende o motivo do seu tratamento com anticoagulantes, e a mesma porcentagem também corresponde a aqueles que recomendariam 0 tratamento a outra pessoa que precisasse, ademais, representa a parcela que se preocupa em se machucar e ter sangramentos. Finalmente, $66,7 \%$ dos pacientes deram nota máxima a melhora da qualidade de vida proporcionada pelo tratamento. Considerações finais: Percebeu-se que a terapêutica farmacológica é bem aceita pelos pacientes em questão, gerando impacto positivo na qualidade de vida desses pacientes. No entanto, a possibilidade de sangramento ainda é inerente a estes pacientes e representam o principal desafio diante dessa terapêutica.

\section{REFERÊNCIAS}

Corbi ISA, Dantas RAS, Pelegrino FM, Carvalho ARS. Qualidade de vida relacionada à saúde de pacientes em uso de anticoagulação oral. Rev. Latino-Am. Enfermagem [Internet]. Jul. - Ago. 2011 [acesso em: 28/05/2019];19(4): [09 . telas]. Disponível em: http:/www.scielo.br/pdf/rlae/v19n4/pt_03.pdf Pelegrino M. F, Dantas S. A. R, Corbi. A. S. I. Carvalho SRA; Schmidt, André, Pazin F, Antônio. Crosscultural adaptation and psychometric properties of the Brazilian-Portuguese version of the Duke Anticoagulation Satisfaction Scale. J Clin Nurs. 2012 Sep; 21(17-18): 2509-2517. Published online 2011 Nov 14. doi: 10.1111/j.1365-2702.2011. 03869.x. Disponível em: https://www.ncbi.nlm.nih.gov/pmc/a

PALAVRAS-CHAVE: Cardiopatias, anticoagulantes, cardiologia, bioética, qualidade de vida. 


\title{
RELAÇÃO DA INCIDÊNCIA DOS SUBTIPOS DE CÂNCER DE MAMA COM A IDADE DAS PACIENTES NO SERVIÇO DE PATOLOGIA DO HOSPITAL DAS CLÍNICAS SAMUEL LIBÂNIO - POUSO ALEGRE - MG
}

\author{
ELISA KEIKO DE SOUZA IGARASHI*; AMANDA MUNIZ FONTES; GUSTAVO BRUNELLI VALLIM; \\ MIRIAM DE FÁTIMA BRASIL ENGELMAN; FIORITA GONZALES LOPES MUNDIM \\ UNIVÁS - Universidade do Vale do Sapucaí
}

INTRODUÇÃO: O tipo de câncer de maior incidência entre as mulheres é o câncer de mama (29,5\%), com exceção do câncer de pele não melanoma. Apresenta subtipos moleculares que expõem-suas individualidades e mostram diferenças significativas em termos de incidência, fatores de risco, prognóstico e sensibilidade ao tratamento. A imuno-histoquímica é um método para identificação dos subtipos tumorais pela detecção de receptores de estrógeno e progesterona; de superexpressão e/ou amplificação do receptor do fator epidérmico de crescimento humano (HER2) e pelo marcador de proliferação celular Ki67 que se torna imprescindível para a conduta médica. A classificação simplificada de subtipos moleculares são: Luminal A, Luminal B (B1 e B2), HER2 positivo, Triplo negativo e basaloide. OBJETIVO: conhecer o perfil dos subtipos moleculares de pacientes do sexo feminino com câncer de mama, abaixo e acima de 40 anos, na região de Pouso Alegre - MG, atendidas pelo Hospital das Clínicas Samuel Libânio (HCSL) e correlacionar com variáveis prognósticas. METODOLOGIA: O estudo caracterizou-se como básico, observacional, analítico, explicativo, documental, longitudinal e retrospectivo. Os dados foram colhidos a partir dos laudos do Laboratório de Anatomia Patológica do HCSL, de 2016 a 2019, e dos respectivos prontuários. Os dados foram tabulados no Microsoft Excel 2016 e submetidos à análise estatística. As variáveis pesquisadas foram: subtipo molecular, idade, receptores de estrógeno e de progesterona, fator epidérmico de crescimento humano (HER2), índice de proliferação celular (Ki-67), tamanho do tumor $(\mathrm{T})$, grau histológico, linfonodos analisados $(\mathrm{N})$, menarca, menopausa, motivo que levou a descobrir o diagnóstico e cidade de origem. Os dados foram tabulados no Microsoft Excel 2016 e submetidos à análise estatística. Foram utilizadas medidas de tendência central para variáveis quantitativas e frequência absoluta e relativa para variáveis categóricas. Foi usado o programa Minitab versão 18.1 e Statistical Package for the Social Sciences, inc (SPSS) Chicago, USA, versão 22.0. O nível de significância foi considerado $5 \%(p<0,05)$. RESULTADOS: Obteve-se um total de 304 pacientes, sendo 74 em 2016, 98 em 2017, 63 em 2018 e 69 em 2019. Pouso Alegre foi responsável por 29,06\% dos casos atendidos no serviço. A maioria das pacientes $(87,79 \%)$ são $>40$ anos, com média de 56,79 anos. Subtipo molecular mais frequente foi o Luminal B1 (42,15\%), seguido do Luminal A (26,16\%). O grau histológico mais frequente foi o grau 2 (38,95\%), seguido do grau $1(28,77 \%)$. As análises das variáveis, quando realizadas de modo anual, demonstraram correlações sem significâncias ou duvidosas. Obtevese, em 2016 e 2017, que a idade $<40$ tem maior Ki-67 do que idade $>40$, ( $p=0,002)$. Em relação aos subtipos moleculares, houve tendência ao decorrer dos anos, do decréscimo na classificação utilizada, correspondendo à tendência de aumento de casos do subtipo molecular luminal $\mathrm{A}$ e diminuição do Luminal B. CONCLUSÃO: As pacientes com idade menor de 40 anos têm maior índice de proliferação celular, o que mostra que quanto mais jovens o câncer de mama é mais agressivo. Em relação ao universo estudado, a tendência a maior frequência de subtipo Luminal $A$, demonstra melhor prognóstico nos casos analisados. Reforça-se ainda a necessidade do diagnóstico precoce para maior controle do câncer de mama.

\section{REFERÊNCIAS}

Abbas, A. K., KUMAR, V., M.D., \& Fausto, N. (2005). Robbins \& Cotran - Patologia: Bases Patologicas Das Doenças, 1616.

Gnant, M., Harbeck, N., \& Thomssen, C. (2017). St. Gallen/Vienna 2017: A Brief Summary of the Consensus Discussion about Escalation and De-Escalation of Primary Breast Cancer Treatment. Breast Care, 12(2), 102-107.

INCA. (2017). Estimativa | 2018.

PALAVRAS-CHAVE: Câncer de Mama, subtipos do câncer de mama, epidemiologia. 


\title{
RELEVÂNCIA DA REABILITAÇÃO FISIOTERAPÊUTICA PARA MINIMIZAR OS IMPACTOS DA SÍNDROME PÓS-COVID: UM ESTUDO OBSERVACIONAL
}

\author{
SIMONE RIBEIRO DA COSTA SOARES*; RICARDO DA SILVA ALVES; BRUNA LEONEL CARLOS \\ UNIVÁS - Universidade do Vale do Sapucaí
}

Uma nova situação de saúde foi gerada pela pandemia da COVID-19: a síndrome pós-covid. Estudos apontam que a pessoa que passa pela doença permanece com as suas consequências por um longo período, e essas consequências são diversas e podem se manifestar de várias formas. A literatura atual traz que pacientes graves terão sequelas e aponta que pacientes que sofreram a forma leve também precisam de monitoramento. Fadiga foi o sintoma dominante, seguido de cefaleia, déficit de atenção e dispneia, sendo que a fibrose pulmonar pode ainda manifestar-se entre o primeiro e o sexto mês após a infecção, ou seja, estamos diante de quadros de consequências irreversíveis. Estudos apontam que cerca de $80 \%$ dos pacientes após infecção por SARS-CoV-2 podem desenvolver ao menos um dos sintomas da síndrome pós-covid, e, por esta razão, a intervenção fisioterapêutica, aliada a uma equipe multidisciplinar, precisa agir de forma rápida. Esses sintomas, se não tratados, carreiam outras complicações funcionais e diminuem a capacidade do indivíduo de retornar às suas atividades de vida diária. Diante de todo esse contexto, o atendimento ambulatorial deve acolher estes pacientes com protocolos estruturados e que possam incluir as necessidades individuais. METODOLOGIA: serão utilizados questionários SF36 para a qualidade de vida e o IPAQ, questionário internacional para a atividade física, em forma de entrevista e os pacientes terão a dor avaliada pela escala de valor analógica (EVA). O esforço e capacidade cardiorrespiratória serão avaliados pela escala Modificada de Borg, e será aplicado o teste de caminhada de seis minutos (TC6). RESULTADOS: espera-se avaliar os efeitos da fisioterapia no tratamento da síndrome pós-covid e a sua contribuição ara o encurtamento do tempo vivido com as sequelas da covid pelo paciente.

\section{REFERÊNCIAS}

$\mathrm{Wu}, \mathrm{F}$., Zhao, S., Yu, B. et al. A new coronavirus associated with human respiratory disease in China. Nature 579, 265-269 (2020). Disponível em: https://doi.org/10.1038/s41586-020-2008-3. Acesso em 31 de maio de2021

LEON, SANDRA LOPEZ et al., MedRxiv - More than 50 long-term effects of covid 19: a Systematic Review and Meta-Analysis. Disponível em: More than 50 Long-term effects of COVID-19: a systematic review and meta-analysis | medRxiv. Acesso em 31 de maio de 2021.

WORLD HEALTH STATISTICS 2021, WHO, - Monitoring health for SDGs, maio de 2021. Disponível em: World Health Statistics 2021: Monitoring Health for the SDGs - World | ReliefWeb. Acesso em 31 de maio de 2021.

PALAVRAS-CHAVE: Síndrome pós-covid. Reabilitação. Fisioterapia. 


\title{
RESISTENCIA MEDICAMENTOSA EM DOENTES EM TRATAMENTO DA TUBERCULOSE COM COMORBIDADE
}

\author{
MAYARA MARQUES LIMA*; LAIZ MANGINI CICCHELERO; ADRIANA ZILLY; MARIA LUZIA \\ TOPANOTTI; REINALDO ANTONIO DA SILVA SOBRINHO
}

INTRODUÇÃO: A tuberculose (TB) segue como problema de saúde pública com elevada mortalidade mundial. Causada pelo bacilo M. tuberculosis (MTB), possui transmissão direta e sintomas como tosse persistente, febre e perda de peso. Seu diagnóstico pode ser realizado por meio do exame de baciloscopia de escarro. Diante do desafio para o manejo, emergem também casos de TB multidroga resistente, sendo necessário ações e estratégias para melhorar a cobertura e qualidade do diagnóstico/tratamento (MINISTÉRIO DA SAÚDE, 2018). METODOLOGIA: Estudo epidemiológico descritivo a fim de levantar o perfil sociodemográfico e epidemiológico. Para identificar os doentes foi utilizado o Sistema de Informação de Agravos de Notificação. Para analisar as variáveis sociodemográficas e epidemiológicas utilizou-se um questionário estruturado, junto as pessoas diagnosticadas com TB em Foz do Iguaçu-PR. A pesquisa foi aprovada pelo Comitê de Ética, sob o parecer nํㅜ 3.393.015. As informações foram coletadas no período de 08/2019 a 03/2020 e analisadas com auxílio do Excel® e do Statistica Statsoft 12.0. RESULTADOS/DESENVOLVIMENTO: como ferramenta para diagnóstico rápido, a plataforma Gene Xpert MTB/Rif $\AA$ está disponível e, por meio da biologia molecular, identifica o complexo MTB e verifica a resistência à rifampicina (Rif), principal medicamento no tratamento da doença. Dos 17 participantes da pesquisa, $94,1 \%$ foram submetidos ao exame, e destes $82,3 \%$ com MTB detectável e resistente. A partir deste resultado, preconiza-se o envio da amostra para realização do teste de sensibilidade antimicrobiana (TSA) para confirmar o resultado, mas somente $47 \%$ dos casos foram testados e apresentaram TSA sensível para todos os fármacos. Quanto ao perfil sociodemográfico, 76,4\% eram do sexo masculino, raça/cor predominante foi a parda e escolaridade a nível de ensino fundamental. Sobre a ocupação, apenas $35,3 \%$ estavam empregados formalmente. A TB é citada como uma doença que envolve vulnerabilidade socioeconômica, pessoas em situação de vulnerabilidade social encontram-se com maior frequência entre os adoecidos. As variáveis clínicas mostram que $88,2 \%$ apresentavam tosse no diagnóstico e a grande maioria, 94,1\%, possuíam a forma pulmonar da doença. A testagem para HIV ocorreu em $41,2 \%$ dos casos. Sobre as comorbidades modificáveis, $35,3 \%$ eram fumantes e $23,5 \%$ extabagistas, $47 \%$ faziam uso de álcool até 4 vezes por semana e 5,9\% de drogas ilícitas. Já para as não modificáveis, 4,9\% afirmaram diagnóstico de HIV e 11,8\% diabetes. Silva et al. (2018), relataram que o tabagismo e o alcoolismo são fatores de risco para o desenvolvimento de resistência medicamentosa. Observou-se que os doentes do sexo masculino fazem uso do tabaco em maior frequência $(83,3 \%)$ e de acordo com o tipo de entrada (casos novos) $88,5 \%$ não foram submetidos ao TSA. CONCLUSÃO: Quanto a resistência medicamentosa, devido o baixo número de casos envolvidos no estudo e a frequência de pacientes submetidos a TSA, não foram encontrados pacientes afetados. A não oferta deste exame é danosa para a identificação e vigilância de casos resistentes. Por outro lado, foi identificado doentes com comorbidades, perfil comum entre doentes de TB com resistência medicamentosa, aspecto que torna 0 desfecho do tratamento desfavorável. É fundamental a oferta do TSA, quando há resistência à Rif, para manejo correto e vigilância dos casos.

\section{REFERÊNCIAS}

MINISTÉRIO DA SAÚDE (Brasil). Secretaria de Vigilância em Saúde. Implantação do Plano Nacional pelo Fim da Tuberculose como Problema de Saúde Pública no Brasil: primeiros passos rumo ao alcance das metas. Boletim Epidemiológico , [s. I.], v. 49, ed. 11, p. 1-18, mar. 2018. DOI . Disponível em: http://portalarquivos2.saude.gov.br/images/pdf/2018/marco/26/2018-009.pdf. Acesso em: 8 maio 2019.

SILVA, Denise Rossato et al. Risk factors for tuberculosis: diabetes, smoking, alcohol use, and the use of other drugs. J. bras. pneumol., [s. I.], v. 44, ed. 02, p. 145-152, mar/abr. 2018. DOI 10.1590/S180637562017000000443. Disponível em:

https://www.scielo.br/j/jbpneu/a/7YmvXDNKGPq39XHRnsRcf9.

PALAVRAS-CHAVE: Tuberculose, Tuberculose Multidroga Resistente, Diagnóstico, Vigilância em Saúde Pública. 


\title{
TUMORES ÓSSEOS:CONDUTAS CLÍNICAS E CIRÚRGICAS DO OSTEOSSARCOMA, CONDROSSARCOMA E SARCOMA DE EWING; REVISÃO DE LITERATURA
}

\author{
MATEUS GOMES POLO*; DAVI JOSÉ DE CARVALHO MACEDO; EUGÊNIO CÉSAR MENDES \\ UNIVÁS - Universidade do Vale do Sapucaí
}

Introdução: Tumores ósseos malignos primários representam aproximadamente $6 \%$ de todas as malignidades da infância. Destes, os osteossarcoma e o sarcoma do Ewing destacam-se como os mais comuns, com uma incidência anual de 8,7 a cada 1 milhão de pacientes com menos de 20 anos.

Osteossarcoma é o tumor ósseo maligno primário mais comum. Geralmente aparece em locais onde os ossos crescem mais rápido e durante a fase de crescimento. É mais comum aos 20 anos e frequentemente tem crescimento rápido. Quando afeta idosos, geralmente é uma complicação da Doença de Paget do osso ou induzido por radiação. O condrossarcoma é um tumor baseado em cartilagem classificado na categoria dos sarcomas. O condrossarcoma primário ocorre mais comumente depois da terceira década da vida e acomete frequentemente a pelve ou os ossos longos, particularmente o fêmur e o úmero Já o sarcoma de Ewing é um tumor maligno que ocorre predominantemente em ossos ou em partes moles, afetando principalmente crianças, adolescentes e adultos jovens, com pico de incidência em torno dos 15 anos. Este estudo de tem por objetivo revisar as principais características clínicas e radiológicas do osteossarcoma e sarcoma de Ewing, bem como técnicas atuais na avaliação, diagnóstico e tratamentodesses tumores. Indicações e alternativas para cirurgia de salvamento do membro versus amputação e seu resultado funcional e a qualidade de vida relacionada à saúde serão discutidas. Métodos: Realizou-se revisão de literatura nas bases de dados vinculadas à saúde, publicados em Inglês, Português e Espanhol. Inicialmente, as palavras chave foram vinculadas aos Descritores em Ciências da Saúde (DECS) e ao Medical Subject Headings (MeSH): vocabulário controlado da National Library of Medicine (NLM), utilizado para indexação de artigos para o PubMed. Utilizou-se a Biblioteca Virtual em Saúde (BVS), que reúne 12 bases de dados da área de saúde. Também, o PubMed, portal da Biblioteca Nacional de Medicina dos Estados Unidos, que inclui referências da base Medline e outros jornais ligados às ciências biológicas de artigos biomédicos. Utilizou-se a biblioteca eletrônica Scientific Electronic Library Online (SciELO), que disponibiliza diversas coleções de periódicos científicos e livros em diversas áreas do conhecimento, incluindo a área da Saúde;. Para classificar o nível de evidência dos estudos selecionados, foram utilizadas as categorias da Agency for Healthcare Research and Quality (AHRQ2016). A pesquisa foi desenhada para focar em três conceitos principais: osteossarcoma, condrossarcoma e sarcoma de Ewing. Assim, foram escolhidos os termos de busca relacionados ao osteossarcoma ("osteossarcoma" OU "Síndrome de Fraumeni"), relacionados ao osteossarcoma ("condrossarcoma" OU "doença de Olliers"), e os relacionados ao Sarcoma de Ewing ( Sarcoma E Ewing OU "FTSE"). Os termos foram pesquisados nos títulos, resumos e palavras-chave dos artigos. Resultados: Foram pesquisadas e compiladas características quanto à apresentação clínica, diagnóstico por imagem, biópsia, tratamento mais indicado e bem como o prognóstico dos três tumores. Ademais, foram feitas ponderações sobre as técnicas cirúrgicas maia avançadas para o salvamento do membro, assim como os métodos diagnósticos maia atuais para cada tumor. Conclusão: $O$ tratamento de tumores ósseos malignos nas últimas décadas progrediu dramaticamente, com mais pacientes tornando-se sobreviventes de longo prazo e uma porcentagem recebendo tratamento de preservação

\section{REFERÊNCIAS}

ADDIN Mendeley Bibliography CSL_BIBLIOGRAPHY 1. Garcia JG, Martinez A, Garcia Filho RJ, Petrilli MT, Viola DC. Características epidemiológicas dos pacientes com tumores pélvicos submetidos a tratamento cirúrgico. Rev Bras Ortop [Internet]. 2018;53(1):33-7. Available from: http://dx.doi.org/10.1016/j.rbo.2016.11.0042.3.4.5.6.7.8.

Garcia Filho RJ. Tumores ósseos e sarcomas dos tecidos moles. Einstein (Säo Paulo). 2008;6(Figura 1):102-19.

Bielack BSS, Kempf-bielack B, Exner GU, Flege S, Helmke K, Kotz R, et al. pronostic facteur dasn OS 2002. 2002;20(3):776-90.

PALAVRAS-CHAVE: Tumores ósseos: osteossarcoma: condrossarcoma: sarcoma de Ewing; 


\title{
USOS E EFEITOS DA RELIGIÃO NA VIDA DE UM DETENTO: UMA REVISÃO BIBLIOGRÁFICA DA LITERATURA A RESPEITO DA INFLUÊNCIA RELIGIOSA NAS PRISÕES BRASILEIRAS
}

\author{
GIOVANA BRAGA SANTOS*; CAMILA CLAUDIANO QUINA PEREIRA \\ UNIVÁS - Universidade do Vale do Sapucaí
}

Introdução: Diante da expansiva presença religiosa nos presídios brasileiros, pesquisadores indicam que a religião acaba sendo o discurso mais frequente dentro do cenário prisional, a qual acaba por direcionar as histórias dos sujeitos presidiários, uma vez que esses, a partir da narrativa religiosa, constituem e recriam antigas crenças. Segato (2005) e Vargas (2005) acreditam que nos presídios brasileiros o discurso religioso é o mais frequente com o qual o detento tem contato, assinalando que o universo prisional é um lugar pobre de alternativas discursivas. Essas autoras consideram que é importante que o detento tenha a possibilidade de pensar a sua vida a partir de outros arcabouços discursivos, de modo que problematize a sua existência com a possibilidade de construir a sua história de vida a partir de distintas narrativas. Objetivo: A presente pesquisa objetiva analisar hipóteses de que a prática religiosa tende a ser um dispositivo de alienação e controle, e quando instituída atua como agente causador de danos à subjetividade, como mecanismo de controle dos corpos e de modelagem de realidades futuras. Metodologia: O presente trabalho se constituiu de uma revisão bibliográfica, sendo analisado os materiais encontrados nas plataformas Scielo, BDTD e BVS diante da pesquisa de palavras chaves referentes a instituições e tecnologias disciplinares, além de instituições religiosas e presídios. Resultados: Os presídios brasileiros são lugares pobres de alternativas discursivas e com essa escassez de narrativas o discurso religioso de "superioridade moral" se faz onipresente e monopoliza e regula a palavra no cárcere e com ela as vias de acesso ao bem, à autorreflexão, à autoavaliação e à redenção. A imitação que o preso faz do discurso do "bem" veiculado pelas instituições religiosas pode ser chamada de "mimese regressiva", como colocada por Segato (2005). O detento copia o discurso cristão, com seus valores familiares e suas fórmulas de boas maneiras de forma mecânica. Na mimese regressiva o sujeito copia assumindo sem reservas a fala do outro, dominante, sobre si. Ele assume e copia a fala dominadora - do cristão, do pastor, do sacerdote, daquele que está identificado com o bem e com a lei. Assim sendo, nega sua própria condição e sacrifica seu lugar de fala. Uma das consequências da mimese regressiva é a produção da morte discursiva daquele sujeito que cometeu o crime, ou seja, não é feito um caminho reflexivo dessa situação, atribui-se tais atitudes ao "demônio", ao homem anterior à Deus. Produz-se, portanto, um sujeito, que tendo seu eu mortificado e reconstruído, repete mimeticamente o discurso do "bem", alienado do seu próprio passado e desprovido do potencial crítico, torna-se um ser docilizado, disciplinado. Considerações Finais: Considera-se, portanto, que seja necessária uma diversidade de narrativas aos sujeitos apenados de forma que esses possam encontrar possibilidades outras, visto que a religião no presídio atua para a docilização desses corpos e não para suas consequentes reinserções na sociedade. Entende-se como sendo necessário a reeducação da própria sociedade de forma que esses indivíduos tenham seus direitos assegurados e sejam punidos de modo adequado, com o objetivo real de reinserção e não apenas de disciplinarização de corpos para a manutenção de uma hegemonia vigente há tempos.

\section{REFERÊNCIAS}

Segato, R. L. (2005). Religião, vida carcerária e direitos humanos. Comunicações do ISER (Religiões e Prisões), n. 61, 40-45.

Vargas, L. O. (2005). Religiosidade: mecanismos de sobrevivência na Penitenciária Feminina do Distrito Federal. Comunicações do ISER (Religiões e Prisões), n.61, 30-39.

PALAVRAS-CHAVE: Instituição Prisional; Religião; Subjetividade 
ANNA GABRIELA ALMEIDA ALVES*; ANA CAROLINA DE OLIVEIRA; BRUNA DE CÁSSIA SOUSA; HELGA DOS SANTOS CABECEIRA; DIBA MARIA SEBBA TOSTA DE SOUZA

UNIVÁS - Universidade do Vale do Sapucaí

INTRODUÇÃO: O aplicativo móvel HC Protection, registrado no Instituto Nacional da Propriedade Industrial número: BR12016000989-6, possui função de auxiliar profissionais da área da saúde na avaliação, prevenção e acompanhamento de trabalhadores com Diabetes Mellitus, com enfoque em sua principal complicação, o pé diabético. A DM é uma doença crônica de prevalência crescente no país, acometendo $7,4 \%$ da população brasileira. Entre suas complicações está o pé diabético, que pode se iniciar com pequenas úlceras e evoluir para amputação do membro, sendo assim é muito séria, dispendiosa e afeta diretamente na funcionalidade do doente. OBJETIVO: Validar o aplicativo HC Protection desenvolvido para acompanhamento de trabalhadores portadores de DM, com risco para pé diabético. METODOLOGIA: Trata-se de estudo analítico, descritivo e com abordagem tecnológica. A validação do aplicativo foi feita por profissionais da área da enfermagem, que o avaliaram por meio de questões respondidas através de um formulário online. Para a análise de confiabilidade, calculou-se o coeficiente alfa de Cronbach e análise estatística do Índice de Validade de Conteúdo (IVC). RESULTADOS/DESENVOLVIMENTO: O questionário foi respondido por 14 profissionais da área da enfermagem, dos quais sete possuem especialização, cinco possuem mestrado e dois possuem doutorado, com idade média de 43,6 anos. Foram respondidas 19 perguntas, das quais 17 eram de múltipla escolha e avaliavam objetivamente o aplicativo. O IVC global foi de $94,96 \%$, mostrando o alto grau de concordância entre os especialistas. Além disso, o alfa de Cronbach foi maior que 0,9, apontando excelente consistência interna do questionário. CONCLUSÃO: O aplicativo foi analisado e as opiniões foram congruentes logo na primeira rodada de avaliação, com valores estatísticos acima dos recomendados, validando assim o software HC Protection como instrumento de auxílio para profissionais de saúde no segmento de trabalhadores diabéticos, com foco no pé diabético.

\section{REFERÊNCIAS}

Brasil. Ministério da Saúde. VIGITEL: estimativas sobre frequência e distribuição sociodemográfica de fatores de risco e proteção para doenças crônicas nas capitais dos 26 estados brasileiros e no Distrito Federal em 2019. [Acesso 13 de outubro de 2021]. Disponível em: https://bvsms.saude.gov.br/bvs/publicacoes/vigitel_brasil_2019_vigilancia_fatores_risco.pdf Pérez-Panero AJ, Ruiz-Muñoz M, Fernández-Torres R, Formosa C, Gatt A, GónzalezSánchez M. Diabetic foot disease: a systematic literature review of patient-reported outcome measures. Qual Life Res. 2021 Jun 9. doi: 10.1007/s11136-021-02892-4. [Acesso 13 de outubro de 2021] Disponível em: https://pubmed.ncbi.nlm.nih.gov/34109501/.

PALAVRAS-CHAVE: Diabetes Mellitus; Pé diabético; Absenteísmo; Trabalhador; Aplicativos Móveis. 